\title{
Specification of Energy Assessment Methodologies to Satisfy ISO 50001 Energy Management Standard
}

\author{
Harish Kanneganti
}

Follow this and additional works at: https://researchrepository.wvu.edu/etd

\section{Recommended Citation}

Kanneganti, Harish, "Specification of Energy Assessment Methodologies to Satisfy ISO 50001 Energy Management Standard" (2014). Graduate Theses, Dissertations, and Problem Reports. 5932.

https://researchrepository.wvu.edu/etd/5932

This Thesis is protected by copyright and/or related rights. It has been brought to you by the The Research Repository @ WVU with permission from the rights-holder(s). You are free to use this Thesis in any way that is permitted by the copyright and related rights legislation that applies to your use. For other uses you must obtain permission from the rights-holder(s) directly, unless additional rights are indicated by a Creative Commons license in the record and/ or on the work itself. This Thesis has been accepted for inclusion in WVU Graduate Theses, Dissertations, and Problem Reports collection by an authorized administrator of The Research Repository @ WVU. For more information, please contact researchrepository@mail.wvu.edu. 
Specification of Energy Assessment Methodologies to Satisfy ISO 50001 Energy

Management Standard

Harish Kanneganti

Thesis submitted

to the Benjamin M. Statler College of Engineering and Mineral Resources at West Virginia University

in partial fulfillment of the requirements for the degree of

Master of Science in

Industrial Engineering

Bhaskaran Gopalakrishnan, Ph.D., P.E., Chair

Majid Jaridi, Ph.D.

Edward Crowe, Ph.D., P.E.

Department of Industrial and Management Systems Engineering

Morgantown, West Virginia

2014

Keywords: Energy Efficiency, Energy Assessment, ISO 50001

Copyright 2014 Harish Kanneganti 


\section{ABSTRACT \\ Specification of Energy Assessment Methodologies to Satisfy Energy Management Standard}

\section{Harish Kanneganti}

Energy management has become more crucial for industrial sector as a way to lower their cost of production and in reducing their carbon footprint. Environmental regulations also force the industrial sector to increase the efficiency of their energy usage. Hence industrial sector started relying on energy management consultancies for improvements in energy efficiency. With the development of ISO 50001 standard, the entire energy management took a new dimension involving top level management and getting their commitment on energy efficiency. One of the key requirements of ISO 50001 is to demonstrate continual improvement in their (industry) energy efficiency. The major aim of this work is to develop an energy assessment methodology and reporting format to tailor the needs of ISO 50001. The developed methodology integrates the energy reduction aspect of an energy assessment with the requirements of sections 4.4.3 (Energy Review) to 4.4.6 (Objectives, Targets and Action Plans) in ISO 50001 and thus helping the facilities in easy implementation of ISO 50001. 


\section{Acknowledgement}

I would like to thank my advisor Dr. B. Gopalakrishnan for his continued support, guidance and encouragement during the course of this research. I also wish to thank Dr. Edward Crowe, Dr. Majid Jaridi and Mr. Mark Pannell for their advice and support. I wish to extend my special thanks to Mr. Kartik Ramamoorthy for his invaluable help and support for the success of this project.

Above all, I wish to thank God and my family for their constant support and blessings. I dedicate this work to Dr. Praveen Chowdary Kanneganti and Mrs. Sai Lahari Kommana for enabling my success and happiness in all my pursuits and endeavors in life. 


\section{Table of Contents}

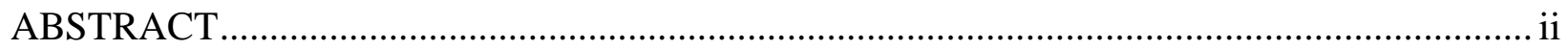

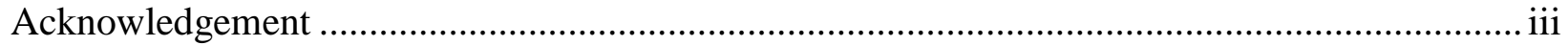

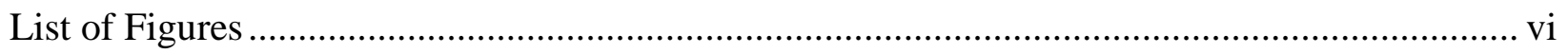

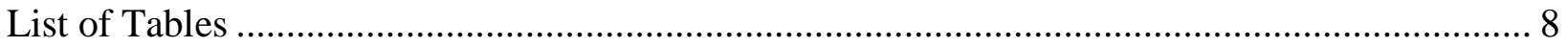

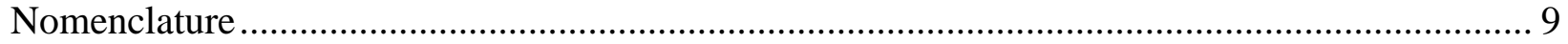

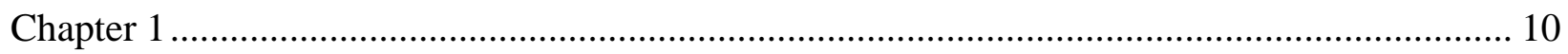

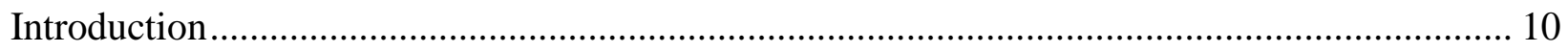

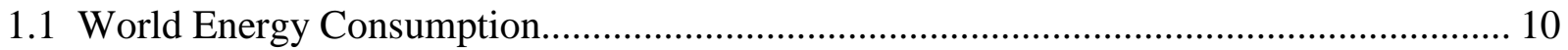

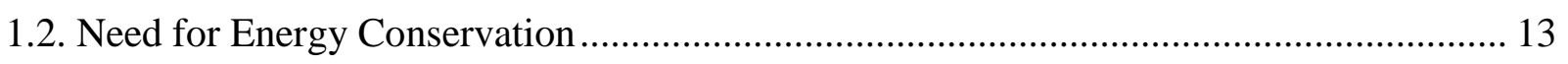

1.3 How to Conserve Energy?......................................................................................... 13

1.4Introduction to Energy Management.............................................................................. 14

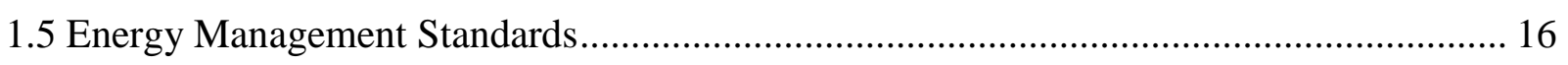

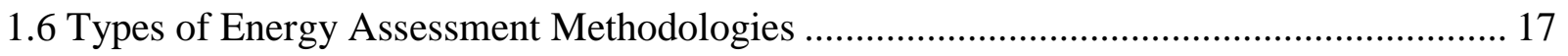

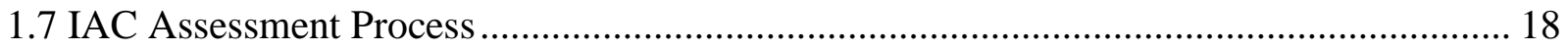

1.8 Enhanced Energy Assessment Process ............................................................................ 18

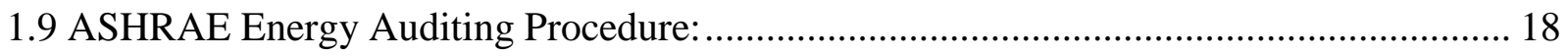

1.10 ASME Energy Auditing Procedure........................................................................... 19

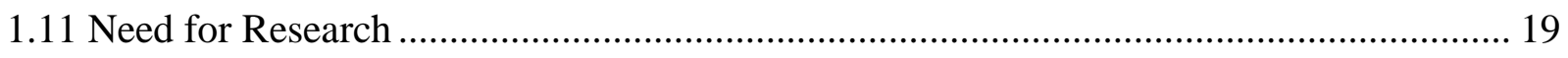

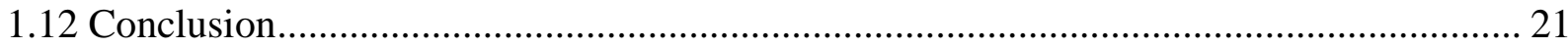

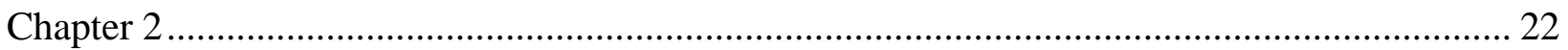

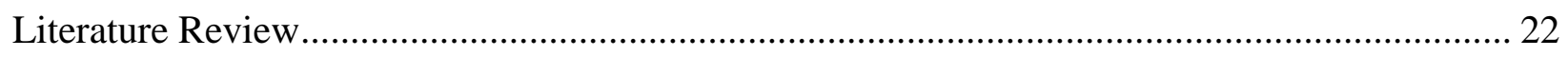

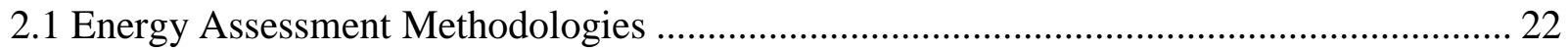

2.2 Energy Assessment Methodologies Supporting Energy Management Systems .................. 24

2.3 ISO 50001 Energy Management Standard ...................................................................... 26

2.4 Section 4.4 ISO 50001-Energy Planning ........................................................................ 28

2.5 Superior Energy Performance (SEP) ........................................................................... 33

2.6 International Performance Measurement and Verification Protocol (IPMVP).................... 34

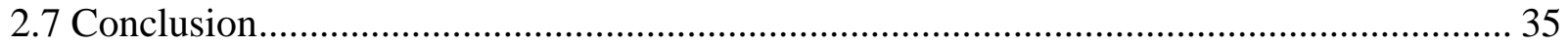

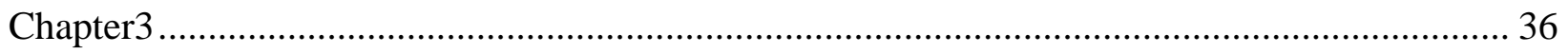

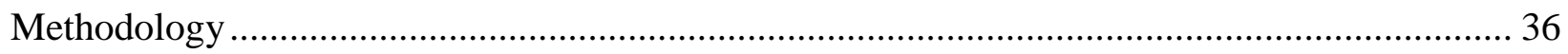




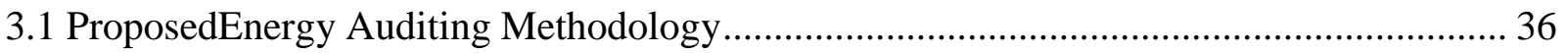

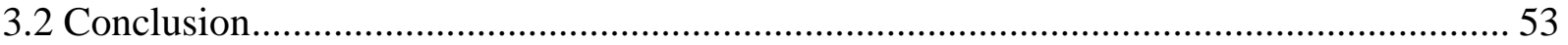

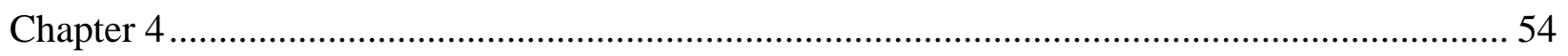

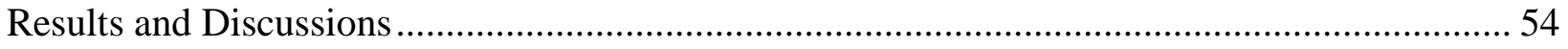

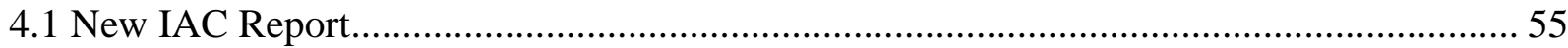

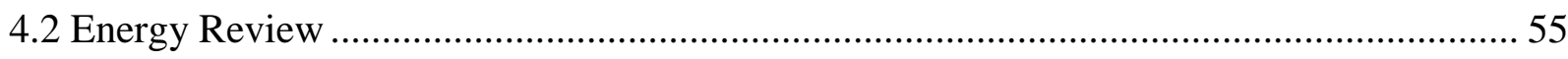

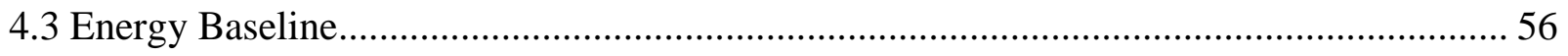

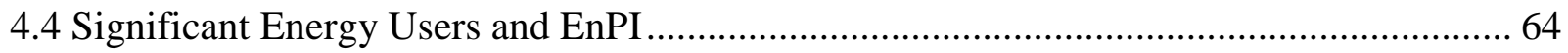

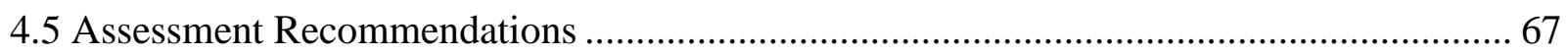

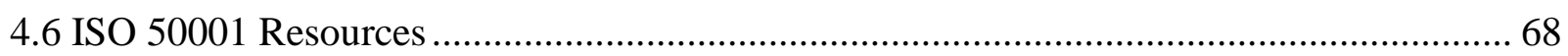

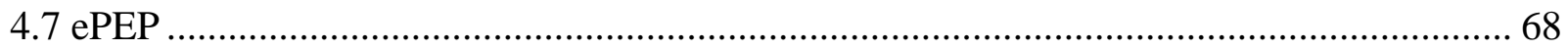

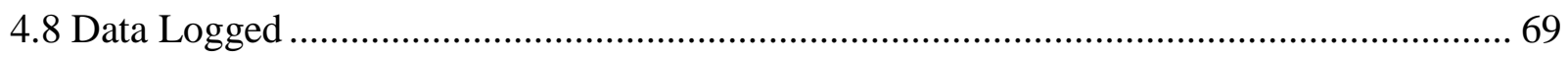

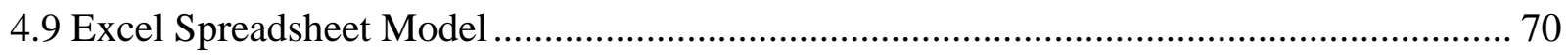

4.10 Energy Consumption of the Facility-2013 ………….................................................... 71

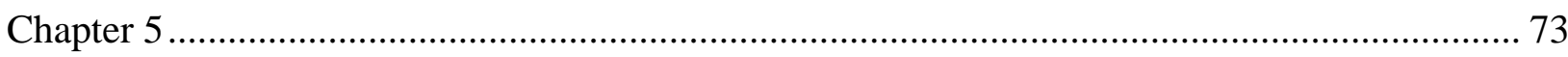

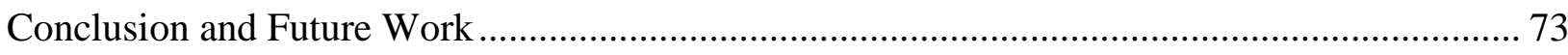

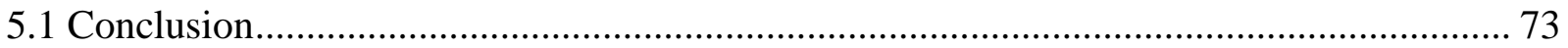

5.2 Comparison between EnPI tool and SAS Models:.......................................................... 74

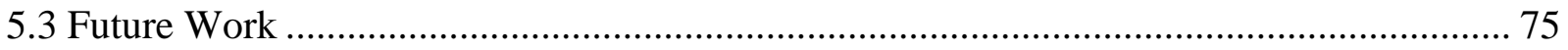

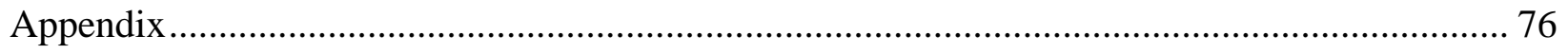

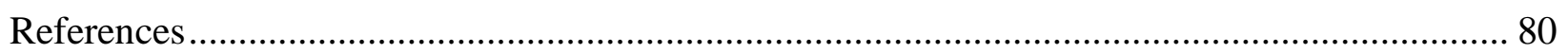




\section{List of Figures}

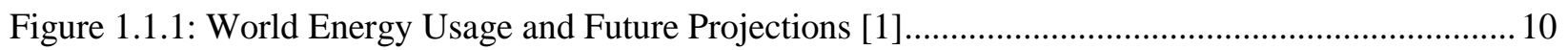

Figure 1.1.2: Industrial Sector and all Other Sectors Energy Consumption [1] ..................................... 11

Figure 1.1.3: Primary Energy Consumption by Source and Sector [1] ................................................ 12

Figure 1.1.4: U.S. Energy Consumption by Source, 2012 [1] ............................................................. 12

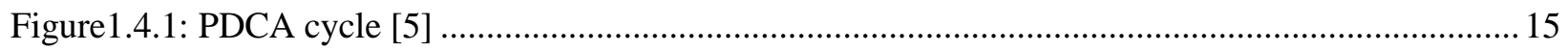

Figure 2.1.1: Overview of Energy Assessment Process [17] ............................................................... 23

Figure 2.2.1: Evolution of Energy Management Systems [18] ..........................................................24

Figure 2.2.2: ASME assessment methodology for process heating [27] ..............................................25

Figure 2.3.1: Energy Management System Model for ISO 50001 [20] ................................................27

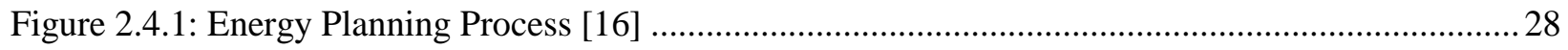

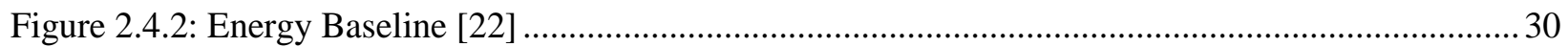

Figure: 2.4.3: Six step Methodology for Developing Energy Baseline [22] .......................................... 30

Figure 3.1.1: Current and Proposed Report Structure .......................................................................... 37

Figure 3.1.2: Current IAC Energy Assessment Process ....................................................................... 38

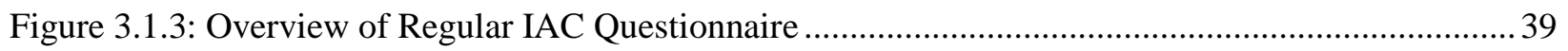

Figure 3.1.4: Proposed General Info Collection Process …................................................................... 40

Figure 3.1.5: Data Collected for Compressed Air System ......................................................................42

Figure 3.1.6: HVAC System General Data Collection Process ............................................................. 43

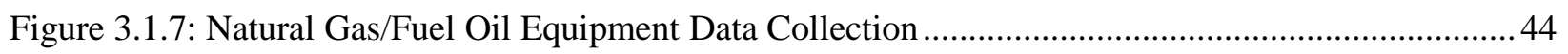

Figure 3.1.8: General Data Collection for all other equipment.......................................................... 45

Figure 3.1.9: Proposed generalized data collection procedure for electrical equipment ..........................46

Figure 3.1.10: Proposed generalized data collection process for fuel burning equipment ........................47

Figure 3.1.11: Current and Proposed Executive Summaries ............................................................... 48

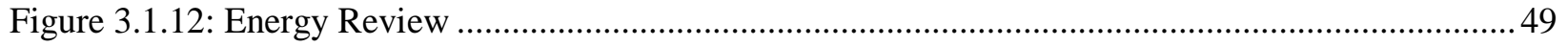

Figure 3.1.13: Baseline Development at Facility Level...................................................................50

Figure 3.1.14: Significant Energy Users and Energy Performance Indicators .......................................51

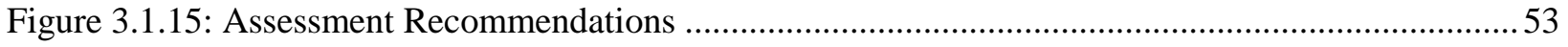

Figure 3.2.1: Final results for proposed methodology ….....................................................................53

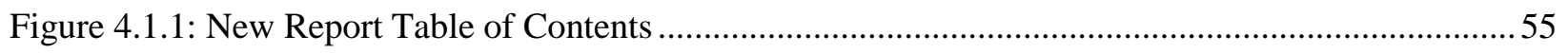

Figure 4.3.1: Data Used for Baseline Development …...................................................................5 57 
Figure 4.3.2: Baseline Model for Electric Energy Consumption.........................................................5

Figure 4.3.3: Baseline Model for Natural Gas Consumption..................................................................6 60

Figure 4.3.4: Baseline Model for Diesel Consumption...................................................................... 61

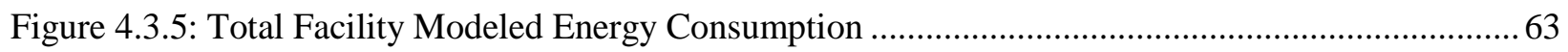

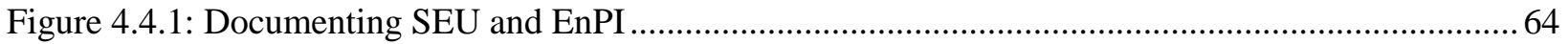

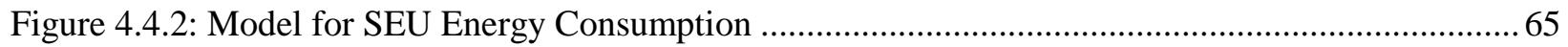

Figure 4.7.1: Energy Consumption and Potential Energy Savings for the Facility .................................6 68

Figure 4.9.1: Objectives, Targets and Action Plan ............................................................................... 70

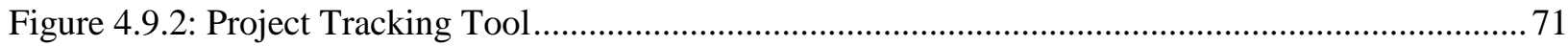

Figure 4.10.1: Energy Consumption of Various Departments in 2013 (MWh) ..................................... 72 


\section{List of Tables}

Table 1.11.1: ISO 50001 requirements and information generated by different assessment

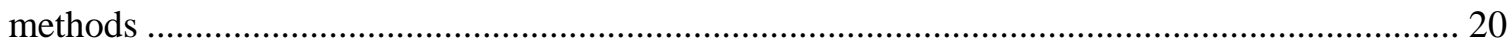

Table 2.4.1: Checklist for Various Types of EnPI's [25] ........................................................... 31

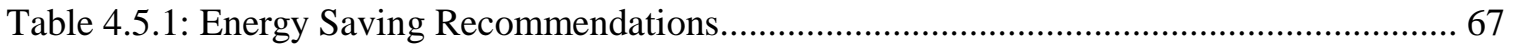

Table 5.2.1: Results from Commercial Stat Package and EnPI Tool .......................................... 74

Table 5.2.2: Predicted vs Actual Energy Consumption - 2013 .................................................... 74 


\section{Nomenclature}

\begin{tabular}{|c|l|}
\hline SEU & Significant Energy User \\
\hline EnPI & Energy Performance Indicator \\
\hline SEP & Superior Energy Performance \\
\hline $\mathrm{kW}$ & Kilo Watt (Power) \\
\hline $\mathrm{kWh}$ & Kilo Watt Hour (Energy Usage) \\
\hline MWH & Mega Watt Hour \\
\hline Btu & British Thermal Unit \\
\hline MMBtu & Million British Thermal Units $=293 \mathrm{kWh}$ \\
\hline ISO & $\begin{array}{l}\text { International Organization for } \\
\text { Standardization }\end{array}$ \\
\hline ANSI & American National Standards Institute \\
\hline HVAC & Heating, Ventilation, and Air Conditioning \\
\hline AR & Assessment Recommendation \\
\hline EIA & Energy Information Administration \\
\hline
\end{tabular}




\section{Chapter 1}

\section{Introduction}

\subsection{World Energy Consumption}

Industrial revolution (1760-1840) changed the nature of manufacturing processes by using mechanical energy. Machine tools started replacing hand production methods which increased the need for energy. Very soon manufacturing sector became a dominant fuel for economic growth worldwide. This transition led to a significant energy use in the world. According to U.S. Energy Information Administration, total world energy usage for the year 2010 was 524 quadrillion Btu and is projected to increase to 630 quadrillion BTU by year 2020 and 820 quadrillion Btu by 2040 [1]. Figure 1.1.1 below shows the energy consumption from 1990 and projections through 2040.

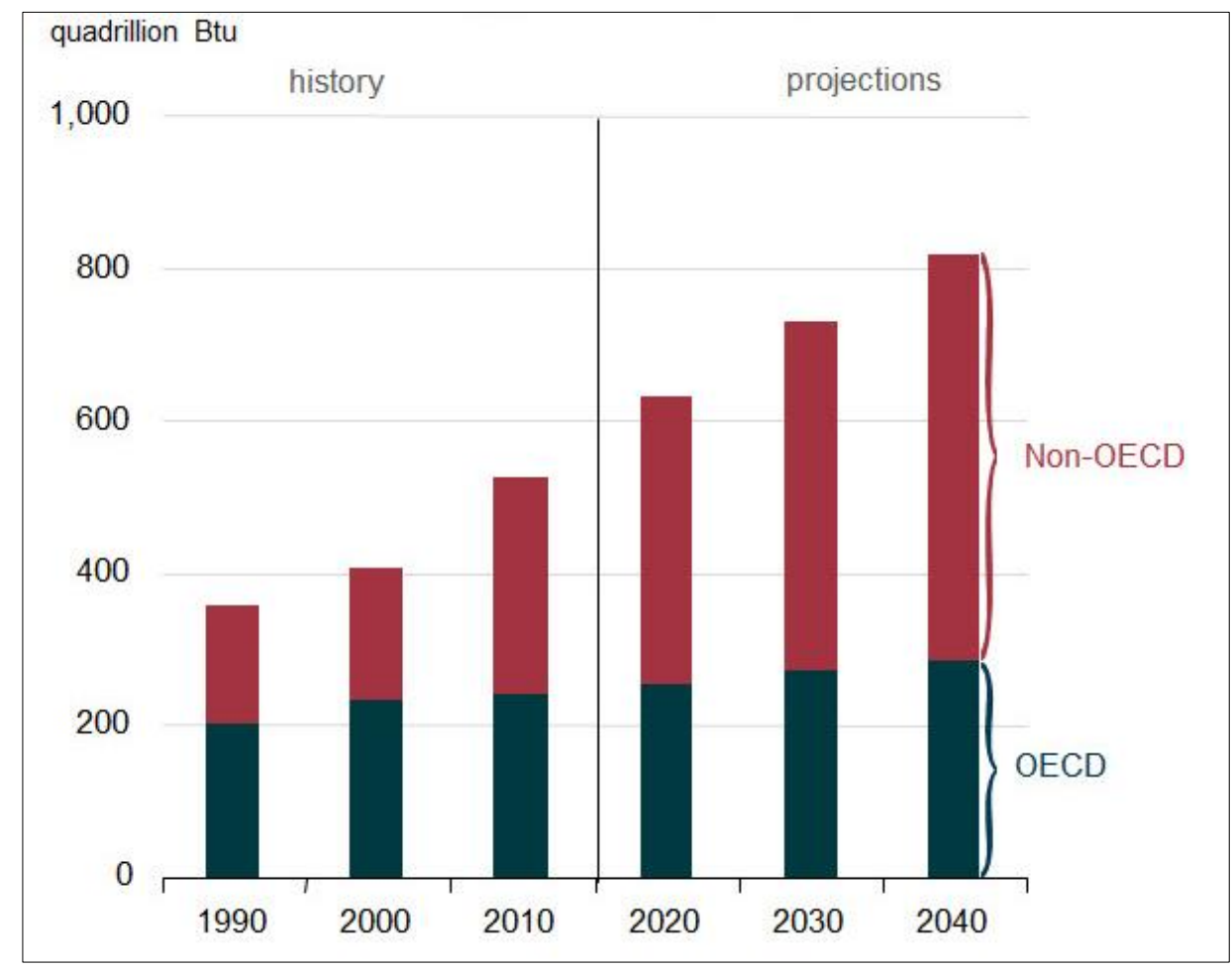

Figure 1.1.1: World Energy Usage and Future Projections [1]

The industrial sector in particular uses more energy than any other sector. About half of the energy produced is consumed by the industrial sector [1]. According to Energy 
Information Administration (EIA), industrial sector primarily comprises of manufacturing (food, paper, chemicals, refining, iron and steel, nonferrous metals, metallic minerals and others) and nonmanufacturing (agriculture, mining and construction). Figure 1.1.2 shows the energy consumption of industrial sector and all other sectors from 2005 to 2040

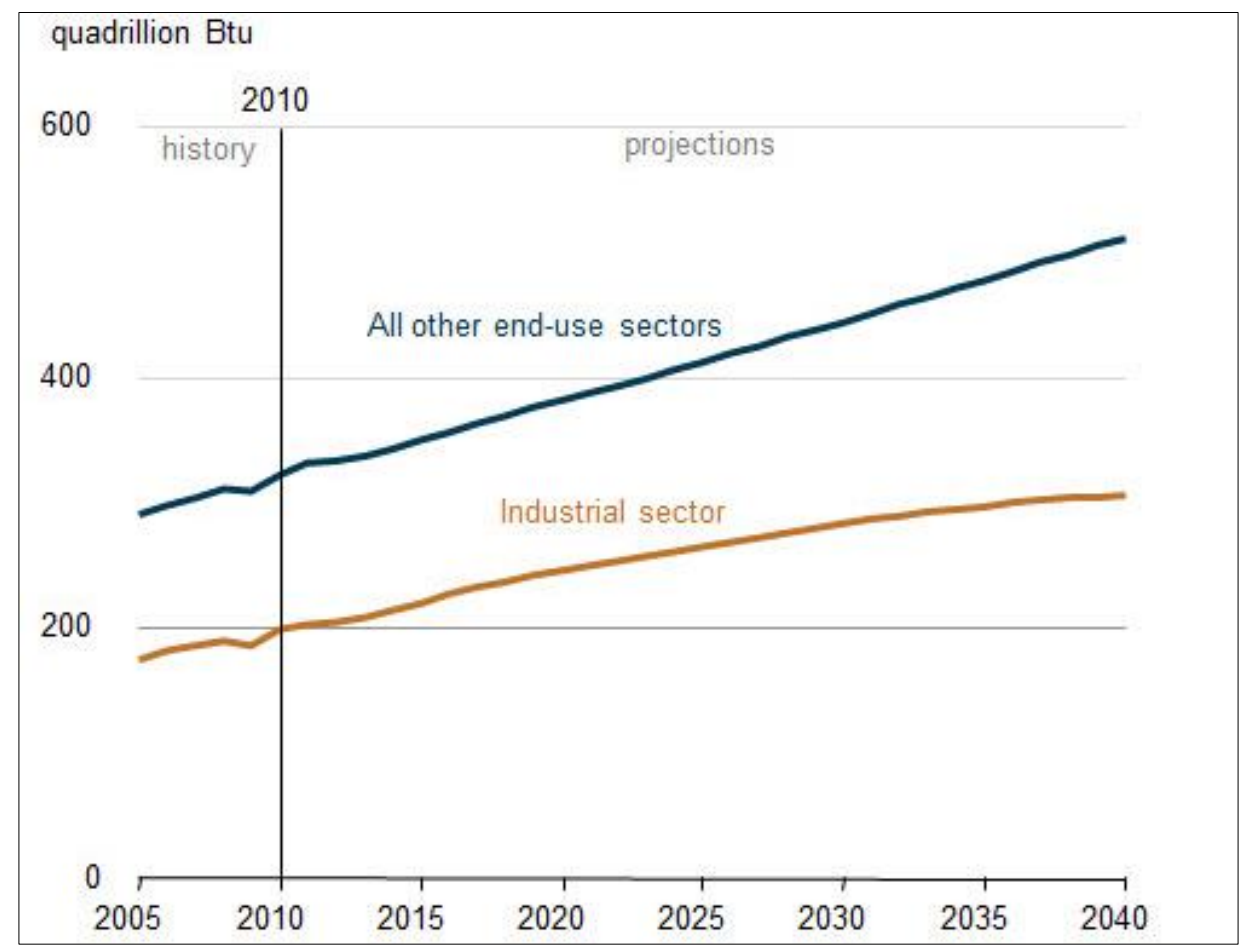

Figure 1.1.2: Industrial Sector and all Other Sectors Energy Consumption [1]

In USA, the total energy use in the year 2012 was 95 quadrillion BTU [1]. The major energy sources consumed in USA are petroleum (oil), natural gas, coal, nuclear and renewables. Figure 1.1.3 shows the amount of energy consumed by various sectors from different sources. 


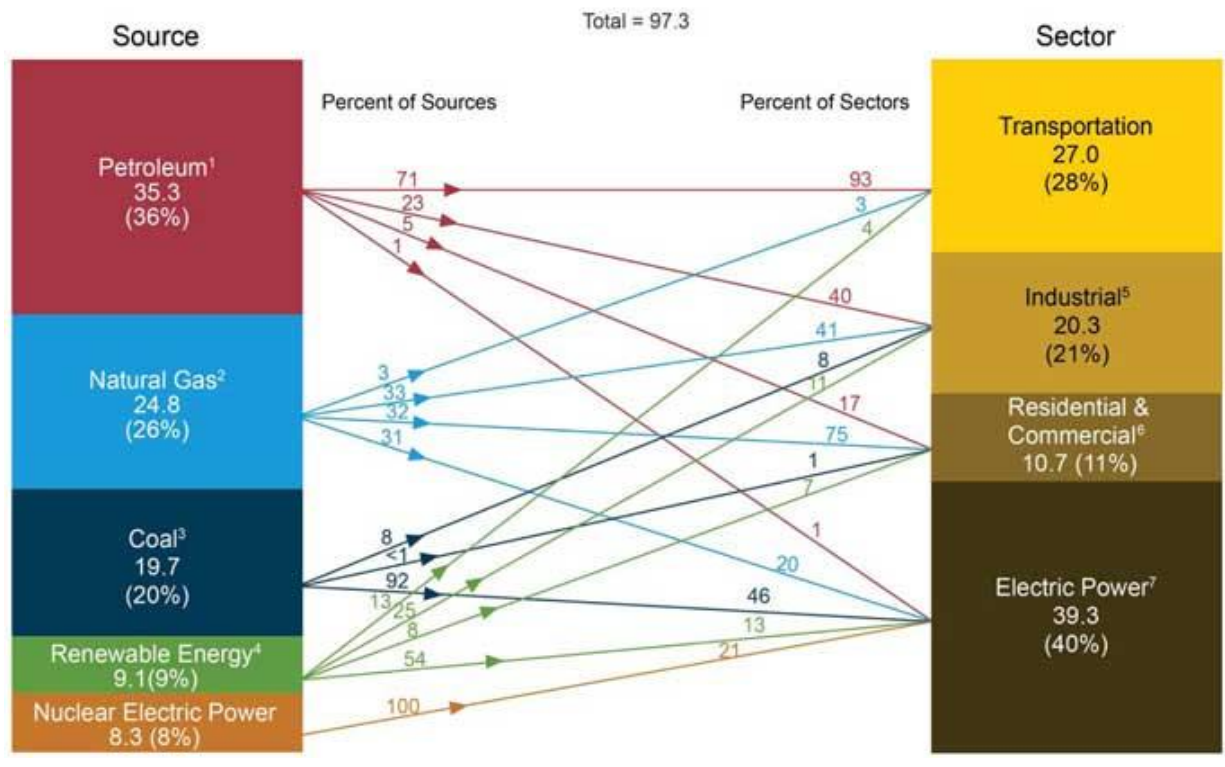

Figure 1.1.3: Primary Energy Consumption by Source and Sector [1]

Even with the technological advancements in the renewable energy, generating major percentage of U.S. energy is from fossil fuels (Petroleum, Natural Gas and Coal). Figure 1.1.4 shows the U.S. energy consumption from each energy source for the year 2012.

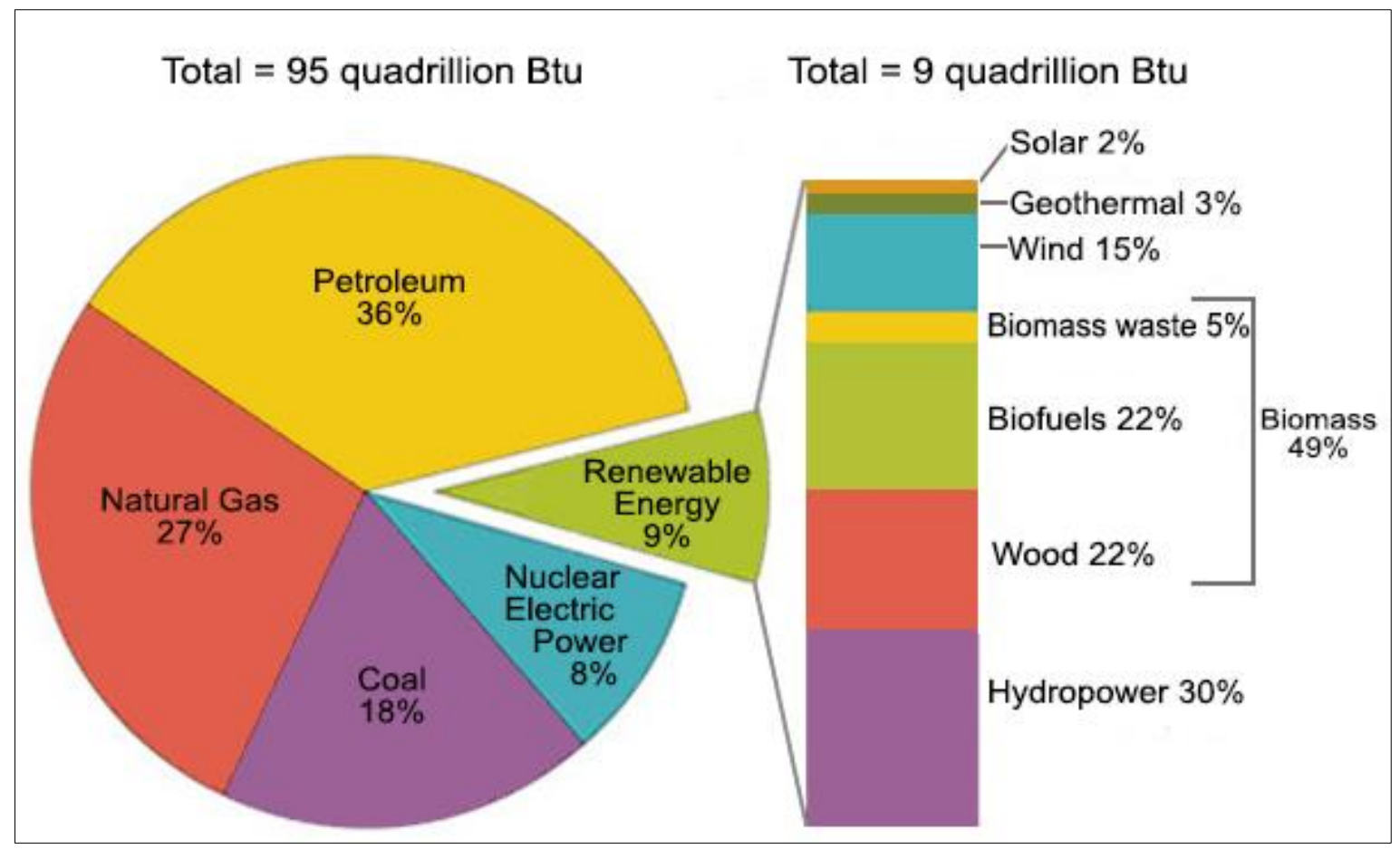

Figure 1.1.4: U.S. Energy Consumption by Source, 2012 [1] 


\subsection{Need for Energy Conservation}

Energy conservation refers to reducing energy consumption through using less of an energy service whereas energy efficiency refers to using less energy for a constant service. In the previous section we observed that there is a significant growth in energy consumption around the planet with time. The by-product of this growth in energy consumption is the increased emissions of greenhouse gases (GHG's) causing global warming. Hence many nations have started focusing on energy conservation and energy efficiency as a way to reduce these greenhouse gases.

According to U.S. Manufacturing Energy Use and Greenhouse Gas Emissions analysis [2], total U.S. manufacturing GHG combustion emissions were equal to 1,261 million metric tons of carbon dioxide in 2006. Out of this, 619 MMT tons or $49 \%$ was from OFFSITE generation of electricity and steam and remaining 643 MMT or $51 \%$ was from ONSITE combustion [2]. These carbon dioxide emissions are the primary reason for increase in earth's temperature by capturing solar radiations.

There are several reasons for reducing the energy intensity apart from environmental perspective. Due to increased globalization and outsourcing, manufacturing facilities need to be highly competitive to sustain in the market. One way of being a market leader is to reduce ones product costs thereby increasing their dollar productivity. Energy cost reduction is one of the key factors in their cost cutting.

Energy conservation is also one of the pillars of sustainability and sustainable development. Our over dependence on non-renewable fossil fuels for various types of energy uses resulted in rapid decrease in their reserves. Studies show that if the world continues to consume fossil fuels at the 2006 rates, the reserves of oil, coal and gas will last a further 40, 200 and 70 years, respectively [3].

\subsection{How to Conserve Energy?}

Conserving energy can be done in several ways, ranging from a simple no-cost behavioral change of the people to using sophisticated technologies. Every approach for 
energy conservation is based on these methodologies. Behavioral change deals with educating the people in the importance of conserving energy. It is based on creating awareness among the people and trying to develop simple habits to save energy. Using latest technologies is the second aspect of conserving energy.

Several technologies have been developed to address the problem of saving energy. The primary questions for the industry in using these technologies are, whether the technologies available in the market are suitable for them or not and how much can they save in terms of energy and cost. Another barrier for implementing new technologies in industrial sector is the investment to put in them and its return. This has opened an entire new domain named "energy auditing" whose primary objective is to evaluate the existing systems and come up with recommendations for saving energy. Conducting an energy assessment and submitting its results will address the above mentioned issues. Energy assessments provide industry with the necessary information on methods to conserve energy.

With the increase in energy prices, industrial facilities are constantly undergoing changes in their systems in order to lower the overall cost of production. This has led to the development of Energy Management Systems which help facilities to develop standard procedures for saving energy. But the energy auditing procedure remains unchanged, creating a huge gap in implementing an energy management system.

\subsection{Introduction to Energy Management}

Energy Management deals with planning and execution of energy related objectives like resource conservation, carbon footprint reduction and cost savings in a continual manner. According to VDI Guideline 4602 defines energy management as "Energy Management is the proactive, organized and systematic coordination of procurement, conversion, distribution and use of energy to meet the requirements, taking into account environmental and economic objectives" [4]. Continual improvement is a key requirement in any energy management system and it can be achieved using the PDCA cycle. 
The concept of PDCA was first introduced by Walter Shewhart and was further developed and popularized by Edwards Deming. The cycle presented in the Figure 1.4.1 below can be used as an effective continuous improvement tool [5].

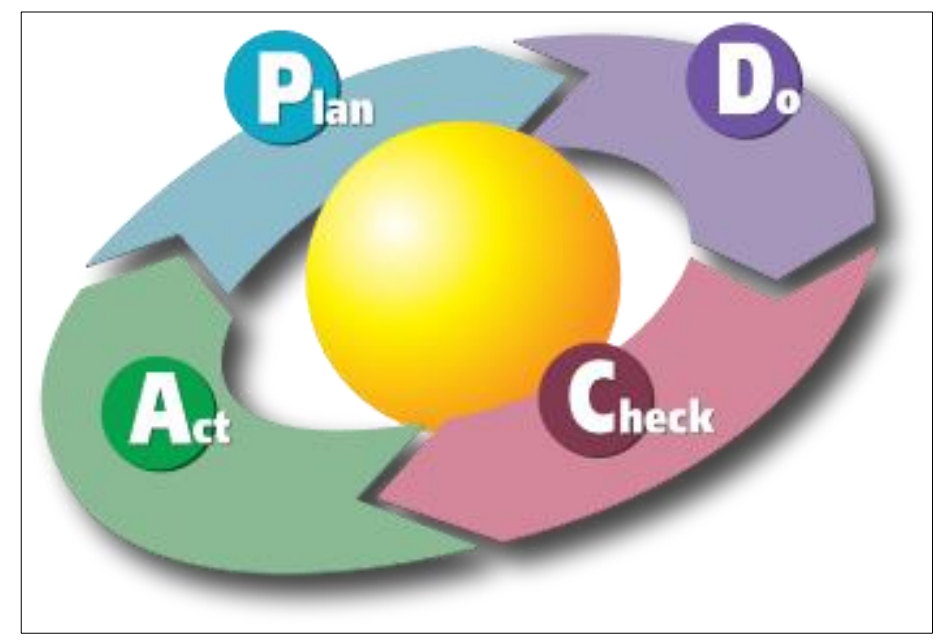

Figure1.4.1: PDCA cycle [5]

The PDCA cycle consists of 4 stages which can be used in systems to assist facilities in addressing processes from problem facing to problem solving situations. The cycle consists of:

- Plan: Planning of system, process and resource allocation to achieve the objective.

- Do: Implementation according to the developed plan and collecting the performance data.

- Check: Analyzing the collected results to verify the implementation conformance with proposed plan

- Act: Corrective actions if any, for deviation from the actual plan based on the results from checking.

After the completion of the Act stage, the cycle moves back again to the Plan stage, giving PDCA cycle the characteristics of continuous improvement [5]. 


\title{
1.5 Energy Management Standards
}

\begin{abstract}
ANSI/MSE 2000:2008
ANSI/MSE 2000:2008 is an energy management standard developed by Georgia Institute of Technology. This standard specifies requirements for a management system for energy (MSE) that helps an organization to take a systematic approach towards continual improvement of energy performance [6]. According to the standard, energy performance may include reduction in energy intensity, increasing the use of renewable energy resources, and reduction in energy costs.
\end{abstract}

This management system for energy covers the supply, demand, reliability, purchase, storage, use and disposal, as appropriate, of primary and secondary energy resources. According to this standard, organizations need to specify reasonable performance improvement goals based on their energy management planning process. ANSI/MSE 2000 is used as one of the resources for developing ISO 50001 (discussed later).

\section{EN 16001:2009}

EN 16001:2009 is the energy management standard developed by British Standards Institution. This standard ensures that energy management becomes integrated into organizational business structure, so that organizations can save energy, costs and improve energy and business performance. The primary objective of this standard is organizations continual improvement in energy performance.

EN 16001:2009 provides a range of possible methodologies and approaches which could be used in both satisfying the standard and ensuring the development and operation of an effective and documented Energy Management System. This standard will not establish any requirements for energy performance nor does it guarantee optimal energy outcomes.

\section{ISO 50001}

ISO 50001 is the latest energy management standard which is a successor of ANSI/MSE 2000 and EN 16001. The draft standard guides an organization to develop and implement 
a policy, identify significant areas of energy consumption and commit to energy reductions. The standard in general does not specify by itself any specific performance criteria just like any other management system standard published by the ISO.

ISO 50001 is based on the management system model of continual improvement also used for other well-known standards such as ISO 9001 or ISO 14001. This makes it easier for organizations to integrate energy management into their overall efforts to improve quality and environmental management. ISO 50001 provides a framework of requirements for organizations to [8]:

Develop a policy for more efficient use of energy

Fix targets and objectives to meet the policy

Use data to better understand and make decisions about energy use

Measure the results

$>$ Review how well the policy works, and

$>$ Continually improve energy management.

\subsection{Types of Energy Assessment Methodologies}

Energy assessment is a detailed evaluation of how a facility uses energy, what the facility pays for energy, and finally, a recommended program for changes for operating practices or energy consuming equipment that will cost effectively reduce utility bills [6]. The various stages of an industrial energy assessment are,

$>$ Analyzing the utility bills and rate schedules

$>$ Pre-assessment planning

Conducting in-plant assessment

$>$ Identifying energy conservation measures (ECM's)

$>$ Energy savings and economic analyses

$>$ Implementation of energy savings recommendations and verifications of calculated savings 


\subsection{IAC Assessment Process}

Industrial Assessment Center (IAC) is a program funded by Department of Energy to conduct no-cost energy assessments for small and medium scale manufacturing facilities across the country. IAC program is a university based program and there are 24 active industrial assessment centers located in various universities. The eligibility criteria for a facility to qualify for an IAC energy assessment are,

- Within standard industrial codes (SIC) 20-39

- Within North American Industry Classification System (NAICS) 311-339

- Within 150 miles of host campus

- Gross annual sales below $\$ 100$ million

- Fewer than 500 employees at the plant site

- Annual utility bills more than $\$ 100,000$ and less than $\$ 2.5$ million

- No in-house professional staff to perform assessment

The exact procedures followed in an IAC assessment are show in Methodology chapter.

\subsection{Enhanced Energy Assessment Process}

Enhanced Energy Assessment Process (EEAP) [9] is developed under DOE AMO Save Energy Now Project (now called as "Better Buildings Better Plants") program. According to this methodology, energy assessment is divided into three stages. They are,

- Pre-assessment

- Assessment

- Post-assessment

The energy assessment part is similar to IAC style but extensive amount of data collection is done for accurate technical analysis in developing investment grade assessments.

\subsection{ASHRAE Energy Auditing Procedure:}

The American Society of Heating Refrigeration and Air-Conditioning Engineers (ASHRAE) defines three levels of energy audits. Each audit level builds on the previous 
level. As audit complexity increases, so does the thoroughness of the site assessment, the amount of data collected and detail provided in the final audit report. There are three levels of audits defined by ASHRAE [10]. They are,

1) Level 1: Site Assessment or Preliminary Audits

2) Level 2: Energy Survey and Engineering Analysis Audits

3) Level 3: Detailed Analysis of Capital-Intensive Modification Audits

One of the primary limitations of ASHRAE energy auditing procedure is that it addresses the needs of residential and commercial building sector but not the industrial sector.

\subsection{ASME Energy Auditing Procedure}

American Society for Mechanical Engineers (ASME) developed standards for conducting energy assessments at industrial facilities and these standards are accredited by American National Standards Institute (ANSI). ASME has separated the major energy consuming equipment in industries under four systems and developed their individual energy auditing procedures. These four systems are [11],

1) ASME EA-1 : Energy Assessment Process Heating Systems

2) ASME EA-2 : Energy Assessment Pumping Systems

3) ASME EA-3 : Energy Assessment Steam Systems

4) ASME EA-4 : Energy Assessment Compressed Air Systems

\subsection{Need for Research}

One of the primary objectives of implementing ISO 50001 is for continual improvement in energy efficiency in any facility. In order to achieve continual improvement, top level management plays a crucial role. Often many energy efficiency improvements do not result in projected savings due to lack of management's commitment towards energy efficiency. All the above mentioned energy auditing procedures cannot fully address the requirements of energy management standard and creating a gap in its implementation [7]. All the auditing procedures developed address the problem of attaining energy efficiency in a technical stand point by taking a snap shot of existing facilities energy consumption and ignore the requirements of ISO 50001. Hence it's becoming difficult for 
facilities to attain ISO 50001 certification as they again need to do go for third party services providers for implementing ISO 50001. Table 1.11.1 provides the specific requirements of the energy planning section of ISO 50001 and the information generated by ASME assessment methodology, IAC methodology and methodology intended to develop here.

Table 1.11.1: ISO 50001 requirements and information generated by different assessment methods

\begin{tabular}{|c|c|c|c|}
\hline $\begin{array}{c}\text { ISO 50001 } \\
\text { Energy } \\
\text { Planning }\end{array}$ & Requirements & $\begin{array}{c}\text { ASME } \\
\text { Methodology }\end{array}$ & $\begin{array}{c}\text { IAC } \\
\text { Methodology }\end{array}$ \\
\hline \multirow[t]{7}{*}{$\begin{array}{l}\text { 4.4.3 Energy } \\
\text { Review }\end{array}$} & $\begin{array}{l}\text { a) Identify Current } \\
\text { Energy Source }\end{array}$ & Yes & Yes \\
\hline & $\begin{array}{l}\text { b) Evaluating Energy } \\
\text { Consumption }\end{array}$ & Yes & Yes \\
\hline & c) Identifying SEU's & No & No \\
\hline & $\begin{array}{l}\text { d) Variables effecting } \\
\text { SEU }\end{array}$ & No & No \\
\hline & $\begin{array}{l}\text { e) Identifying EnPI's } \\
\text { for facility }\end{array}$ & No & No \\
\hline & $\begin{array}{l}\text { f) Estimate future } \\
\text { energy consumption }\end{array}$ & No & No \\
\hline & $\begin{array}{l}\text { g) Identifying } \\
\text { Opportunities }\end{array}$ & Yes & Yes \\
\hline $\begin{array}{l}\text { 4.4.4 Energy } \\
\text { Baseline }\end{array}$ & $\begin{array}{l}\text { a) Establishing } \\
\text { Facility level } \\
\text { Baseline }\end{array}$ & No & No \\
\hline $\begin{array}{l}\text { 4.4.5 Identifying } \\
\text { EnPI's }\end{array}$ & $\begin{array}{l}\text { a) Identifying EnPIs } \\
\text { for SEU's }\end{array}$ & No & No \\
\hline \multirow{4}{*}{$\begin{array}{l}\text { 4.4.6 Energy } \\
\text { Objectives, } \\
\text { Targets and } \\
\text { Action Plans }\end{array}$} & a) Energy Objectives & No & No \\
\hline & b) Energy Targets & No & No \\
\hline & $\begin{array}{l}\text { c) Action Plans for } \\
\text { SEU's }\end{array}$ & No & No \\
\hline & d) M \& V Plans & No & No \\
\hline
\end{tabular}

The above table clearly shows a gap in existing methodologies for achieving ISO 50001 and the necessity for developing a new energy assessment methodology. This forces the 
facilities to undergo various auditing procedures for complying with the requirements of the standard and thus increasing their overall cost of implementing the energy management system. Hence the primary objectives of this research are to:

1) Develop an energy assessment methodology for integrating Energy Planning section of ISO 50001 with standard assessment procedure,

2) Develop a reporting format which acts as a supporting document for the requirements of energy planning section of ISO 50001 thus helping the plants in implementation of Energy Management System, and

3) Validate the proposed methodology in a manufacturing facility for checking its effectiveness in implementing ISO 50001

\subsection{Conclusion}

This chapter helps in understanding the present energy consumption across the world and the need for an energy management system similar to the quality and environmental management system in a manufacturing facility. It also helps in understanding the different types of energy assessment standards that are in place and their limitation in addressing the requirements of ISO 50001 energy planning section. 


\section{Chapter 2}

\section{Literature Review}

\subsection{Energy Assessment Methodologies}

The concept of energy auditing was born shortly after the oil energy crisis in 1970's [16]. It is a measure of efficiency in a manufacturing process, thus leading to interest in energy performance of machines and plants directly associated with it [12]. The type of energy assessment conducted depends on size of the facility and the level of accuracy needed in the energy efficiency recommendations. But in general, the energy audits for industrial facilities are classified into two broader categories namely preliminary or walk-through audit and a diagnostic audit [13]. The primary objectives of a walk-through audit is to provide the facility with general opportunities in energy efficiency whereas in a diagnostic audit sophisticated data logging equipment are used to collect the relevant data for specific recommendations and is analyzed. Studies show that there will be a savings potential of around 15\% of total energy consumption and $10-30 \%$ reduction in greenhouse gas emissions by implementing the recommendations of energy assessments [14] [15].

According to enhanced energy assessment process developed under Save Energy Now program, there are three main phases in any type of energy assessment and they are preassessment, assessment and post-assessment. Each of these phases consists of several sub tasks associated with them. Figure 2.1.1 shows energy assessment methodology developed by Lawrence Berkley National Laboratories in collaboration with various industry partners [17]. The assessment methodology as seen below is classified into four categories involving specific tasks that are to be performed. Very few private consultancy firms provide all the services together, but often facilities are forced to undergo various assessments for fulfilling tasks in below shown flow chart thus resulting in a drastic increase in cost of implementing energy efficiency measures. 


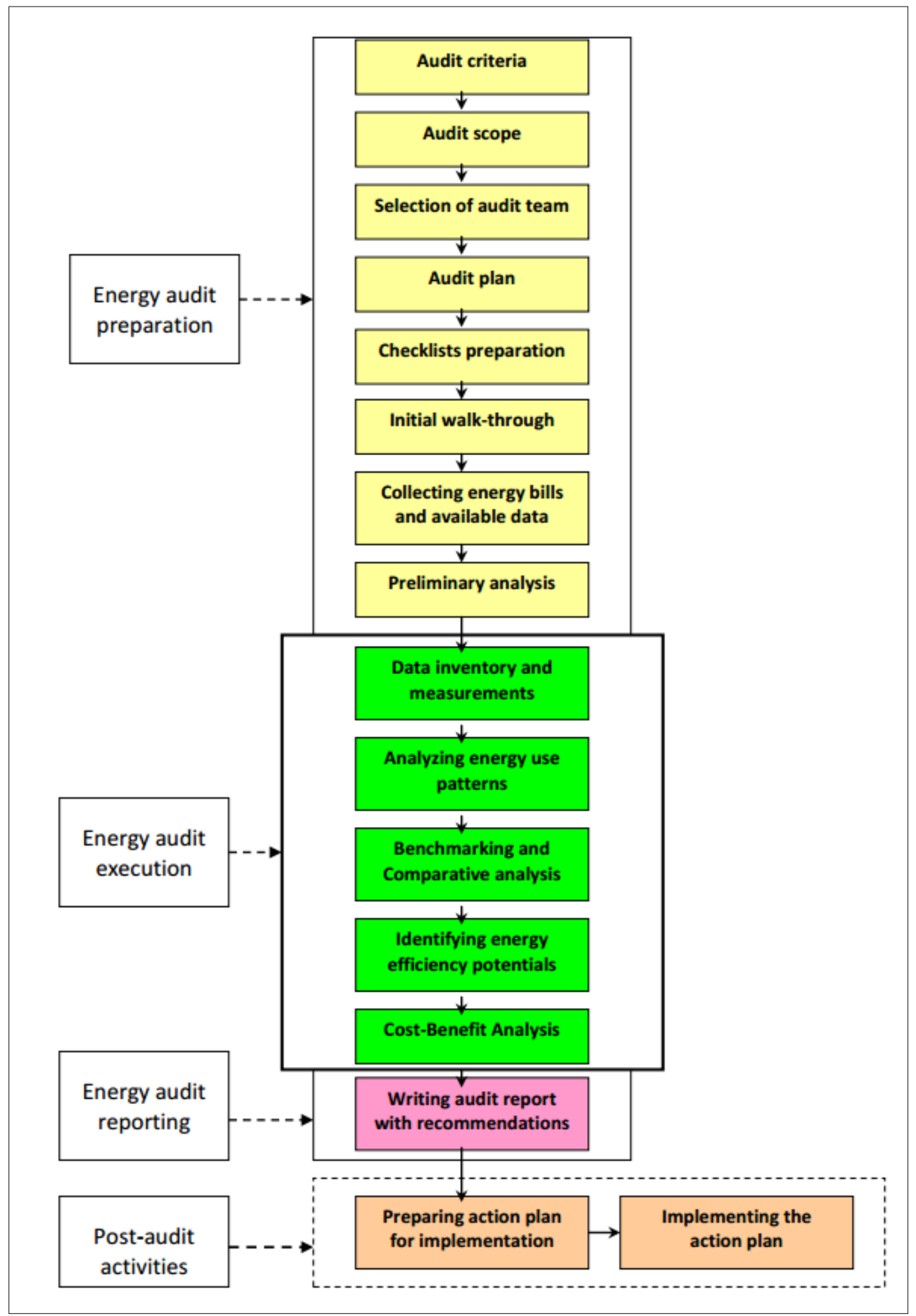

Figure 2.1.1: Overview of Energy Assessment Process [17]

Figure 2.1.1 shows the various activities associated with an energy assessment. The first stage is the energy audit preparation and it involves preparing an audit plan, selection of 
audit team, scope (entire facility or any specific energy system), utility bill analysis and initial walk-through of the facility. The second phase is the execution phase consisting of data collection for the necessary recommendations that are identified during the facility walk-through and performing a cost-benefit analysis of potential recommendations. The third phase is the reporting of energy assessment and final phase is developing the action plans to implement the recommendations and implementing them.

\subsection{Energy Assessment Methodologies Supporting Energy Management Systems}

An Energy Management System systematically records the energy consumption and serves as a basis mainly for investment in improving energy efficiency. It provides a structured approach for continuous improvement in energy efficiency. Figure 2.2.1 shows the worldwide evolution of energy management systems.

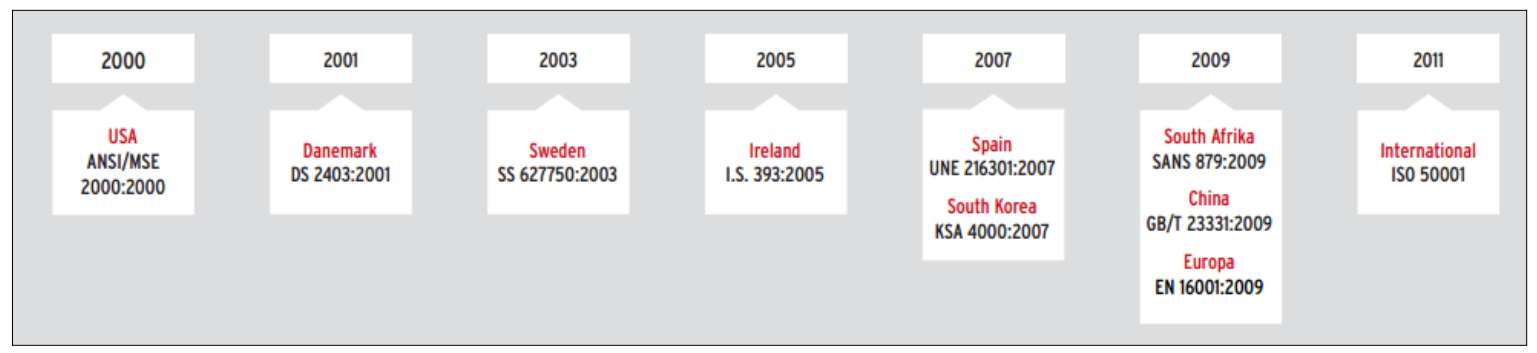

Figure 2.2.1: Evolution of Energy Management Systems [18]

Any energy management system strongly relies on Plan-Do-Check-Act cycle of continual improvement for achieving energy efficiency. Energy auditing is the starting point for achieving energy efficiency of a system. As discussed earlier, there are several assessment methodologies for conducting energy audit. The most prominent standard for conducting energy assessment in U.S. industrial sectors is ASME Systems Standards for Energy Assessments. ASME provides guidelines for performing energy audits for compressed air systems, process heating, steam systems and pumps helping auditors to estimate the energy savings whereas IAC assessment address the issue at the facility level. Since these are just guidelines, auditors do not have any obligation to follow these for conducting energy assessments thus attaining a fraction of potential savings [19]. 
Figure 2.2.2 shows the energy assessment methodology followed by ASME (same approach at system level) and at industrial assessment center. From ASME methodology and industrial assessment methodology we can say that the former method is system specific and the later is at overall facility level. ISO 50001 bridges the gap between the systems approach and the overall facility level approach and acts as a driver for continual improvement in energy performance. Both the assessment methodologies cannot fully address the requirements of energy planning section of ISO 50001. One of the major requirements in Section 4.4.3 (discussed later in the section) in ISO 50001 is to develop a facility level baseline and identify significant energy users and develop energy performance indicators. All these requirements are not addressed in the above mentioned methodology or in ASME energy assessment standard. Figure 2.2.2 shows ASME energy assessment methodology for process heating.

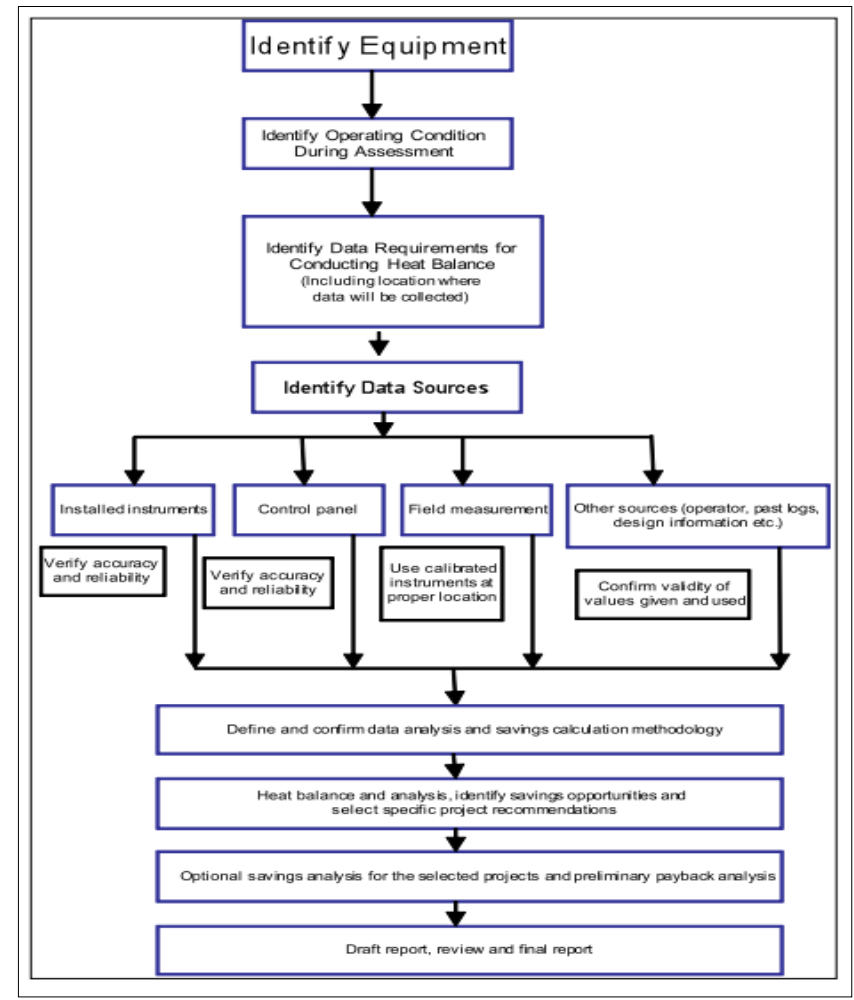

Figure 2.2.2: ASME assessment methodology for process heating [27] 


\subsection{ISO 50001 Energy Management Standard}

ISO is the International Organization for Standardization with 160 national standards bodies from different parts of the world. The most common ISO standards that are in use in the U.S. are ISO 9001 (Quality Management Systems Standard) and ISO 14001 (Environmental Management Systems Standard). The purpose of ISO 50001 is to enable organizations to establish processes necessary to improve energy performance, including energy efficiency, use and consumption [20].

ISO 50001 specifies requirements for establishing, implementing, maintaining and improving an energy management system, whose purpose is to enable an organization to follow a systematic approach in achieving continual improvement of energy performance, including energy efficiency, energy use and consumption.

\subsubsection{Scope of ISO 50001}

ISO 50001 specifies requirements applicable to energy use and consumption, including measurement, documentation and reporting, design and procurement practices for equipment, systems, processes and personnel that contribute to energy performance. It is applied to all the variables that affect energy performance. This standard provides methodology for continual improvement in energy performance without explicitly specifying any performance criteria that has to be attained with respect to energy.

ISO 50001 provides a framework of requirements enabling organizations to [20] as follows:

1) Develop a policy for more efficient use of energy

2) Fix targets and objectives to meet the policy

3) Develop indicators for energy use and consumption

4) Measure and Documenting the results

5) Review the effectiveness of the policy

6) Continually improve energy management system 
This standard is based on Plan-Do-Check-Act (PDCA) continual improvement framework and in the context of energy management; this PDCA approach is outlined as follows:

- Plan: conducting energy review, developing baselines and energy performance indicators, objectives, targets and action plans

- Do: implementation

- Check: measuring performance against the energy policy, objectives and reporting the results

- Act: actions for continual improvement

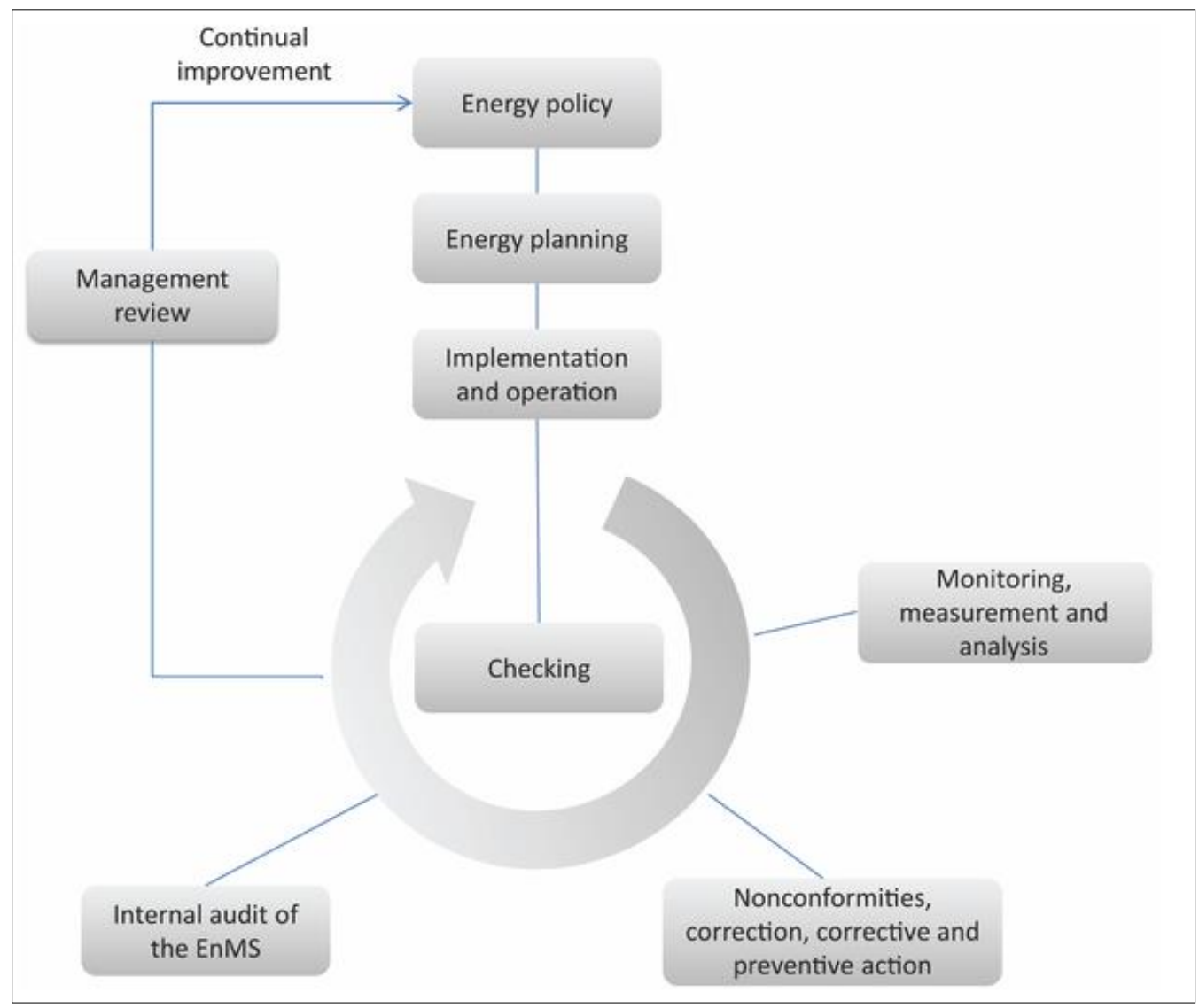

Figure 2.3.1: Energy Management System Model for ISO 50001 [20] 


\subsection{Section 4.4 ISO 50001-Energy Planning}

Important sub-section in section 4.4 of ISO 50001 is briefly discussed below:

\subsubsection{Section 4.4.1-General}

Energy planning is a broader term which requires the organization to develop and document the necessary methodology for attaining continuous improvement in energy efficiency which is a mandatory requirement for ISO 50001 standard. It is also required that, the organization shall review the activities affecting the energy performance.

ISO 50001standard Annexure A gives a simple diagram for this energy planning process and is shown below in Figure 2.4.1,

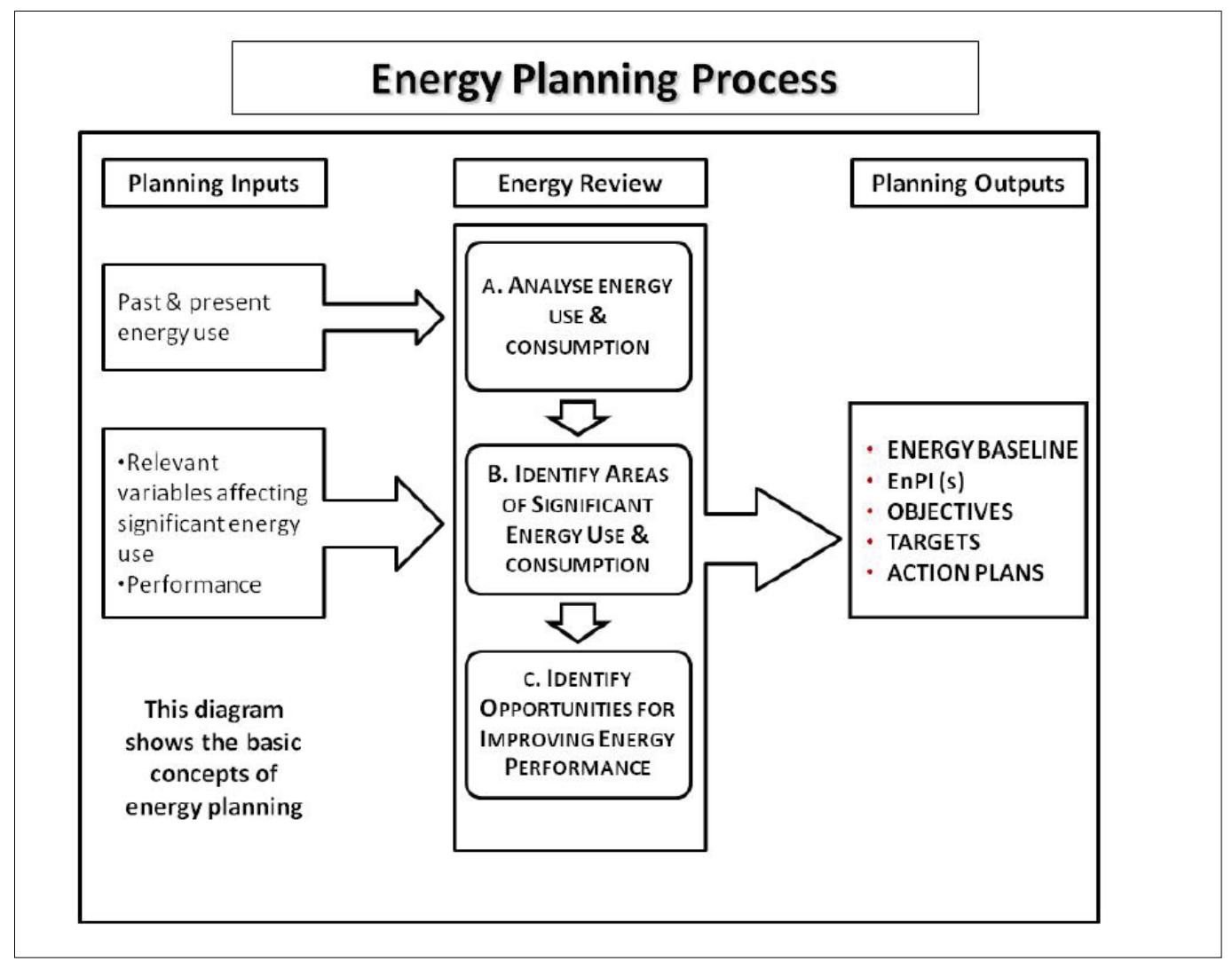

Figure 2.4.1: Energy Planning Process [16] 


\subsubsection{Section 4.4.3 Energy Review}

Energy review involves the organization firstly to identify their current energy consumption involving all types of energy (electricity, natural gas, fuel oil etc.) and identify the equipment or processes with significant energy usage.

This energy review involves three basic steps and is mandated according to ISO 50001. Those are,

1. Analyzing current energy sources and evaluating the past and present energy use and consumption

2. Identifying the areas of significant energy use

3. Identifying and prioritizing the opportunities available for energy efficiency improvement

ISO 50001 requires the organization to update the energy review process at defined intervals of time or if there is a major change in facilities equipment, process or systems. As a part of energy review process, organization shall identify the variables affecting the significant energy users and determining their current performance.

According to ISO 50001, significant energy users are defined as the equipment or processes which consume major portion of energy or with major number of efficiency improvement opportunities.

\subsubsection{Section 4.4.4 Energy Baseline}

Baselining the current energy consumption of a facility is the starting stage in evaluating the effectiveness of any energy efficiency improvement measures [22]. Often, in an industrial facility it is not possible to identify the savings associated with any energy efficiency measures without developing a baseline. Figure 2.4.2 shows the baseline for a facility's electrical consumption. 


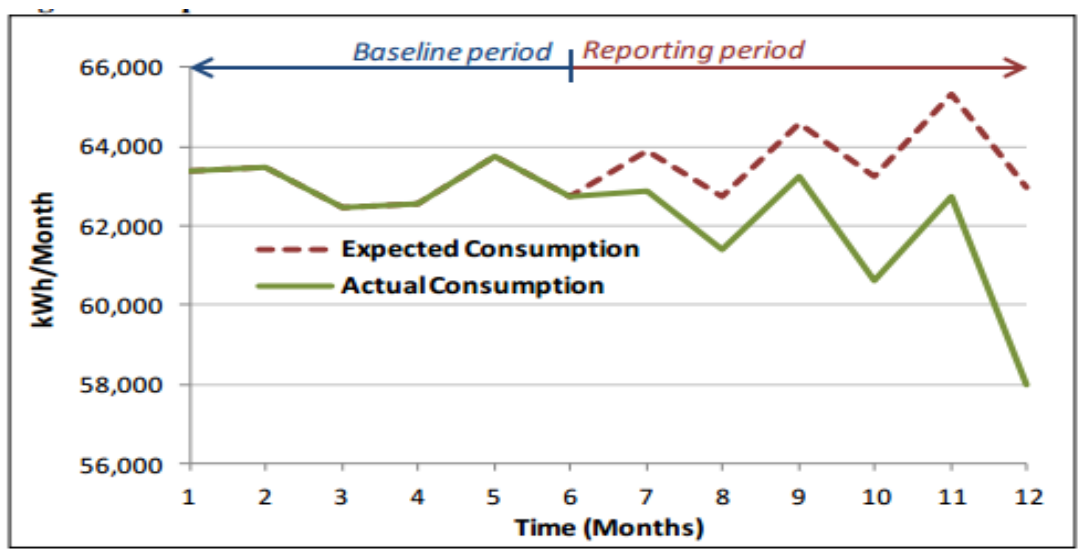

Figure 2.4.2: Energy Baseline [22]

Baseline energy consumption can be expressed in several units like GJ/unit produced, $\mathrm{kWh} / \mathrm{unit}$ produced etc. Energy baseline can be developed at a facility level or individual system level which means, there can be a separate baseline for compressors, chillers, boilers, furnaces or any individual energy consuming system. As an example, for compressor energy consumption, baseline can be cfm of compressed air generated by one kilo-watt of power supplied and the energy savings associated by implementing any measures on a compressor can be verified by using the already developed baseline $(\mathrm{cfm} / \mathrm{kW})$. Northwest Energy Efficiency Alliance developed a six step approach for developing energy baseline and is shown in Figure 2.4.3.

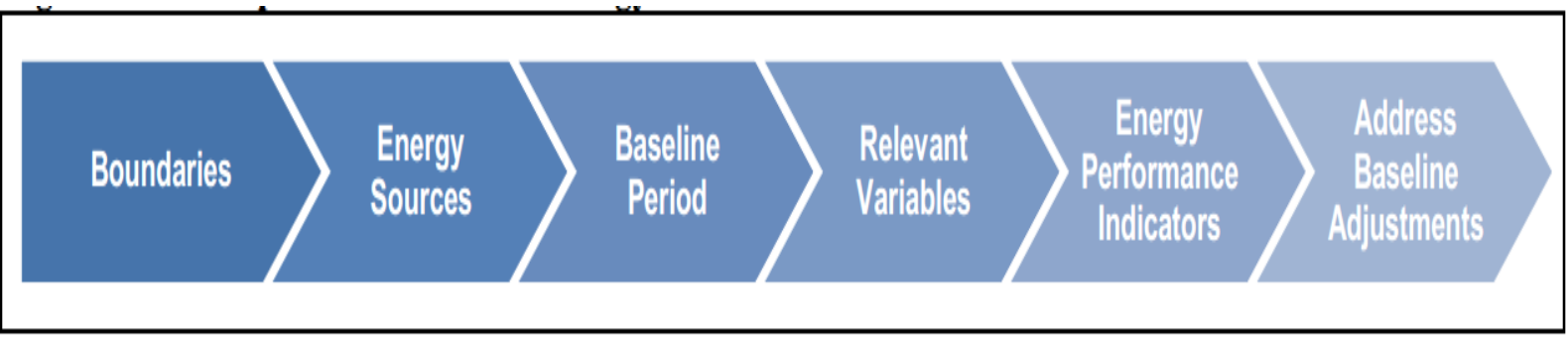

Figure: 2.4.3: Six step Methodology for Developing Energy Baseline [22]

The above shown methodology can be used at the entire facility level or at an individual system level. 


\subsubsection{Section 4.4.5-Energy Performance Indicators}

Energy performance indicators are the quantitative values primarily developed as a benchmark for an energy consuming system to evaluate its performance. These metrics will give one single value that summarizes overall performance of the system [23] [33]. These can be as simple as metered energy usage to a complex function involving several variables [24]. According to ISO 50001 standard, a facility should demonstrate continual improvement with-in the boundary of the management system. Often with-in these boundaries several sub-systems exits. Hence there can be a separate EnPI for each individual system.

There are no standard guidelines for choosing EnPI's and they vary from one facility to another. But usually an appropriate EnPI is one which has the minimum cost and effort to monitor and provides a good feedback on the effectiveness of energy improvement measures. Checklist for potential EnPI's is developed by Georgia Tech Research Corporation and is shown in Table 2.4.1.

Table 2.4.1: Checklist for Various Types of EnPI's [25]

\begin{tabular}{|c|c|c|c|}
\hline Type & Output, units & $\begin{array}{c}\text { Energy } \\
\text { Input, } \\
\text { units }\end{array}$ & EnPI \\
\hline \multirow{6}{*}{ Plant } & Mass: lb., ton & Btu & Btu/lb, Btu/ton \\
\hline & $\begin{array}{l}\text { Units produced: } \\
\text { autos, widgets }\end{array}$ & Btu & Btu/widget \\
\hline & $\begin{array}{l}\text { Clients served: } \\
\text { customers }\end{array}$ & Btu & Btu/customer \\
\hline & Mass: lb., ton & $\mathrm{kWh}$ & $\begin{array}{l}\mathrm{kWh} / \mathrm{lb} \\
\mathrm{kWh} / \mathrm{ton}\end{array}$ \\
\hline & $\begin{array}{l}\text { Units produced: } \\
\text { autos, widgets }\end{array}$ & $\mathrm{kWh}$ & $\mathrm{kWh} /$ widget \\
\hline & $\begin{array}{l}\text { Clients served: } \\
\text { customers }\end{array}$ & $\mathrm{kWh}$ & $\mathrm{kWh} /$ customer \\
\hline
\end{tabular}




\begin{tabular}{|c|c|c|c|}
\hline Type & Output, units & $\begin{array}{l}\text { Energy } \\
\text { Input, } \\
\text { units }\end{array}$ & EnPI \\
\hline \multirow{6}{*}{$\begin{array}{l}\text { Production } \\
\text { line }\end{array}$} & $\begin{array}{l}\text { Mass: lb., ton from } \\
\text { line }\end{array}$ & $\begin{array}{l}\text { Btu input } \\
\text { to line }\end{array}$ & $\begin{array}{l}\text { Btu/lb, Btu/ton } \\
\text { for line }\end{array}$ \\
\hline & $\begin{array}{l}\text { Units produced: } \\
\text { autos, widgets on } \\
\text { line }\end{array}$ & $\begin{array}{l}\text { Btu input } \\
\text { to line }\end{array}$ & $\begin{array}{l}\text { Btu/widget for } \\
\text { line }\end{array}$ \\
\hline & $\begin{array}{l}\text { Clients served: } \\
\text { customers on line }\end{array}$ & $\begin{array}{l}\text { Btu input } \\
\text { to line }\end{array}$ & $\begin{array}{l}\text { Btu/customer for } \\
\text { line }\end{array}$ \\
\hline & $\begin{array}{l}\text { Mass: lb., ton from } \\
\text { line }\end{array}$ & $\begin{array}{l}\mathrm{kWh} \text { input } \\
\text { to line }\end{array}$ & $\begin{array}{c}\mathrm{kWh} / \mathrm{lb}, \\
\mathrm{kWh} / \text { ton for line }\end{array}$ \\
\hline & $\begin{array}{l}\text { Units produced: } \\
\text { autos, widgets on } \\
\text { line }\end{array}$ & $\begin{array}{l}\mathrm{kWh} \text { input } \\
\text { to line }\end{array}$ & $\begin{array}{l}\mathrm{kWh} / \text { widget for } \\
\text { line }\end{array}$ \\
\hline & $\begin{array}{l}\text { Clients served: } \\
\text { customers on line }\end{array}$ & $\begin{array}{l}\mathrm{kWh} \text { input } \\
\text { to line }\end{array}$ & $\begin{array}{l}\mathrm{kWh} / \text { customer } \\
\text { for line }\end{array}$ \\
\hline \multirow{5}{*}{ Process } & $\begin{array}{l}\text { Mass: } 1 \mathrm{lb} ., \text { ton } \\
\text { through process }\end{array}$ & $\begin{array}{l}\text { Btu input } \\
\text { to process }\end{array}$ & $\begin{array}{l}\text { Btu/lb, Btu/ton } \\
\text { for process }\end{array}$ \\
\hline & $\begin{array}{l}\text { Units produced: } \\
\text { autos, widgets in } \\
\text { process }\end{array}$ & $\begin{array}{l}\text { Btu input } \\
\text { to process }\end{array}$ & $\begin{array}{l}\text { Btu/widget for } \\
\text { process }\end{array}$ \\
\hline & $\begin{array}{l}\text { Clients served: } \\
\text { customers in } \\
\text { process }\end{array}$ & $\begin{array}{l}\text { Btu input } \\
\text { to line }\end{array}$ & $\begin{array}{l}\text { Btu/customer for } \\
\text { process }\end{array}$ \\
\hline & $\begin{array}{l}\text { Mass: lb., ton } \\
\text { through process }\end{array}$ & $\begin{array}{l}\mathrm{kWh} \text { input } \\
\text { to line }\end{array}$ & $\begin{array}{l}\mathrm{kWh} / \mathrm{lb}, \\
\mathrm{kWh} / \text { ton for } \\
\text { process }\end{array}$ \\
\hline & $\begin{array}{l}\text { Units produced: } \\
\text { autos, widgets in } \\
\text { process }\end{array}$ & $\begin{array}{l}\mathrm{kWh} \text { input } \\
\text { to line }\end{array}$ & $\begin{array}{l}\mathrm{kWh} / \text { widget for } \\
\text { process }\end{array}$ \\
\hline
\end{tabular}




\begin{tabular}{||c|c|c|c|}
\hline Type & Output, units & $\begin{array}{c}\text { Energy } \\
\text { Input, } \\
\text { units }\end{array}$ & EnPI \\
\hline & $\begin{array}{c}\text { Clients served: } \\
\text { customers in } \\
\text { process }\end{array}$ & $\begin{array}{c}\mathrm{kWh} \text { input } \\
\text { to line }\end{array}$ & $\begin{array}{c}\mathrm{kWh} / \text { customer } \\
\text { for process }\end{array}$ \\
\hline
\end{tabular}

\subsubsection{Section 4.4.6: Energy Objectives, Targets and Action Plans}

Once all forms of energy entering the boundary of energy management system are accounted and significant energy users are identified and energy efficiency opportunities are prioritized, the next stage is to develop the objectives, targets and action plans. Energy objectives are developed based on the organization's energy policy. Once the objectives are finalized, detailed metrics are developed to set the targets and finally action plans defines the activities to meet the organization's energy objectives and targets. Together these three form the crucial component in attaining continual improvement for any facility.

Energy objectives are the specified outcomes that a facility sets to implement its energy policy. These are the goals that should be made aware to everyone in the organization and provided a starting point for developing targets and action plans [26]. Once the objectives are defined, one or more targets are developed to achieve the objective. These targets provide metrics and quantitative information regarding the achievement of energy objectives. According to ISO 50001 standard, these energy objectives and targets are to be approved by the management before being communicated in the organization.

\subsection{Superior Energy Performance (SEP)}

ISO 50001 do not define any quantitative requirements in energy performance. The system only makes sure that an organization has the ability to improve its energy performance. Superior Energy Performance (SEP) is the continuation of ISO 50001 which defines the energy performance requirements. ISO 50001 and MSE 50021 are the pre-requisites before applying for SEP certification [27]. 


\subsection{International Performance Measurement and Verification Protocol (IPMVP)}

As a mandatory requirement of ISO 50001 certification process, a facility should demonstrate continual improvement in energy efficiency. In order to achieve this, there should be a proper methodology to quantify the savings associated with any energy efficiency improvement measures. International Performance Measurement and Verification Protocol (IPMVP) has evolved into a worldwide standard for measurement and verification of energy savings associated with assessment recommendations and is used in more than forty countries [29].

Based on the type of the system and conditions of the facility any one of the four options can be adopted. These are [30],

\section{Option A: Partially Measured Retrofit Isolation}

In this option savings are determined by partial field measurements of the system to which energy conservation recommendations are implemented, separate from the rest of the facility. This option involves the short-term or continuous measure of key parameters influencing the energy consumption of the system. This option is used for simple recommendations like lighting retrofits.

\section{Option B: Retrofit Isolation}

In this option savings are determined by field measurement of the system to which energy conservation recommendations are implemented, separate from the rest of the facility. It involves short-term or continuous measurement of all the key parameters affecting the energy consumption during the post-retrofit period. This option requires data for the key parameters before retrofit. This type of approach is commonly applied for motors and pumps to verify savings associated with installing variable speed drives. A $\mathrm{kWh}$ meter is used to monitor the electrical energy consumption before and after the variable frequency drive installation. 


\section{Option C: Whole Facility}

Savings are determined by measuring energy usage at the facility level. Utility meter data is used to estimate the savings with any retrofitting. This option uses simple tools like meter comparison to more sophisticated regression analysis. This approach is followed when an energy savings recommendation implemented on a particular system results in considerable savings from different systems in the facility.

\section{Option D: Calibrated Simulation}

This is the most complex option of all the available options. It requires simulating the energy consumption of entire facility in pre and post retrofit situations thus estimating the energy savings from simulation models. This is a very rarely used option and is only opted when there is no historical data on energy consumption even at the facility level.

\subsection{Conclusion}

This chapter started with introducing the concerns that have to be addressed by an energy management system. It is followed by the ISO 50001 standard and the requirements of the standard. All the requirements related to the energy planning section of ISO 50001 are described and the approaches associated with it. Later part of this chapter discussed about the general guidelines of energy assessment and the guidelines developed by ASME for process specific assessments. Based on the above discussions it is clear that there is a huge gap between the existing energy assessment methodologies and the requirements of energy management standard [32]. The later chapters of this work provide a framework for conducting energy assessments in order to generate a report which helps the facility people with respect to energy planning section of the standard. A brief introduction to various methods followed in international performance measurement and verification protocol to estimate the savings of energy efficient retrofits were discussed in general. 


\section{Chapter3}

\section{Methodology}

\subsection{Proposed Energy Auditing Methodology}

As discussed earlier, energy assessment procedures followed by various organizations are developed for addressing energy efficiency improvement opportunities from purely technical point of view and there is no proper methodology developed for incorporating the requirements of ISO 50001 standard in regular energy auditing and reporting process. The methodology formulated here follows a reverse engineering approach. The requirements in ISO 50001 for sections 4.4.3, 4.4.4, 4.4.5 and 4.4.6 (energy review to objectives, targets and action plans) are clearly mentioned in the standard. Based on the analysis of these requirements, a modified version of energy assessment report is suggested first. Based on the newer report style, the methodology for conducting an energy assessment is developed. A series of flow charts are designed to assist with the energy assessment and reporting process for easy implementation of ISO 50001 part related to energy.

This chapter consists of 16 flow charts out of which 7 (from Figure 3.1.2 to 3.1.8) are based on the existing energy assessment methodology and using these seven flow charts are designed for new assessment methodology that will integrate energy assessment and reporting structure with ISO 50001(Section 4.4.3 to 4.4.6) requirements. These flow charts are divided into two basic categories:

- Flow charts for data collection process

- Flow charts for report development 


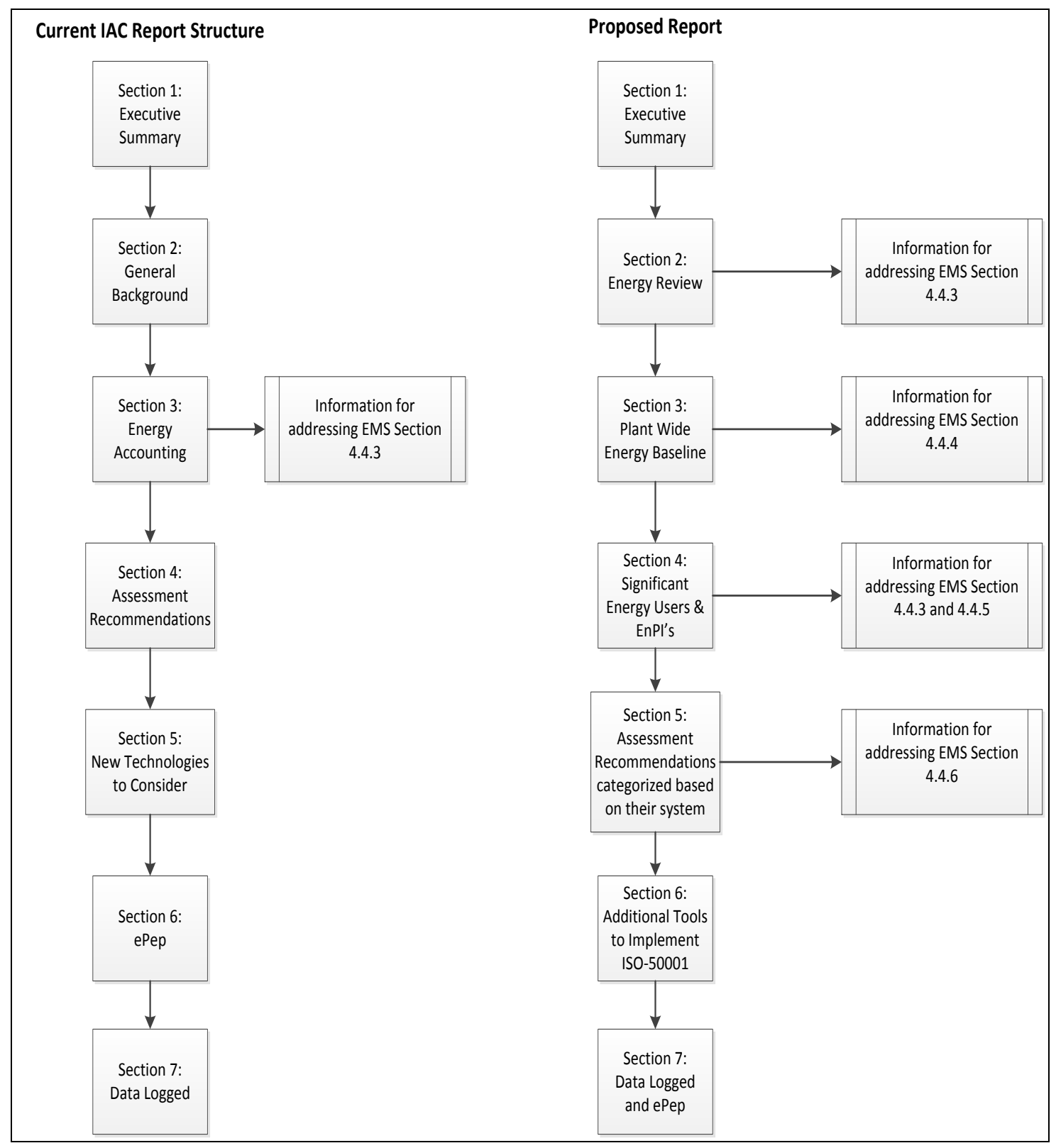

Figure 3.1.1: Current and Proposed Report Structure

Figure 3.1.1 shows the existing procedure to generate an IAC report, after a one day energy assessment is performed at the facility. This involves a series of processes resulting in the final report and the current methodology for assessment which is shown in Figure 3.1.2 


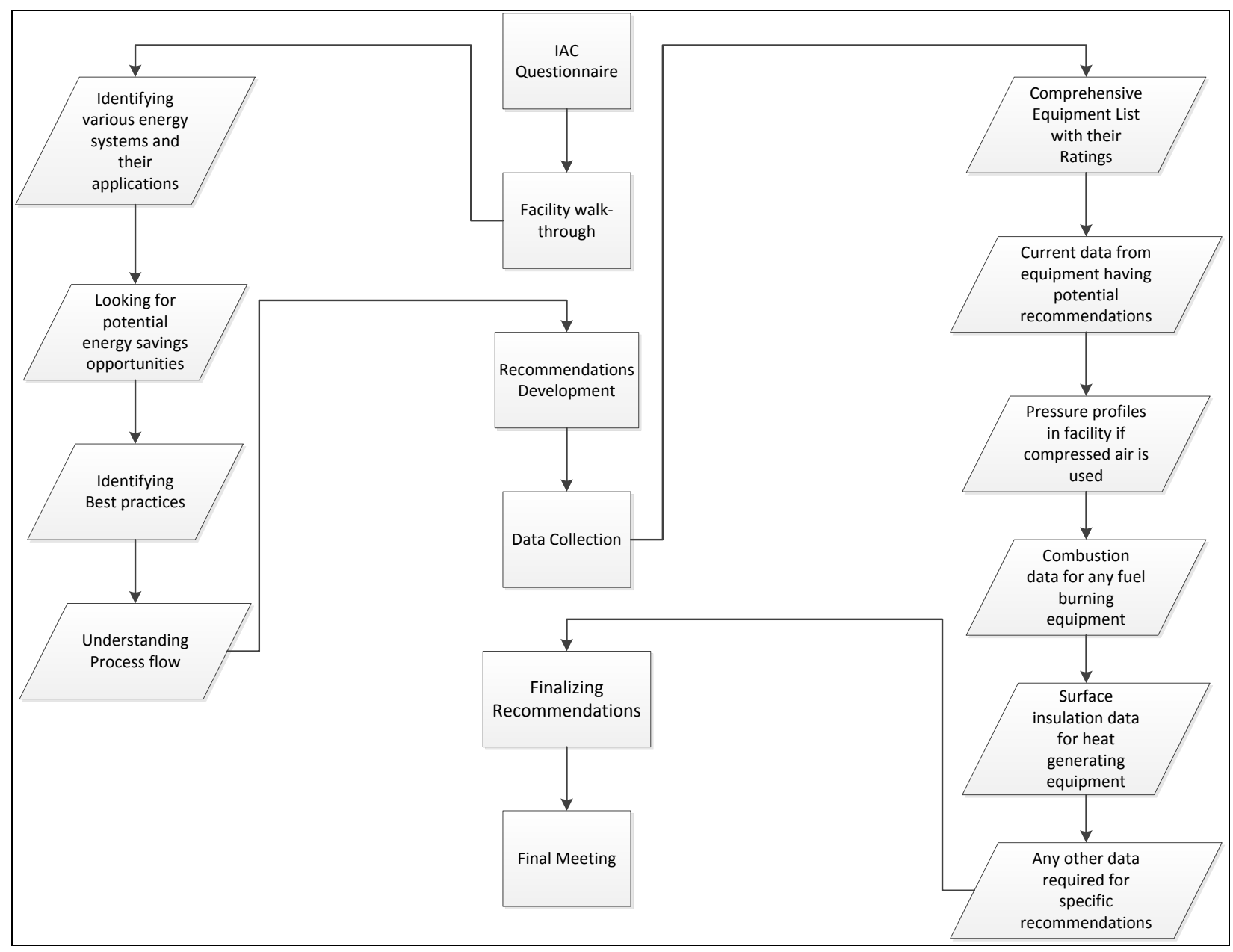

Figure 3.1.2: Current IAC Energy Assessment Process

As shown in Figure 3.1.2, IAC energy assessment methodology starts with a meeting to discuss the contents of questionnaire. It gives the team a fairly reasonable idea of what to expect in the facility. The questionnaire consists of general facility information like operating hours of the facility, energy consumption and various types of general energy systems involving HVAC, compressed air, boilers, chillers and cooling towers. The contents of the questionnaire are shown in Figure 3.1.3. 


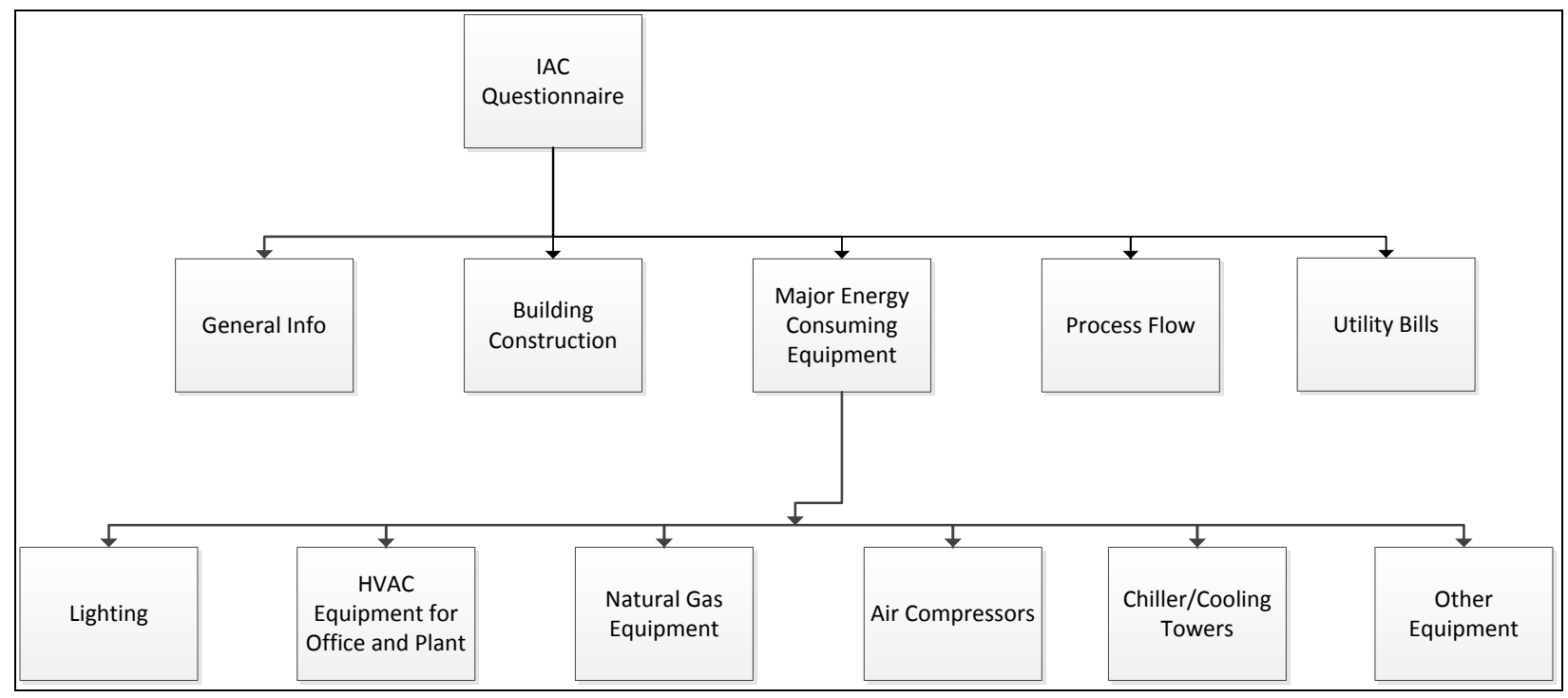

Figure 3.1.3: Overview of Regular IAC Questionnaire

Figure 3.1.3 shows the components of IAC assessment questionnaire. The general info part consists of facilities production schedule, annual production rate, raw material used, utility bills (for all types of energy source used) etc. The most important information gathered in this general info section is utility bills of the facility for a minimum of the last 12 months. These bills are used for Energy Accounting section of the current report format.

The proposed methodology uses existing IAC questionnaire as a base and builds up on it. It requires exhaustive modifications in general info section of questionnaire and data collection process of the regular assessment. The recommended information that has to be collected for the proposed report is shown in Figure 3.1.4. 


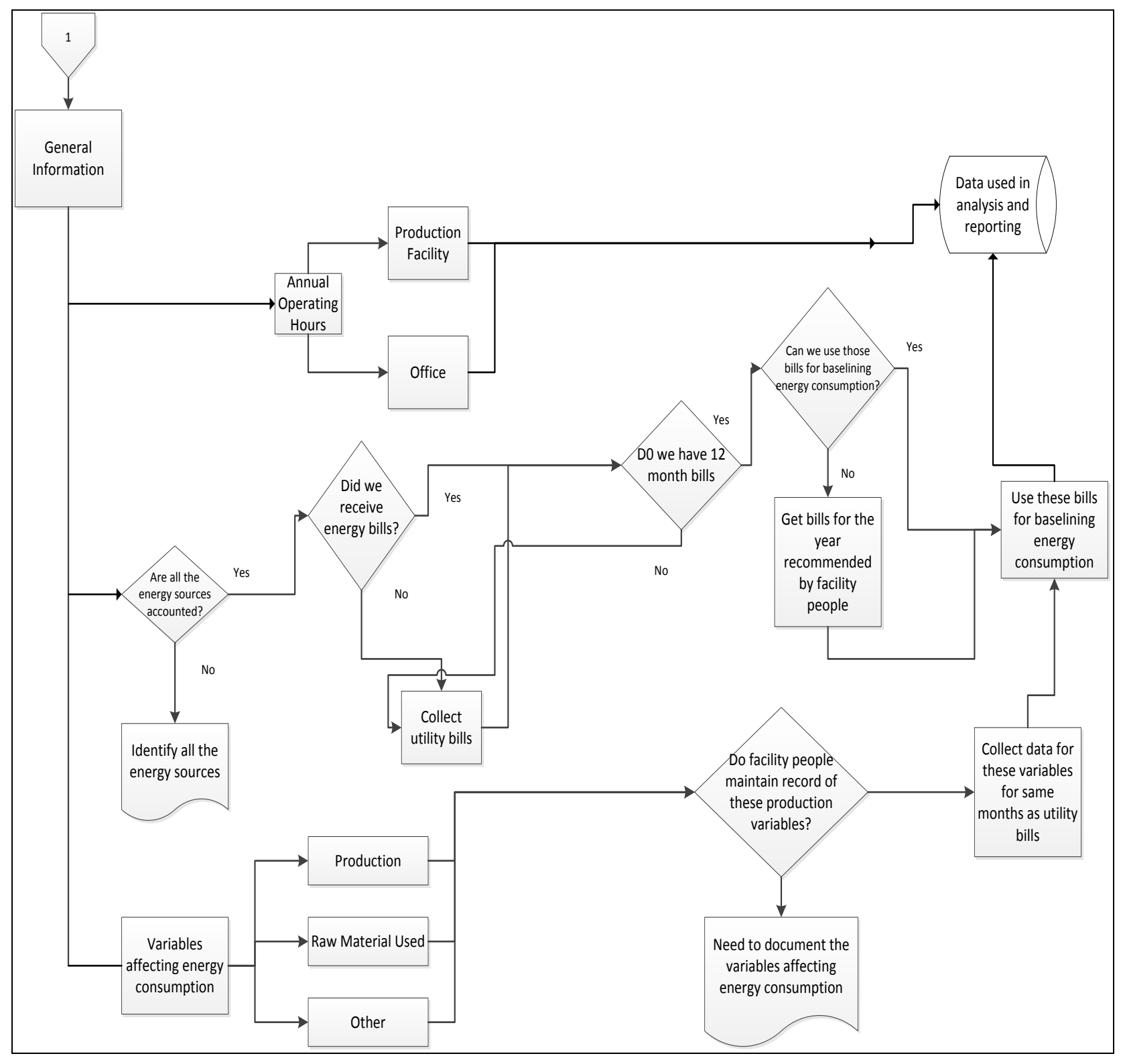

Figure 3.1.4: Proposed General Info Collection Process

There are two key modifications done to the process of collecting general information. First modification done to this section is the collection of all utility bills for baseline energy consumption development if the facility people feel a particular 12 month period is a good indicator other than latest 12 month data. Usually in a regular IAC assessment, we try to get last 12 month utility bills and the primary objective for that is to calculate the cost of energy stream per particular unit. But according to ISO 50001, it is not mandatory to use the latest 12 month data for developing facility wide baseline. The 
second modification done to this process is, adding the section of variables that can affect the facility's energy consumption. These variables can be production, raw material used, scrap generated, heating degree days, cooling degree days or any other parameter that can significantly affect the facilities energy consumption. It is required to have the data for these variables for the same period which is recommended for developing energy baseline. The information gathered according to the above shown flow chart will be used to develop Section 3 (Energy Baseline) in the proposed report.

Once the general information is collected, the second phase of an assessment is a walkthrough tour of the facility. There are no changes needed in this part of the assessment, as the information gathered here will be the same to generate the proposed report. After the tour, the energy team will have a group discussion on the findings of the tour and possible energy efficiency improvement opportunities that should be evaluated further. This is called the assessment recommendations development phase (shown in Figure 3.1.2). Once the possible recommendations are finalized, the team breaks into groups to collect relevant data for further analysis of proposed recommendations. This data collection involves measuring a series of parameters and identifying the name plate data of the equipment on which the assessment recommendation are expected to be implemented.

The next four flow charts show the existing methodology for general data collection of various types of energy systems and later a generalized data collection methodology for proposed report is presented. The general methodology developed calls for current methodology based on the requirements in the facility. Four major energy systems are shown in the following flow charts (Figure 3.1.5, 3.1.6, 3.1.7 and 3.1.8) along with their general data collection process,

- Compressed Air

- HVAC

- Boilers, Ovens and Furnaces

- Chillers and Cooling Towers 
- Other major energy consuming equipment

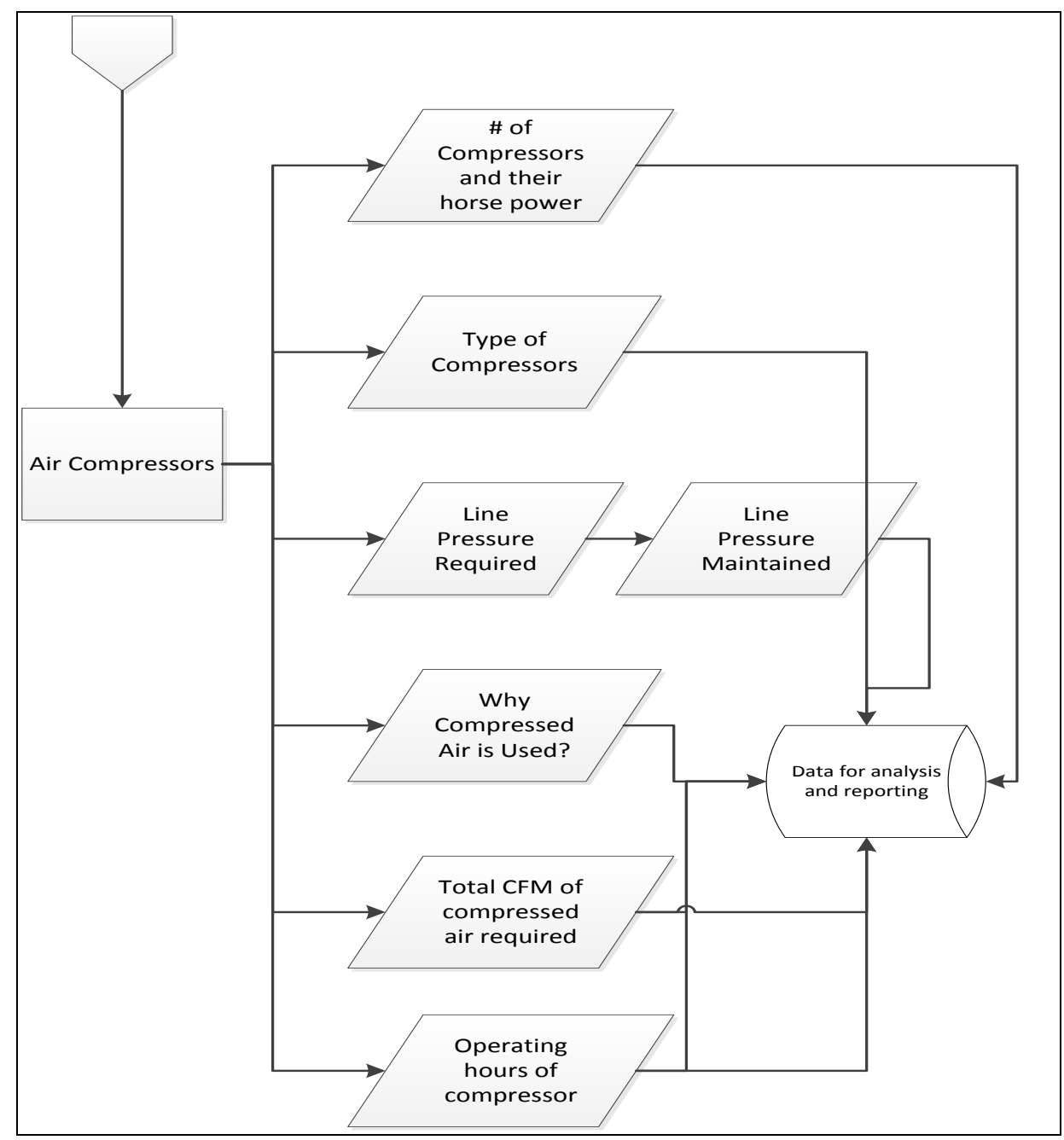

Figure 3.1.5: Data Collected for Compressed Air System

Figure 3.1.5 shows the flow chart for the general data which will be collected during assessment for compressed air system. The basic information in compressed air system is the number of compressors, type of compressors, size of each compressor (horse power or $\mathrm{kW}$ ), type of control on these compressors (load/unload, inlet modulation, VSD etc.), pressure setting on the compressors and the minimum pressure required to operate the equipment of the plant. Based on the information obtained, subsequent questions are asked during the assessment to get an in-depth understanding of the whole compressed 
air system. During walk-through session of the facility, any other observations related to potential energy savings opportunities are noted down for further investigation.

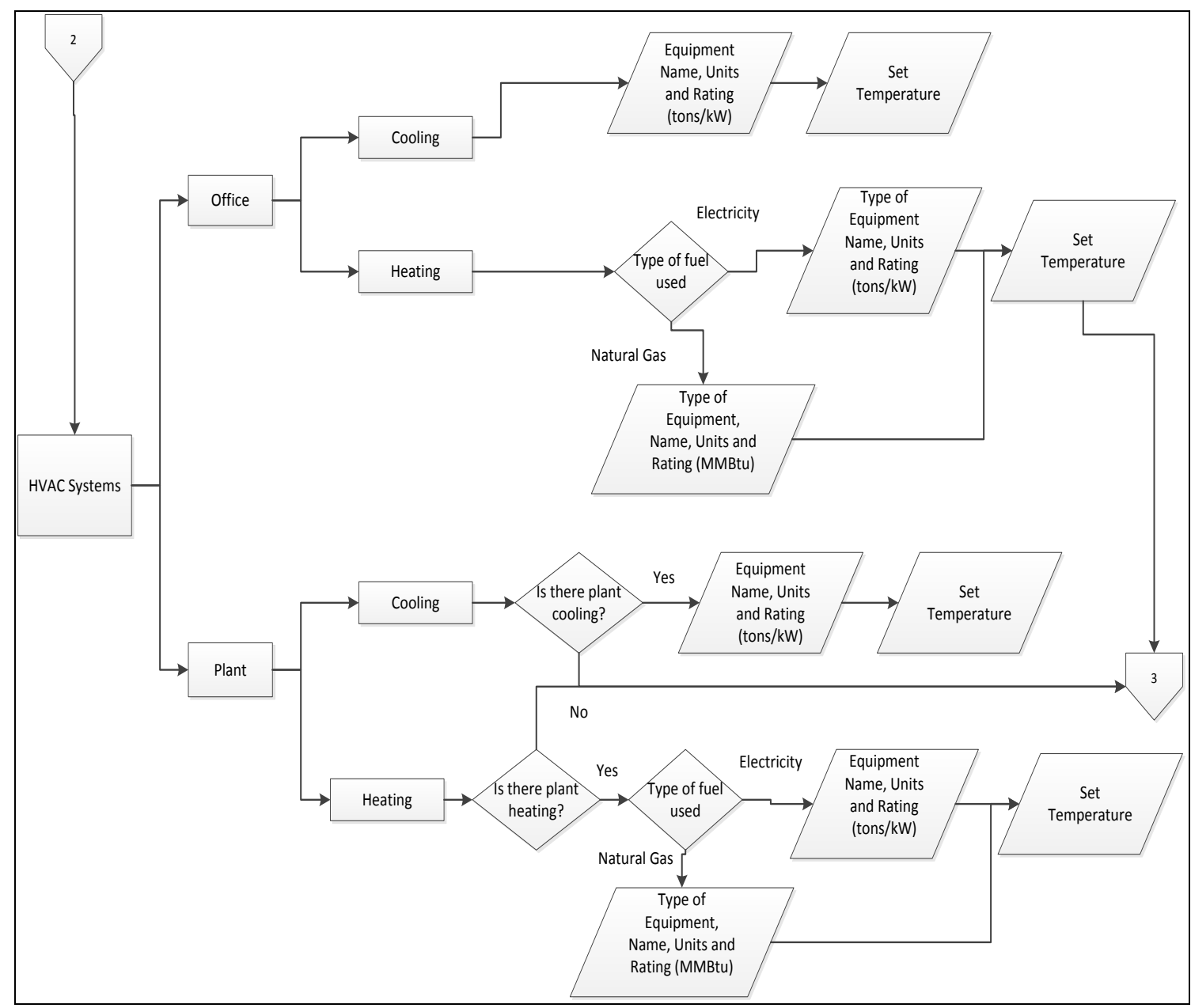

Figure 3.1.6: HVAC System General Data Collection Process

Figure 3.1.6 shows the general information that is collected during the initial discussions on the HVAC system. In most of the assessments, office HVAC systems are separated from the plant. For offices, usually a single unit will perform heating and cooling functions. In production area, there can be various types of equipment to assist in plant cooling and heating. As there are several types of equipment for heating and cooling purposes, the flow chart described above will act as a starting point for further investigation. 


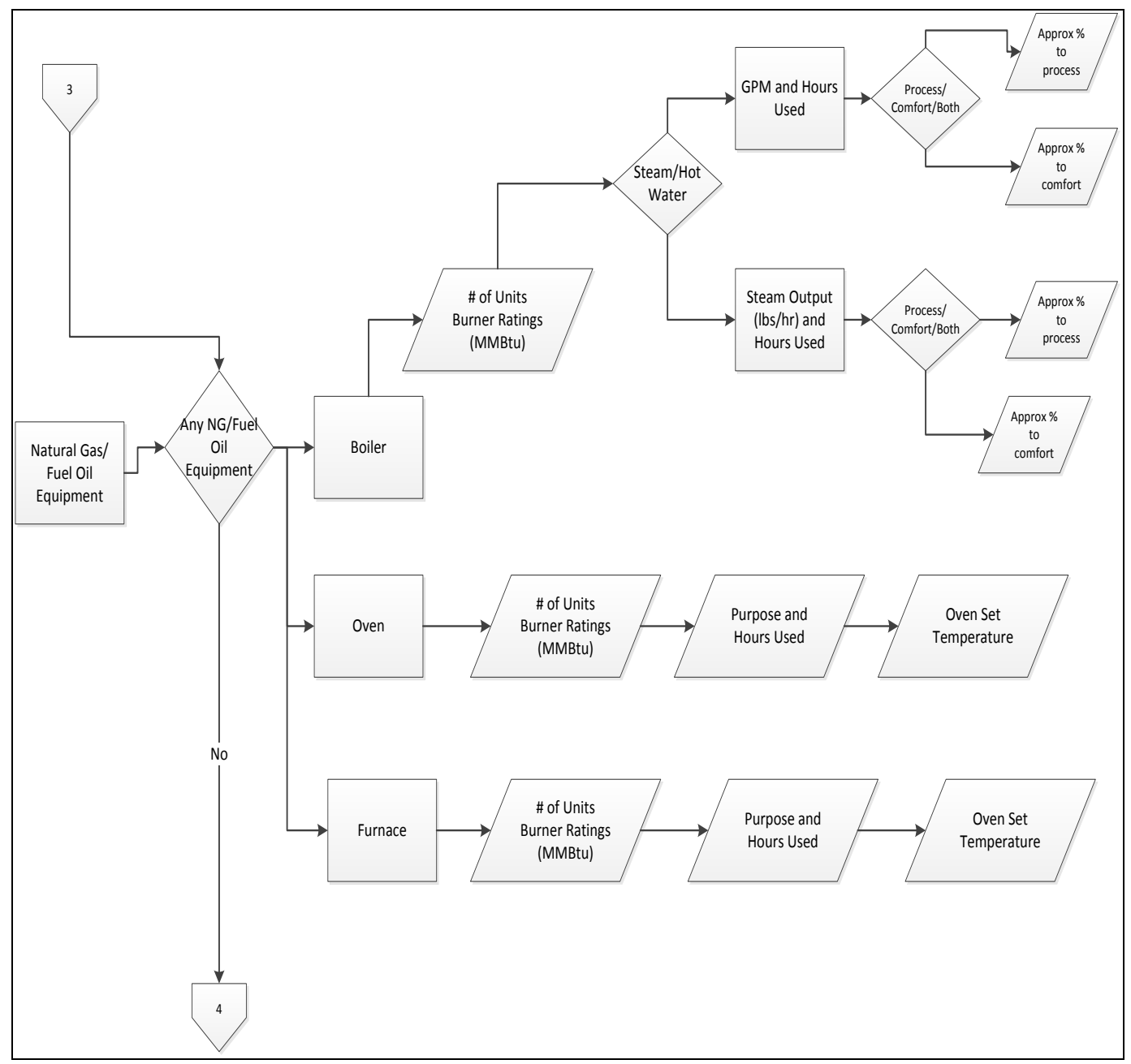

Figure 3.1.7: Natural Gas/Fuel Oil Equipment Data Collection

Figure 3.1.7 shows the existing IAC general data collection procedure for any fuel burning equipment during the initial meeting. . Facilities use various type of equipment which burn fuel to accomplish the necessary task. Most common equipment involves boilers and ovens and generally uses natural gas for their operation. Boilers are most commonly used for either steam generation or for hot water which are used for several other manufacturing purposes are for comfort heating. Ovens are used for heat treating parts for imparting specific physical properties to the products. These equipments consist of burners to burn the fuel and produce heat for process. The combustion products are exhausted out to the atmosphere using a chimney. In any kind of fuel burning equipment, combustion analysis is performed to evaluate the burner efficiency, percentage of oxygen 
in the flue gases and the temperature of the flue gases. This data will be used for any recommendations related to fuel burning equipment.

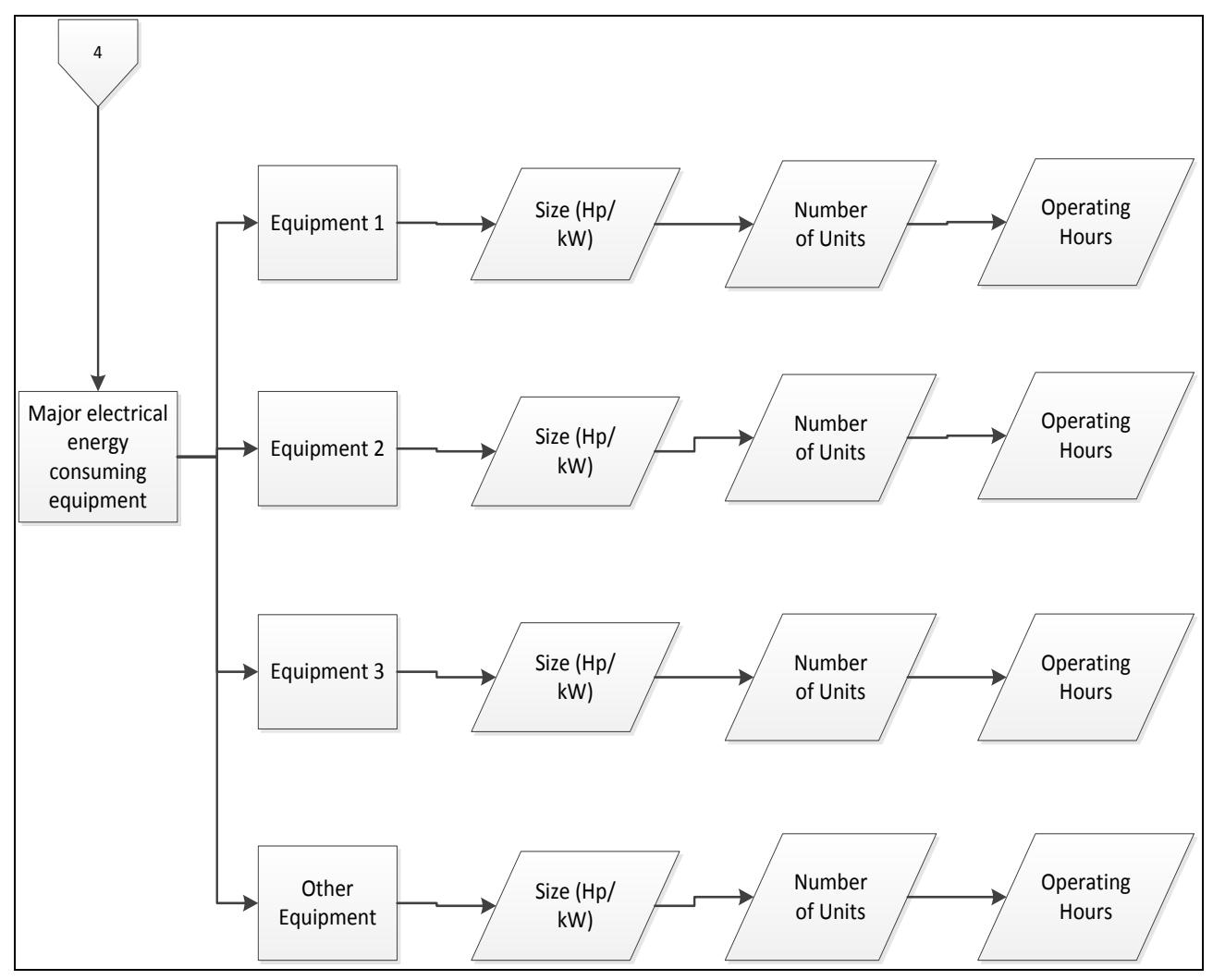

Figure 3.1.8: General Data Collection for all other equipment

Figure 3.1.8 is used only if the equipment does not come under any specific energy systems as mentioned earlier. The next two flow charts are designed to assist the proposed report format and is a generalized version for any energy system. These two flow charts will use any of the above four general data collection methods as part of their process. Figure 3.1.9 shows the basic data collection process for electrical equipment. 


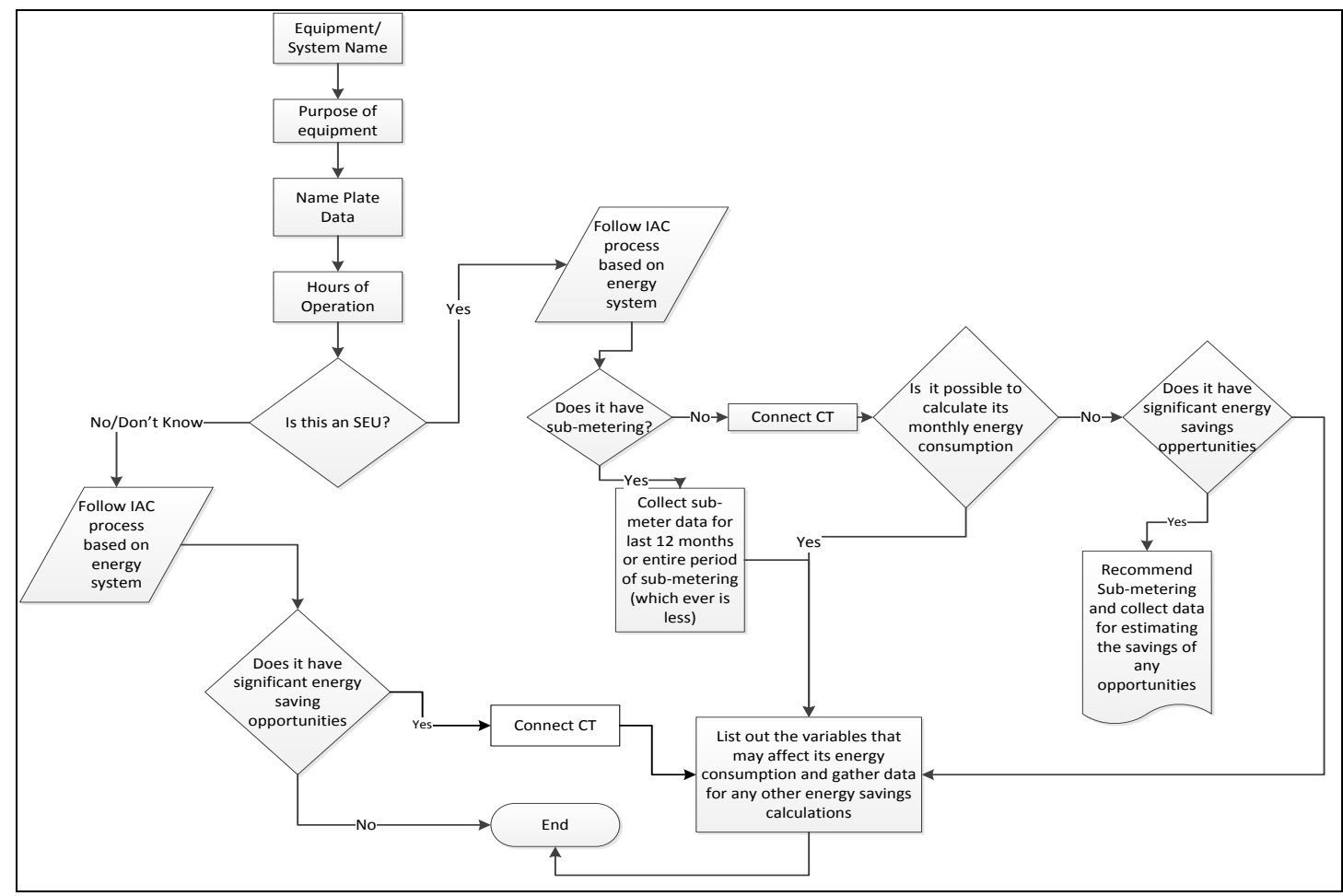

Figure 3.1.9: Proposed generalized data collection procedure for electrical equipment

Figure 3.1.9 shows the generalized data collection system that has to be followed for electrical equipment in order to consider them for significant energy users and to evaluate their performance using EnPIs. The starting step is to know the primary purpose of the equipment. Next, all the manufacturer name plate data has to be recorded including the operating hours from the plant personnel or from the control panel of the equipment if it keeps track of the operating hours. The next process is to decide whether it can be a significant energy user or not. If the output of the question is a "Yes", then follow IAC procedure for initial data collection.

The next part is to verify if the system has any sub-metering or if it is possible to estimate the energy consumption of the equipment on a monthly basis. If there is a sub-metering, then it is necessary to collect the sub-metered data for a period of minimum 12 months or to the maximum available time period if the sub-metering system is less than 12 months old. If there is no sub-metering, it is advised to connect a current transducer to the equipment to monitor its energy consumption. After the current transducer is in place, the next step is to decide whether it is possible to estimate its monthly energy consumption 
with the available data. If the energy consumption can be estimated, then a list of the significant factors or variables that can affect the energy consumption of the equipment should be collected. This information can be obtained easily from the instruction manual of the equipment or a discussion with the operators of the equipment. If it is not possible to estimate the monthly energy consumption, then the next step is to check if it has any significant energy savings opportunities or not. If there are significant energy savings opportunities, then the installation of sub-metering would be recommended as it can be termed as a significant energy user according to ISO 50001.

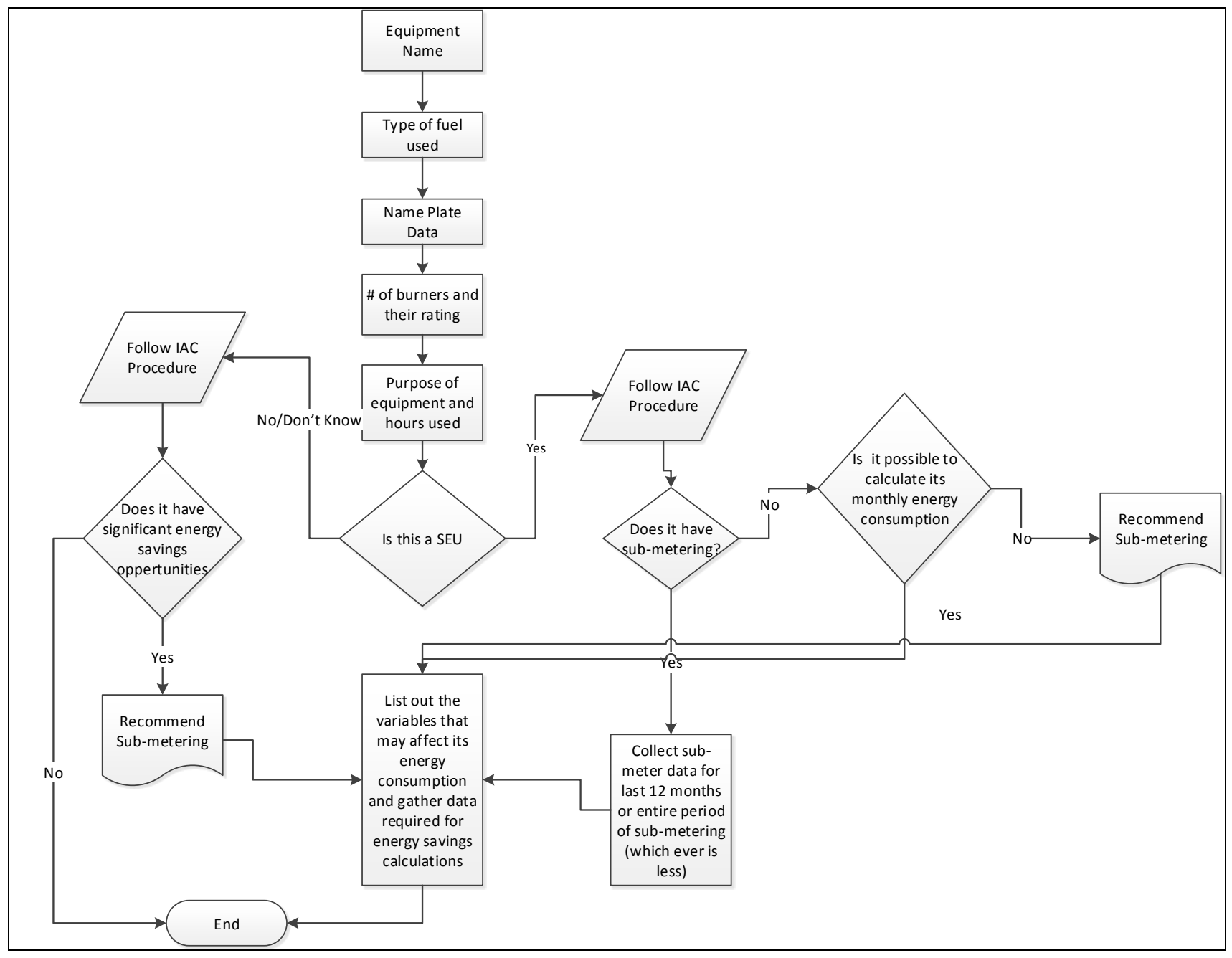

Figure 3.1.10: Proposed generalized data collection process for fuel burning equipment 
Figure 3.1.10 shows the basic methodology for collecting necessary data in case of fuel burning equipment. The approach followed here is exactly similar to the one followed for collecting data for electrical equipment. Once the above mentioned data collection methodology is followed, all the required information to develop a new style of report as shown in Figure 3.1.1 will be available.

As shown in Figure 3.1.1, the first section of the report is the executive summary. There are no significant changes made in this section in the proposed report from the existing report other than combining general background of IAC report with executive summary creating only one section. The new executive summary is shown in figure 3.1.11.

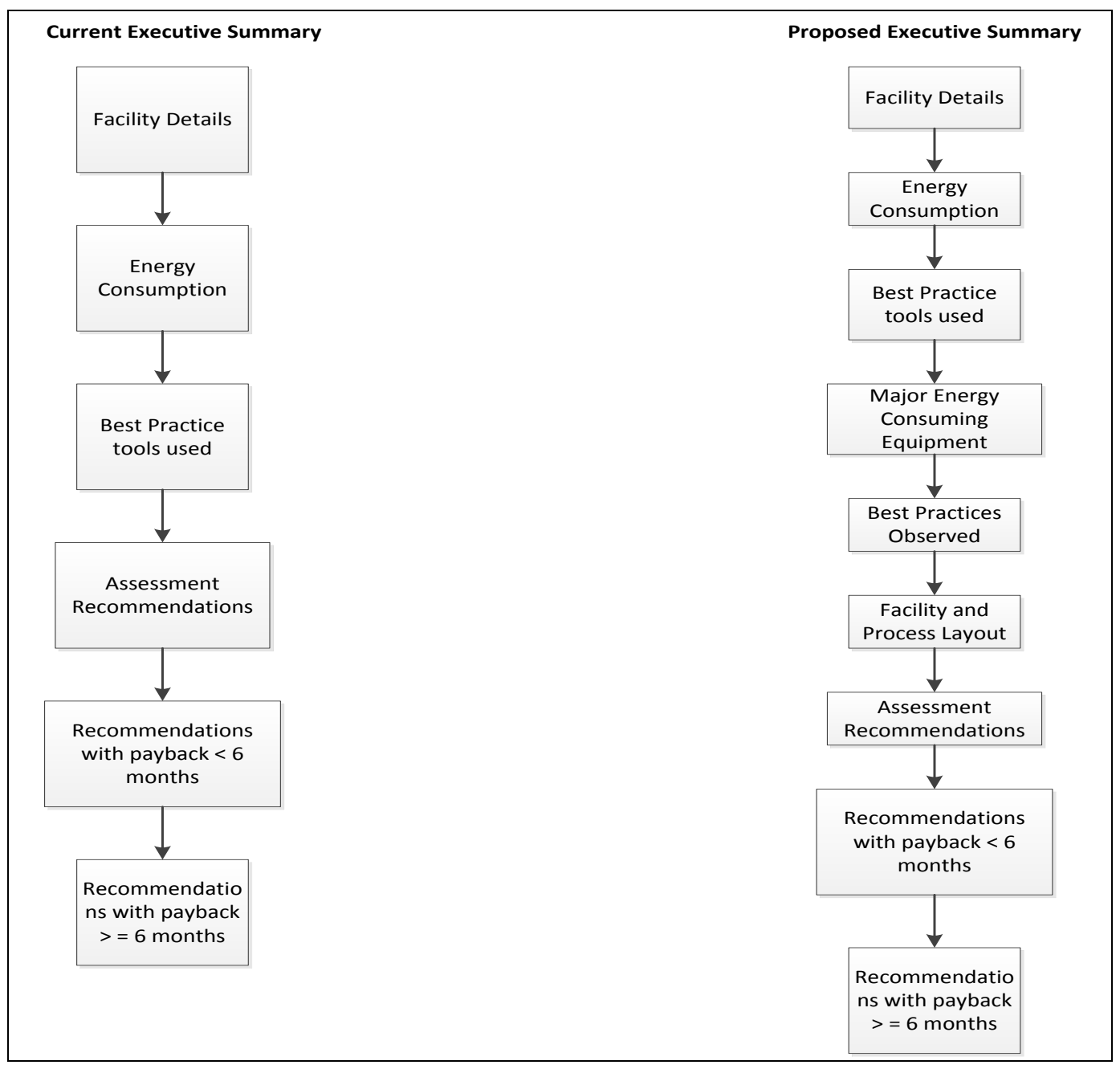

Figure 3.1.11: Current and Proposed Executive Summaries 
Section 2 of the proposed report includes the energy review section of ISO 50001. It consists of the energy consumption of the facility. ISO 50001 requires that all forms of energy entering into facilities to be accounted. Figure 3.1.12 shows the energy review of the proposed section and this is exactly similar to the existing format of reporting other than adding the energy consumption data for the baseline year depending on the circumstances.

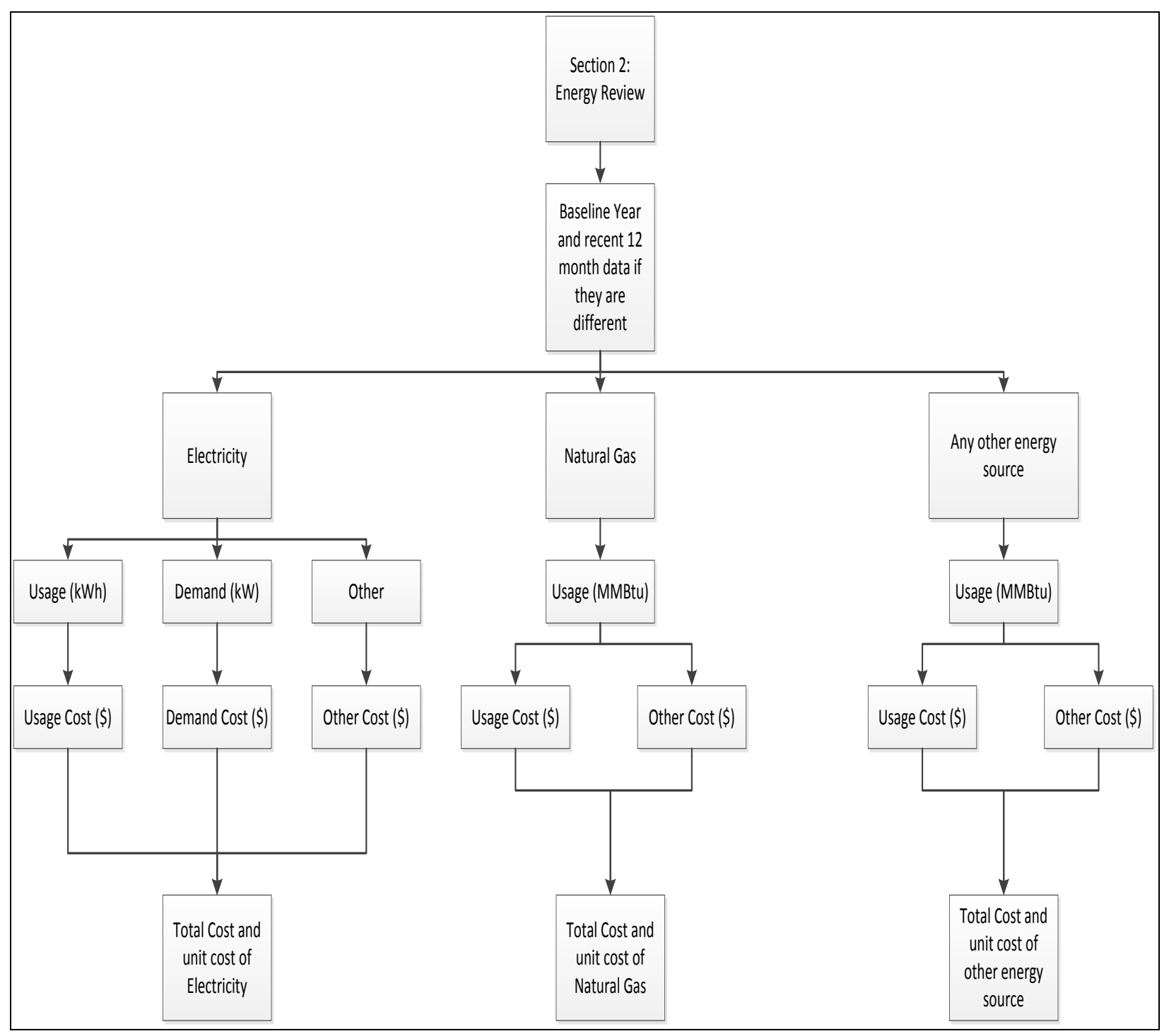

Figure 3.1.12: Energy Review 
Section 3 is a new addition to the existing report style. It deals with the energy baseline development at the facility level. Energy Performance Indicator Tool (EnPI) is used to develop the baseline for all the energy sources at the facility level. Figure 3.1.13 shows the inputs and outputs given to the tool for baseline development. All the inputs along with the regression model are presented in the document. These regression models can be used to estimate the future energy consumption of the facility [32].

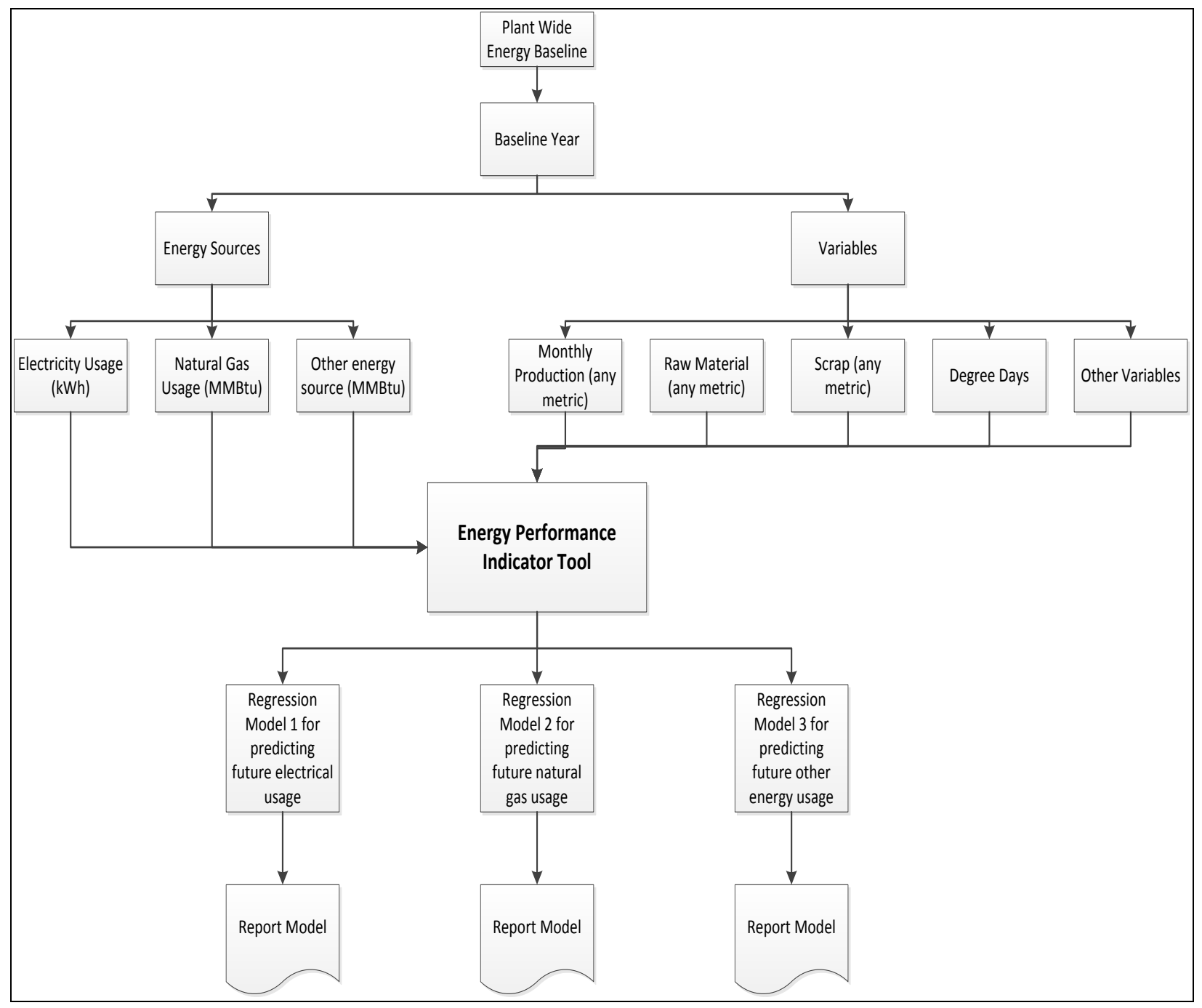

Figure 3.1.13: Baseline Development at Facility Level

The latest version of ISO 50001 does not specify any criteria for model selection in terms of R-Square value or model " $p$ " value. Any of the variables shown above may be left out of the model if there is no logical mechanism by which the variable would affect 
consumption of the energy source. This same baseline for facility methodology is used to develop the baseline for all the identified significant energy users.

Section 4 of the proposed report is "Significant Energy Users and EnPI's". Figure 3.1.14 shows the documenting methodology for reporting SEU's and EnPI's.

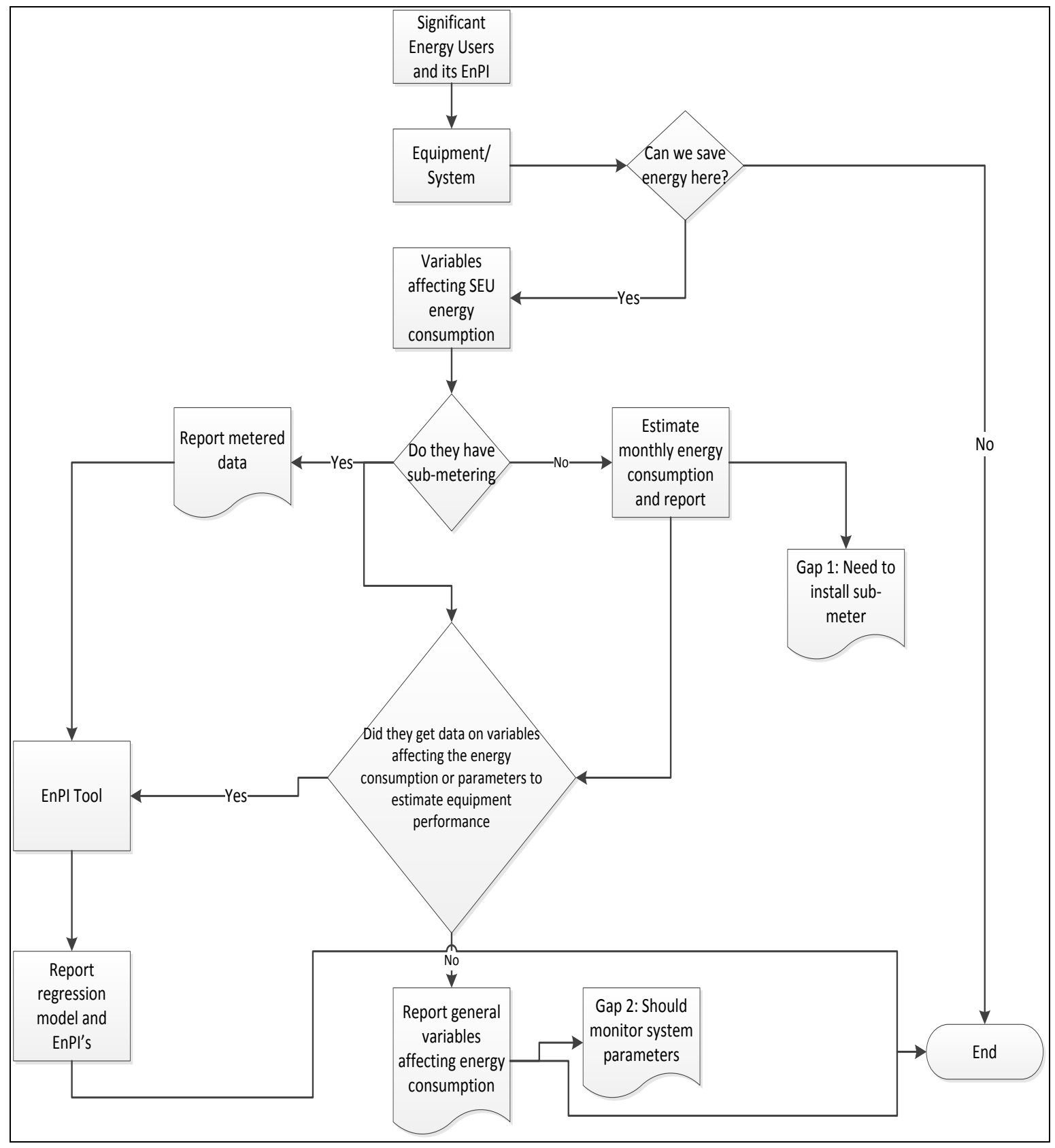

Figure 3.1.14: Significant Energy Users and Energy Performance Indicators 
As discussed in literature review, identifying EnPIs can be a complicated task and requires analysis for several days. Most common EnPIs for various systems are given in Table 2.2.1. This list of EnPIs can be used as a good starting point. The process flow mentioned in the above flow chart also can be used as a gap analysis tool during the starting phase of EnPI selection also.

Section 5 is the assessment recommendations part. In the current format, all the recommendations are kept together and are sorted in the descending order of their cost savings. In the proposed methodology, energy savings recommendations are grouped according to their corresponding energy systems like lighting, compressed air, HVAC etc. These sub-groups are in-turn arranged in the descending order of the cumulative savings of all the recommendations in that group. One more major addition in this section is including the verification methodology for validating the savings, effect of particular recommendation on system level EnPI and facility level EnPI. Figure 3.1.15 shows the assessment recommendations part of any system.

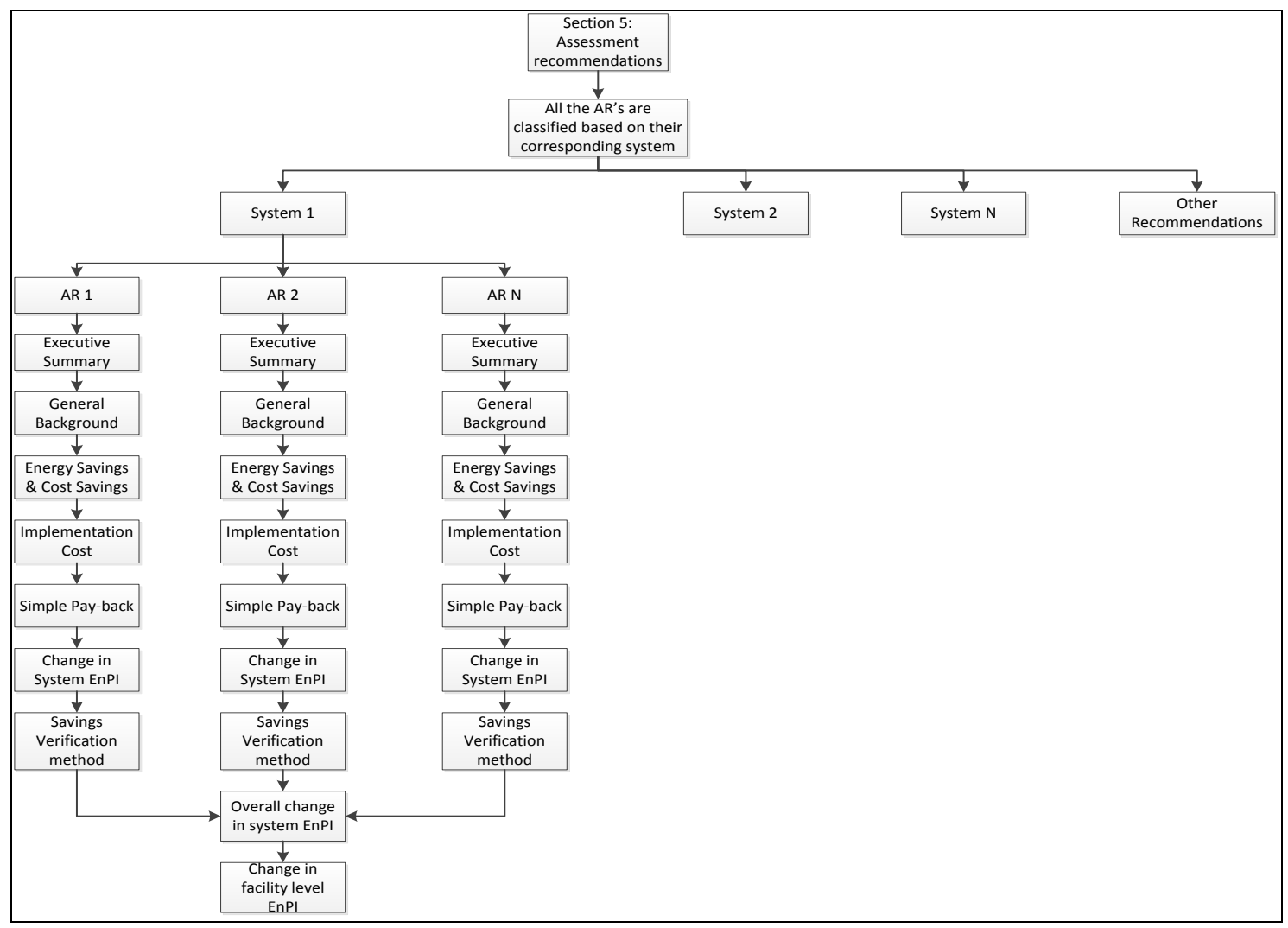




\section{Figure 3.1.15: Assessment Recommendations}

Section 6 of the proposed report deals with tools which can help in implementing ISO 50001 and Section 7 consists of all the data collected during the assessment process and an energy profile model for entire plant developed using plant energy profiler software.

\subsection{Conclusion}

By using the above developed methodology, the report generated by an energy assessment can be of significant use for any facility for implementing ISO 50001. The developed method addresses various requirements in Energy Planning section of ISO 50001. The intended value addition for the facility people with this type of report is shown in Figure 3.2.1.

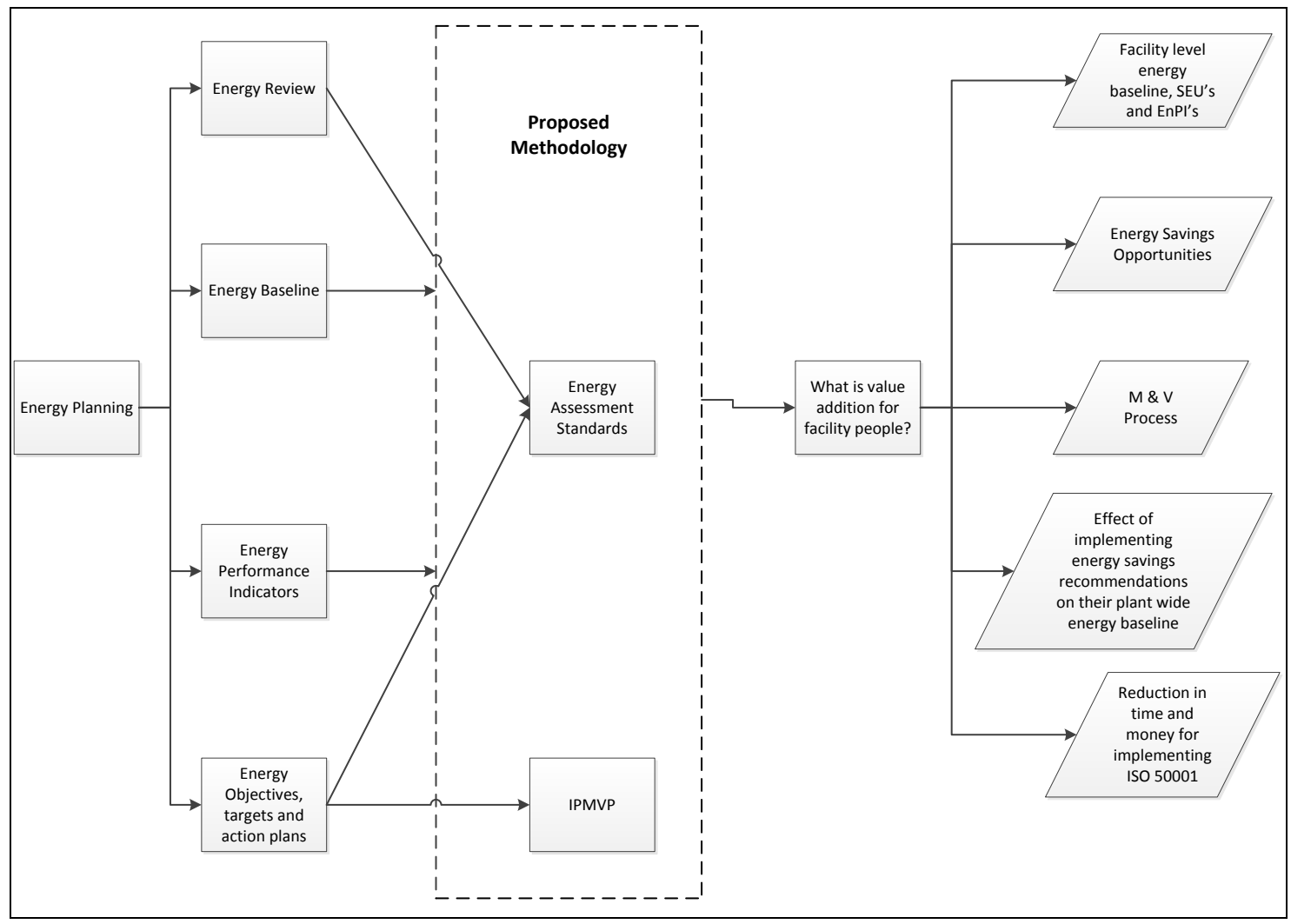

Figure 3.2.1: Final results for proposed methodology 


\section{Chapter 4}

\section{Results and Discussions}

Based on the above mentioned assessment methodology, a new assessment was conducted for a manufacturing facility which is in the process of implementing ISO 50001. By following the new assessment process designed in Figure 3.1.10, Heat Treat department is identified as the significant energy user at the facility and is considered for further analysis. All the natural gas equipment data for the heat treat department is collected. The department is under un-interruptible natural gas supply line and has a dedicated gas meter. Hence the meter data is used for the analysis in the new report.

Initially the methodology designed in Figure 3.1.9 is used to identify the possible significant energy users that run on electricity, but none of the equipment/systems could be considered as a logical output of the assessment method. Table 4.1.1 shows the results obtained from the above developed methodology.

Table 4.1.1: Results from the Various Procedures Developed in Methodology Section

\begin{tabular}{|l|c|c|c|}
\hline \multicolumn{1}{|c|}{ Requirement } & Process Figure & Result & $\begin{array}{c}\text { Usage of Data } \\
\text { Obtained }\end{array}$ \\
\hline $\begin{array}{l}\text { General } \\
\text { Information }\end{array}$ & Figure 3.1.4 & In Reporting \\
\hline SEU - Electric & Figure 3.1.9 & $\begin{array}{c}\text { No system } \\
\text { selected }\end{array}$ & Analysis/Reporting \\
\hline SEU-Natural Gas & Figure 3.1.10 & Heat Treat & Analysis/Reporting \\
\hline Energy Review & Figure 3.1.12 & Utility Data & Analysis/Reporting \\
\hline $\begin{array}{l}\text { Baseline } \\
\text { Development }\end{array}$ & Figure 3.1.13 & $\begin{array}{c}\text { Data } \\
\text { collected for } \\
\text { relevant } \\
\text { variables }\end{array}$ & Analysis/Reporting \\
\hline
\end{tabular}

Three more Excel based supporting files were also presented to the facility. Supporting files are provided to the facility so that any changes that might be required in future can be easily done by its personnel. The documents presented to the facility are:

1. New format IAC Report 
2. Comprehensive Excel file addressing section 4 of ISO 50001

3. Energy baseline file (EnPI tool)

4. SEU performance monitoring file (EnPI tool)

\subsection{New IAC Report}

The IAC report is modified in such a way that it addresses all aspects of the energy planning section of the ISO 50001. The new table of contents is shown in Figure 4.1.1

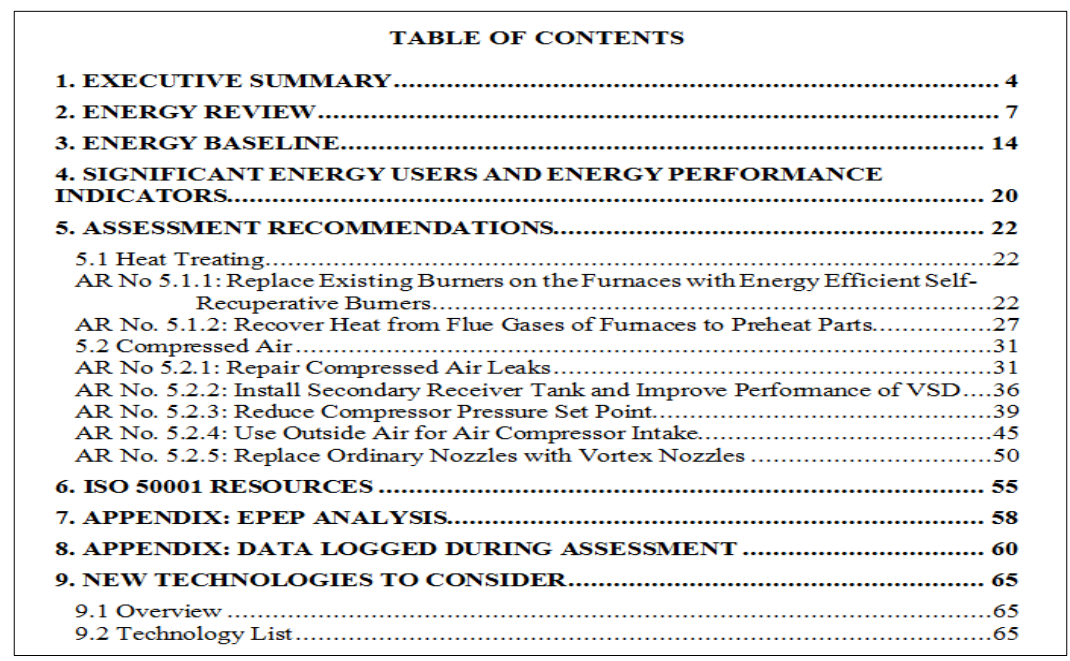

Figure 4.1.1: New Report Table of Contents

As discussed in the methodology, the main modifications done to the report are including energy baseline information, significant energy users, energy performance indicators and segregation of assessment recommendations based on the energy system and their influence on significant energy users.

\subsection{Energy Review}

In energy review section, utility costs are estimated based on the energy bills obtained from the facility. Based on the analysis, the unit cost of various energy sources are estimated as,

Electrical Energy Cost: $\$ 0.05486 / \mathrm{kWh}$

Electric Demand Cost: $\$ 2.16 / \mathrm{kW}$ 
Natural Gas Cost: \$5.18/MMBtu

\subsection{Energy Baseline}

Methodology designed in Figure 3.1.13 is used here. The key findings presented for the facility in the report for energy baseline are shown in the following figures. Figure 4.3.1 shows the data used in the EnPI tool to develop the energy baseline for various energy sources. Figures 4.3.2, 4.3.3, 4.3.4 and 4.3.5 show the baseline model for various energy sources and finally the total energy baseline model at the facility level.

The variables identified for this particular facility are production, heating degree days (HDD) and cooling degree days (CDD). Production data is the number of units produced by the facility per month. Heating degree days (HDD) are a measure of how much (in degrees), and for how long (in days), outside air temperature was lower than a specific set temperature inside the facility. Cooling degree days are a measure of how much (in degrees), and for how long (in days), outside air temperature was higher than a specific set temperature inside the facility. Both HDD and CDD are used to estimate the effects of weather on energy consumption. 


\begin{tabular}{|c|c|c|c|c|c|c|c|c|c|c|}
\hline \multicolumn{8}{|c|}{2011 Energy Consumption } & \multirow{2}{*}{$\begin{array}{c}\begin{array}{c}\text { Production } \\
\text { Count }\end{array} \\
\text { Total } \\
\text { Engines }\end{array}$} & \multicolumn{2}{|c|}{$\begin{array}{c}\text { Weather } \\
\text { Data }\end{array}$} \\
\hline Month & $\begin{array}{c}\text { kWh } \\
\text { consumption }\end{array}$ & $\begin{array}{c}\text { Natural } \\
\text { Gas } \\
\text { (MCF) }\end{array}$ & $\begin{array}{c}\text { Diesel } \\
\text { (Gallons) }\end{array}$ & $\begin{array}{c}\text { Electricity } \\
\text { MMBtu }\end{array}$ & $\begin{array}{c}\text { Natural } \\
\text { Gas } \\
\text { MMBtu }\end{array}$ & $\begin{array}{c}\text { Diesel } \\
\text { MMBtu }\end{array}$ & $\begin{array}{c}\text { Total } \\
\text { MMBtu }\end{array}$ & & CDD & HDD \\
\hline Jan-11 & $3,077,000$ & 27,596 & 58,679 & 10,499 & 28,424 & 8,138 & 47,061 & 3,541 & - & 1,162 \\
\hline Feb-11 & $3,758,000$ & 21,446 & 55,932 & 12,822 & 22,089 & 7,757 & 42,669 & 3,339 & - & 830 \\
\hline Mar-11 & $3,586,000$ & 21,970 & 56,999 & 12,235 & 22,629 & 7,905 & 42,770 & 4,079 & - & 701 \\
\hline Apr-11 & $3,773,000$ & 15,119 & 48,880 & 12,873 & 15,573 & 6,779 & 35,225 & 3,950 & 33 & 317 \\
\hline May-11 & $3,821,000$ & 11,388 & 59,130 & 13,037 & 11,730 & 8,201 & 32,968 & 4,721 & 106 & 86 \\
\hline Jun-11 & $4,599,000$ & 9,739 & 70,955 & 15,692 & 10,031 & 9,841 & 35,564 & 5,883 & 257 & 1 \\
\hline Jul-11 & $4,434,000$ & 6,089 & 45,578 & 15,129 & 6,272 & 6,321 & 27,722 & 4,077 & 465 & - \\
\hline Aug-11 & $3,999,000$ & 7,649 & 50,433 & 13,645 & 7,878 & 6,995 & 28,518 & 4,983 & 298 & - \\
\hline Sep-11 & $4,436,000$ & 9,497 & 70,561 & 15,136 & 9,782 & 9,786 & 34,704 & 5,318 & 129 & 49 \\
\hline Oct-11 & $3,646,000$ & 14,470 & 89,322 & 12,440 & 14,904 & 12,388 & 39,732 & 6,153 & - & 353 \\
\hline Nov-11 & $3,943,000$ & 16,698 & 105,452 & 13,454 & 17,199 & 14,625 & 45,278 & 5,363 & - & 500 \\
\hline Dec-11 & $3,514,000$ & 19,621 & 98,472 & 11,990 & 20,210 & 13,657 & 45,856 & 4,013 & - & 777 \\
\hline Total & $46,586,000$ & 181,282 & 810,391 & 158,951 & 186,720 & 112,393 & 458,065 & 55,420 & 1,289 & 4,775 \\
\hline
\end{tabular}

Figure 4.3.1: Data Used for Baseline Development 


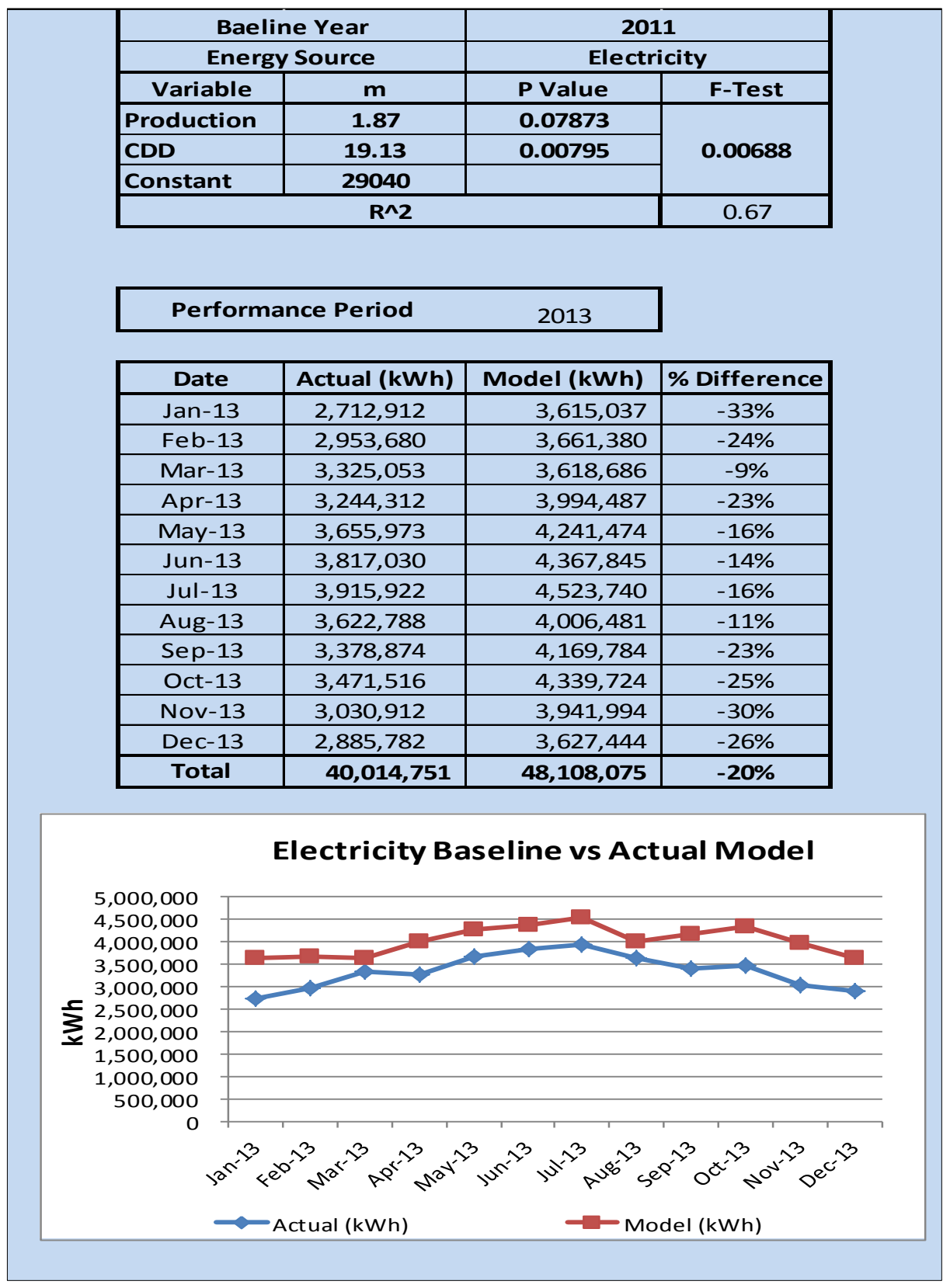

Figure 4.3.2: Baseline Model for Electric Energy Consumption

Figure 4.3.2 shows the results based on the output from the EnPI tool for electric energy consumption.

EnPI tool is used to perform multiple linear regression analysis. The general formula for a multiple linear model is:

$$
\hat{y}=b_{0}+b_{1} x_{1}+b_{2} x_{2}+\ldots b_{p} x_{p}
$$


In this formula, $\hat{y}$ is the predicted dependent variable. The measured dependent variable is depicted by the $\mathrm{y}^{*}$. The difference between the predicted and measured dependent variable is called the residual (also known as error or deviation).

$$
r_{j}=y_{j}^{*}-\hat{\mathrm{y}}_{j}
$$

The goal of regression analysis is to determine the coefficients $\left(b_{1}, 2 \ldots i\right)$ that result in a minimized error sum of squares. The error sum of squares (SSE) is calculated by:

$$
S S E=\sum\left(r_{j}-r_{a v g}\right)^{2}
$$

The regression equation for electrical energy consumption obtained from the EnPI tool is shown below,

$$
\text { Electricity Consumption }=2,9040+(1.87 * \text { Production })+(19.13 * \text { CDD })
$$

As shown in the above equation, variables selected for modeling the electric energy usage are production and cooling degree days. The resultant regression model has an R-square value of $67 \%$. The p-values for the variables selected are 0.07873 and 0.00795 for production and cooling degree days (CDD) respectively. The p-value of the model variables is an indicator of the importance of that particular variable in the model. The difference between the predicted energy usage and the actual energy consumption gives electric energy savings which is estimated to be $20 \%$. 


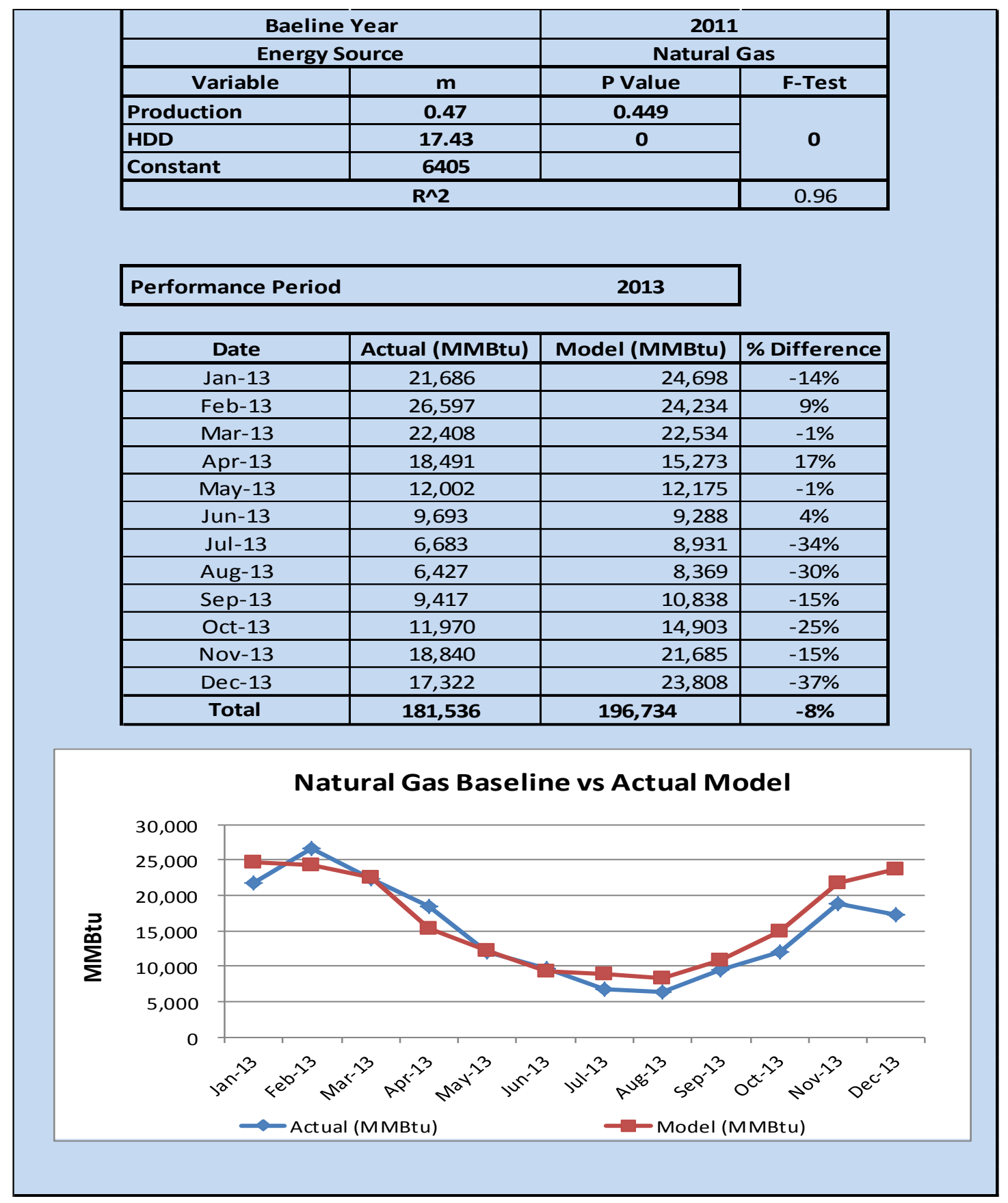

Figure 4.3.3: Baseline Model for Natural Gas Consumption

Figure 4.3.3 shows the results based on the output from the EnPI tool for natural gas usage. The regression equation for natural gas consumption obtained from the EnPI tool is shown below,

$$
\text { Natural Gas Consumption }=6,405+(0.47 * \text { Production })+(17.43 * \text { HDD })
$$


The variables selected for modelling the natural gas usage are production and heating degree days. The resultant regression model has an $\mathrm{R}$-square value of $96 \%$. The difference between the predicted energy usage and the actual energy consumption gives electrical energy savings which is equal to $8 \%$.

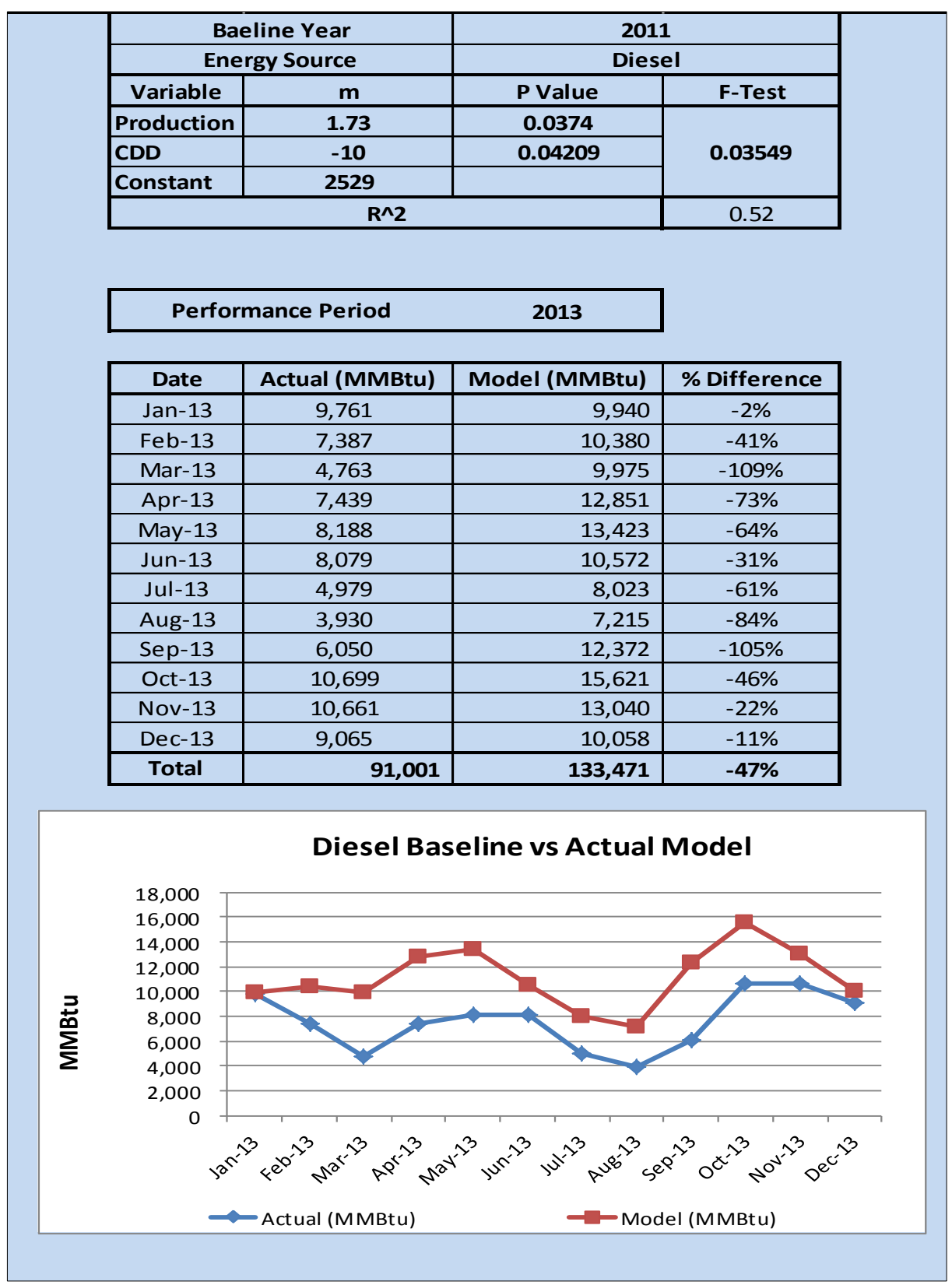

Figure 4.3.4: Baseline Model for Diesel Consumption

Figure 4.3.4 shows the results based on the output from the EnPI tool for diesel usage. The variables selected for modelling the natural gas usage are production and cooling 
degree days. The resultant regression model has an R-square value of $52 \%$. The difference between the predicted energy usage and the actual energy consumption gives electrical energy savings which is equal to $47 \%$. The regression equation for diesel consumption obtained from the EnPI tool is shown below,

Diesel Consumption $=2,529+(1.73 *$ Production $)-(10 * C D D)$ 


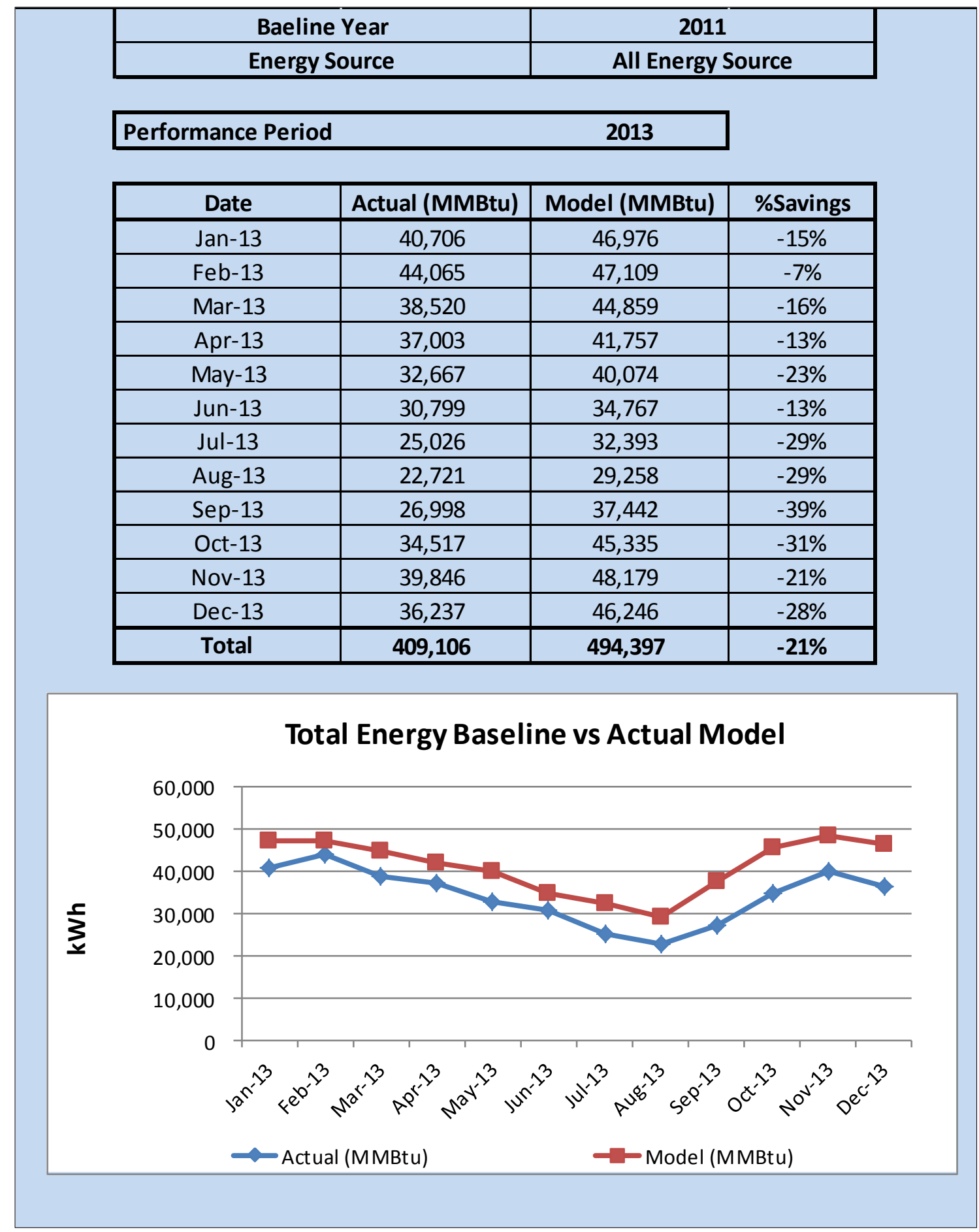

Figure 4.3.5: Total Facility Modeled Energy Consumption

Figure 4.3 .5 shows a performance improvement of $21 \%$ by the end of 2013 with. The facility corporate data indicates an improvement of $20 \%$ for the above mentioned period and hence the model developed can accurately predict the future energy consumptions. 


\subsection{Significant Energy Users and EnPI}

As the principal product of the facility is automotive engines, "MWh/Engine" is identified to be the effective energy performance indicator.

Table 4.4.1: SEU and EnPI

\begin{tabular}{|l|l|}
\hline Significant Energy User & Heat Treat Department \\
\hline Facility EnPI & MWh/Engine \\
\hline
\end{tabular}

\begin{tabular}{|c|c|c|c|c|}
\hline \multicolumn{2}{|c|}{ Baseline and EnPI Infromation } & & & \\
\hline Level & Dependent Variable & EnPI & EnPI Determination Methodology & $\begin{array}{c}\text { Updating } \\
\text { Methodology }\end{array}$ \\
\hline $\begin{array}{l}\text { Facility } \\
\text { Level }\end{array}$ & Total Energy Consumption & MWhUnit & $\begin{array}{l}\text { High' correlation for total units produced, also } \\
\text { ease of tracking with corporate goal }\end{array}$ & \multirow{2}{*}{$\begin{array}{l}\text { Monthly; Spreadshee } \\
\text { Located in the } \\
\text { Corporate Directory }\end{array}$} \\
\hline SEU Level & Heat Treat & MWh/Unit & High correlation for total units produced. & \\
\hline
\end{tabular}

Figure 4.4.1: Documenting SEU and EnPI

Figure 4.4.1 shows the template for document describing the EnPI determination methodology. This includes the level for which EnPI is selected, dependent variables, EnPI, EnPI determination methodology and the information regarding its update.

Heat treating the final product components is performed in the Heat Treat department. It has multiple natural gas users. The major energy users in Heat Treat department are the carburizing furnaces and the RX gas generators. Natural gas supply for this department is on un-interruptible contract with its own metering arrangements. Since the entire department is considered as the significant energy user, any energy savings measures performed on the natural gas equipment can be verified by monitoring the meter reading. EnPI tool can be used as a verification tool for the energy savings improvements performed in the Heat Treat area. Apart from using the sub-metering provision, an energy model for the SEU is also developed by using EnPI tool and is shown in Figure 4.4.2. 


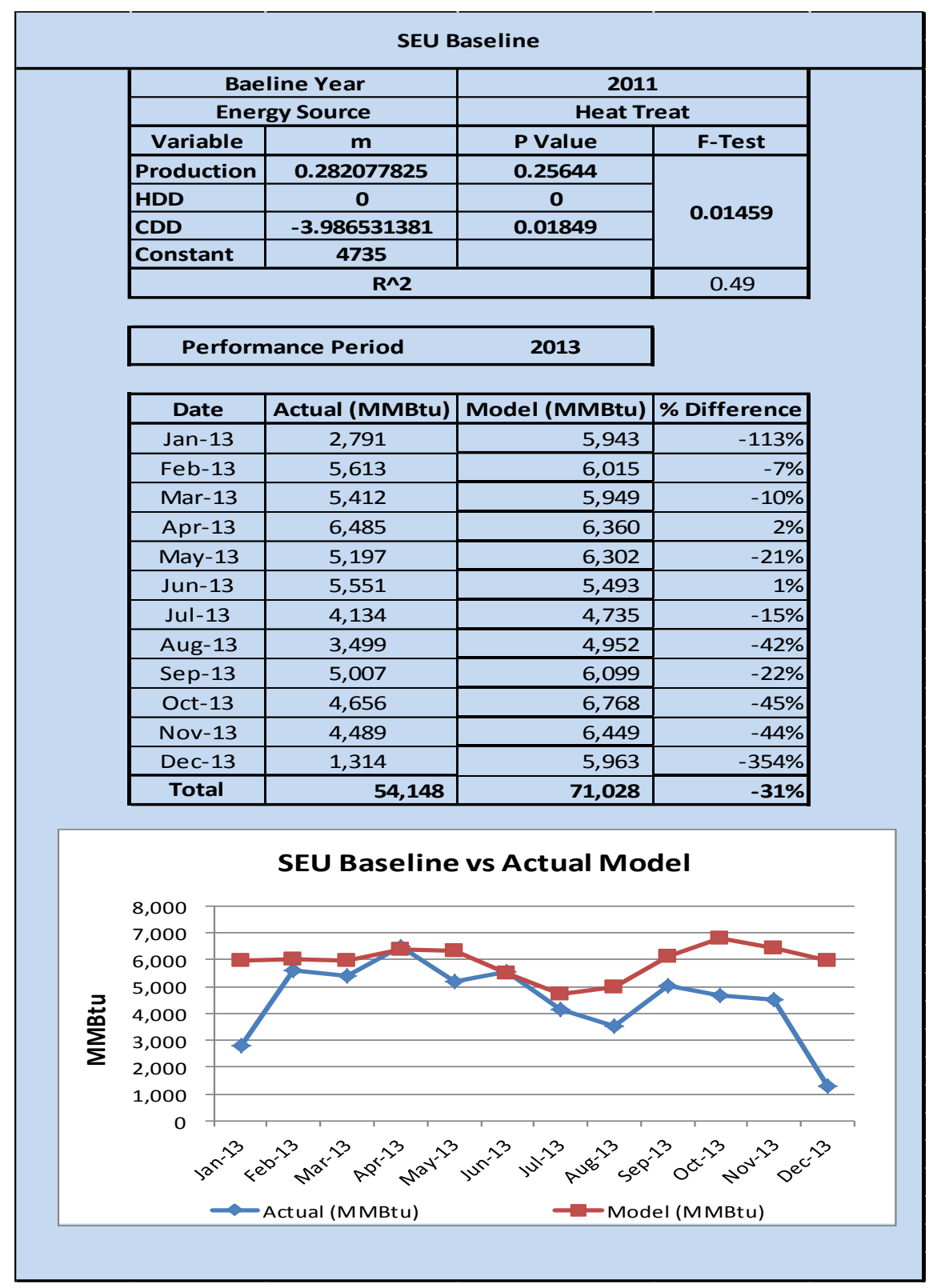

\section{Figure 4.4.2: Model for SEU Energy Consumption}

Figure 4.4.2 shows the baseline model for Heat Treat area. The variables selected for modeling the natural gas usage are production and cooling degree days. The resultant regression model has an R-square value of $49 \%$. The difference between the predicted energy usage and the actual energy consumption gives natural gas savings which is equal to $31 \%$. The regression equation for natural gas consumption for heat treat area is obtained from the EnPI tool ass shown below, 


$$
\text { Natural Gas Consumption }=4,735+(0.2802 * \text { Production })-(3.985 * C D D)
$$

Figure 4.2.2 shows a large deviation between the actual and the estimated natural gas usage. This is an indicator of the lack of model's ability to predict the natural gas usage reliably. Since natural gas usage in seasonal, complex time series-analysis (Winters' method, for example) has to be performed for designing the energy usage prediction models which is beyond the scope of this work. A part of this huge variation in actual and predicted energy consumption in Heat Treat department can also be attributed to the equipment de-commissioning in that area. 


\subsection{Assessment Recommendations}

Reporting of the assessment recommendations, follow the methodology shown in Figure 3.1.15/ According to the methodology developed, assessment recommendations are segregated based on the corresponding energy system. In the new report generated for the facility audited, the major systems considered for identifying energy savings are heat treating furnaces and compressed air system. The executive summary of the proposed recommendations is shown in Table 4.5.1

Table 4.5.1: Energy Saving Recommendations

\begin{tabular}{|c|c|c|c|c|c|c|}
\hline \multirow[t]{2}{*}{ Description } & \multicolumn{2}{|c|}{$\begin{array}{c}\text { Annual Potential } \\
\text { Conservation }\end{array}$} & \multirow{2}{*}{$\begin{array}{c}\text { Potential } \\
\text { Savings } \\
\text { (\$/Yr) }\end{array}$} & \multirow{2}{*}{$\begin{array}{c}\text { Resource } \\
\text { Conserved }\end{array}$} & \multirow{2}{*}{$\begin{array}{c}\text { Estimated } \\
\text { Cost } \\
(\$)\end{array}$} & \multirow{2}{*}{$\begin{array}{c}\text { Simple } \\
\text { Payback } \\
\text { (months }\end{array}$} \\
\hline & MMBtu & kWh & & & & \\
\hline $\begin{array}{l}\text { Replace Existing Burners on the Furnaces with } \\
\text { Energy Efficient Self-Recuperative Burners }\end{array}$ & 16,052 & - & 83,149 & Natural Gas & 50,000 & 8 \\
\hline $\begin{array}{l}\text { Recover Heat from Flue Gases of Furnaces to } \\
\text { Preheat Parts }\end{array}$ & 6,590 & - & 34,136 & Natural Gas & 82,440 & 29 \\
\hline $\begin{array}{l}\text { Install Secondary Receiver Tank and Improve } \\
\text { Performance of VSD }\end{array}$ & & 200,329 & 10,990 & Electricity & 570 & 4 \\
\hline Repair Compressed Air Leaks & - & 30,382 & 1,857 & Electricity & 7,560 & 9 \\
\hline Reduce Compressor Pressure Set Point & - & 23,215 & 1,419 & Electricity & 70 & 1 \\
\hline Use Outside Air for Air Compressor Intake & - & 22,261 & 1,359 & Electricity & 487 & 5 \\
\hline $\begin{array}{ll}\text { Total } \\
\end{array}$ & 22,561 & 276,187 & 132,910 & & 141,127 & 13 \\
\hline
\end{tabular}

The total energy cost savings would amount to approximately \$132,910and $219 \mathrm{~kW}$-month peak demand reduction for this facility. The total estimated implementation cost is $\$ 141,127$ which gives an average simple payback of around 13 months. Simple payback is 
the ratio between the estimated cost and the potential savings per year. The ratio calculated will be the simple payback in years and it is multiplied by 12 to get the simple payback time in month.

The total natural gas usage for the year 2013 by the heat treat department (SEU) is 54,148 MMBtu (15,865 MWh). The energy performance indicator for the heat treat department is identified to be "MWh/Engines Built" which is equal to $0.240 \mathrm{MWh} /$ Engine. By implementing the above mentioned recommendations on the heat treat department, the natural gas usage drops to $31,957 \mathrm{MMBtu} / \mathrm{yr}$ and for the same production level, the energy performance indicator will be $0.141 \mathrm{MWh} / \mathrm{yr}$ which is approximately $41 \%$ improvement in energy performance.

\subsection{ISO 50001 Resources}

The primary objective of this section is to provide the facility with additional resources that can be used in the implementation of ISO 50001. Information regarding department of energy's eGuide for ISO 50001, EnPI tool, SEM checklist and DoE best practice tools are explained. All the required web-links are provided for easy download of all the mentioned tools.

\section{7 ePEP}

Plant Energy Profiler (ePEP) is used to estimate the potential of savings that can be achieved in the facility for various energy systems. Figure 4.7.1 shows the ePEP output for the facility,

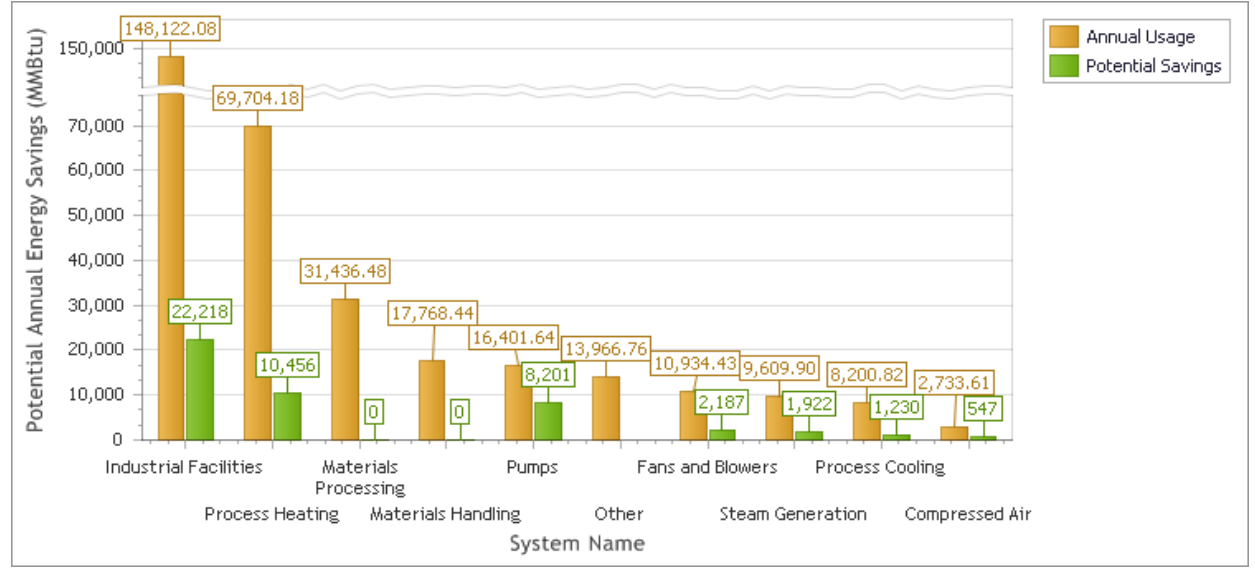

Figure 4.7.1: Energy Consumption and Potential Energy Savings for the Facility 
From the plant energy profiler output, it can be seen that Industrial facilities (lighting and HVAC) consumes maximum amount of energy and also have significant amount of energy savings opportunities.

\subsection{Data Logged}

The data collected during the day of assessment are presented here. During the assessment electrical energy consumption of some major motors is monitored. The compressed air pressure pattern around the plant is also monitored and this data is used in the estimation of savings for various recommendations developed in Section 4.5. 


\subsection{Excel Spreadsheet Model}

An Excel spreadsheet is created for all the information presented in the results chapter. It includes the calculations performed for all the future energy estimates, significant energy users and energy performance indicators. Apart from these calculations, templates were provided for addressing the various requirements for objectives, targets and action plans according to the ISO 50001 standard. Template for objectives, targets and action plans is shown in Figure 4.9.1.

\begin{tabular}{|c|c|c|c|c|c|}
\hline \multicolumn{6}{|c|}{ Energy Management Action Plan \#1.1.1 } \\
\hline Objective \# & 1 & \multicolumn{4}{|c|}{$\begin{array}{l}\text { To meet all the requirements of the ISO } 50001 \text { and meet the set corporate energy } \\
\text { reduction goal every year. Volvo corporate goal for } 2013 \text { is X Mwh/Unit }\end{array}$} \\
\hline Target \# & 1.1 & & & & \\
\hline \multicolumn{6}{|l|}{ Project Name } \\
\hline \multicolumn{6}{|c|}{ Project Target Improvement } \\
\hline \multicolumn{6}{|c|}{ Additional information } \\
\hline Issue date & & $\begin{array}{c}\text { Revision } \\
\text { Date }\end{array}$ & NA & $\begin{array}{c}\text { Person in- } \\
\text { charge }\end{array}$ & Due Date \\
\hline \multicolumn{6}{|l|}{ Project Results } \\
\hline \multicolumn{6}{|l|}{ Target Achieved } \\
\hline \multicolumn{6}{|c|}{ Target Verification } \\
\hline Approved By & & & Ap & d Date & \\
\hline
\end{tabular}

Figure 4.9.1: Objectives, Targets and Action Plan

A project tracking tool is provided for the facility to track the on-going projects on significant energy users that can give a summary status with respect to PDCA cycle of ISO 50001 and is shown in Figure 4.9.2. 


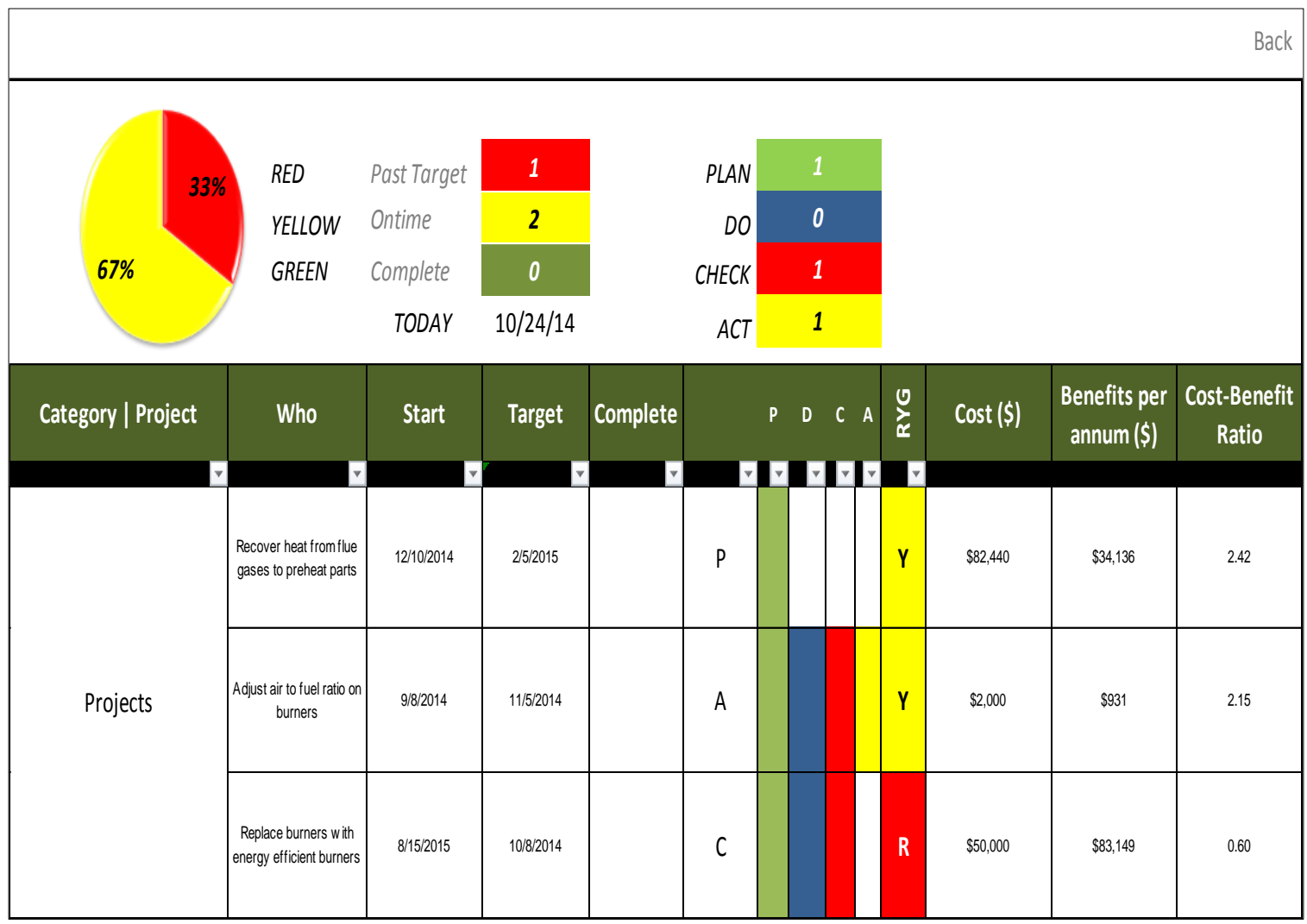

Figure 4.9.2: Project Tracking Tool

\subsection{Energy Consumption of the Facility-2013}

All the equipment in the facility is segregated into their corresponding departments and their energy consumption for the year 2013 is estimated. All the energy sources (electricity, natural gas and diesel) are converted into a single unit "MWH" for consistency. Figure 4.10.1 shows the energy consumption of various departments in 2013. 


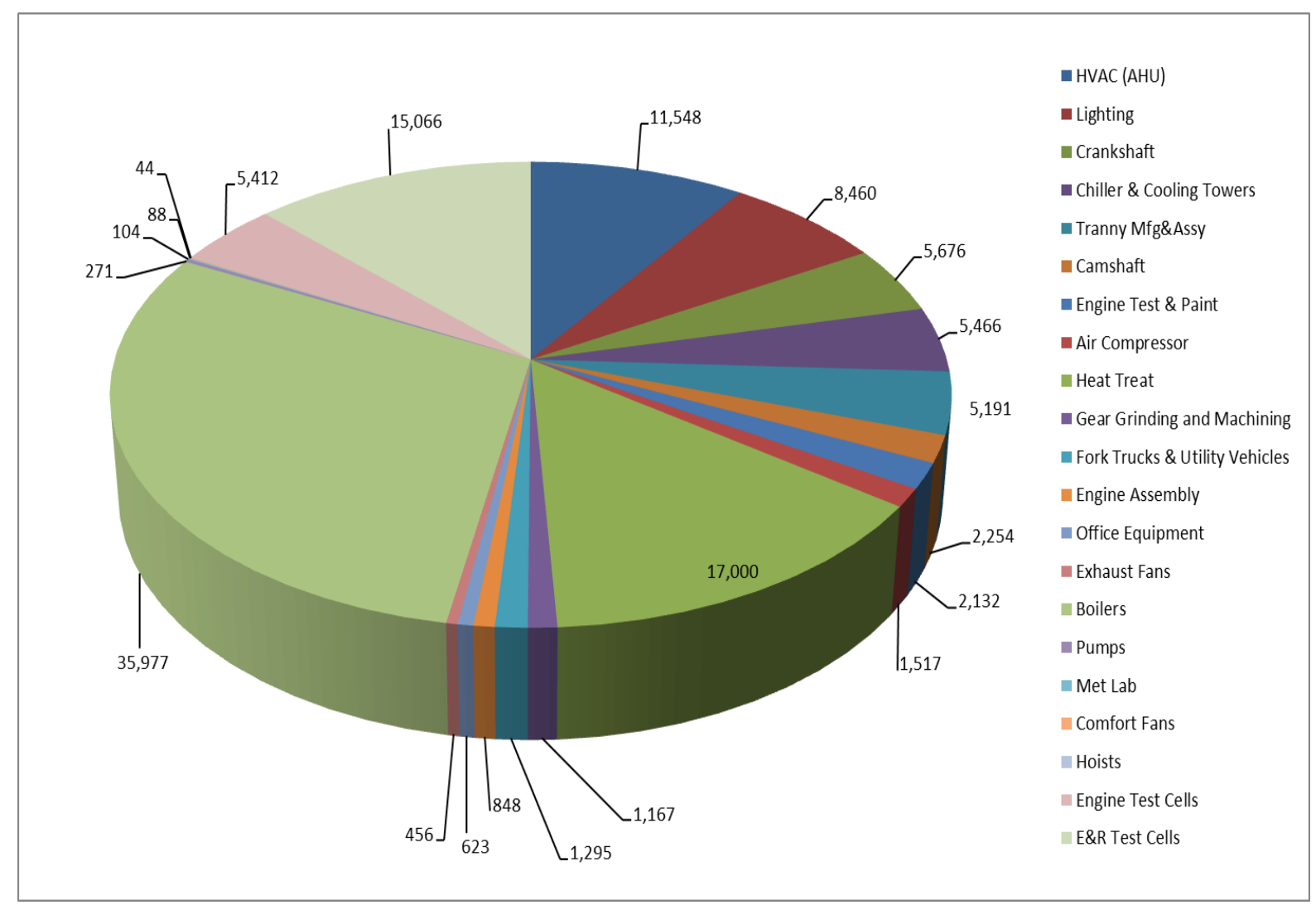

Figure 4.10.1: Energy Consumption of Various Departments in 2013 (MWh) 


\section{Chapter 5}

\section{Conclusion and Future Work}

\subsection{Conclusion}

A new report was created for an automotive engine manufacturing facility based on the new assessment methodology and three Excel files were also submitted to the facility as supporting documents. The calculations for various parameters mentioned in the report are performed by using Excel spreadsheets. The key features of the report are,

1. Energy Review: Addressing Section 4.4.3 of ISO 50001

2. Energy Baseline: Addressing Section 4.4.4 of ISO 50001

3. SEU's and EnPI: Addressing Sections 4.4.3 and 4.4.5 of ISO 50001

4. Assessment Recommendations: Addressing Section 4.4.6 of ISO 50001

The Energy Performance Indicators developed as a result of this process are found to be suitable for the facility and hence the same EnPI is used for the ISO 50001 certification audit. Based on the new report, the facility selected the "Heat Treat" system as its significant energy user and the assessment recommendations in the report are documented as the opportunities for improvement on significant energy user. The variables used to develop regression models to predict future energy estimates are also accepted by the facility personnel and the models developed for various energy sources (electricity, natural gas and diesel) proved to be adequate for the estimation of future energy consumptions based on the ISO 50001 standard.

Apart from the assessment report, the Excel spreadsheet presented to the facility includes several key templates that helped them to develop objectives and targets for SEU's, equipment calibration records and measurement and verification plans. The project tracking tool provided as a part of Excel spreadsheet is used to keep track of on-going projects with respect to the PDCA cycle of ISO 50001.

Feasibility studies were being performed at the facility for the other assessment recommendations to improve their energy performance. Recommendations on compressed air system are presently under the review of maintenance department for implementation. 


\subsection{Comparison between EnPI tool and SAS Models:}

In the assessment report submitted to the facility, EnPI tool is used to develop the regression models for making future energy estimates of electricity, natural gas and diesel. As a validation procedure SAS is used to develop the regression models for estimating future energy consumption based on 2011 energy usage. The results obtained from EnPI tool and commercial stat package are presented in Table 5.2.1.

Table 5.2.1: Results from CommercialStat Package and EnPI Tool

\begin{tabular}{|c|c|c|c|c|c|c|}
\hline & \multicolumn{3}{|c|}{ SAS Model Energy Prediction - 2013} & \multicolumn{3}{|c|}{ EnPI Model Energy Prediction - 2013} \\
\hline & Electricity (MMBTU) & Natural Gas (MMBTU) & Diesel (MMBTU) & Electricity (MMBTU) & Natural Gas (MMBTU) & Diesel (MMBTU) \\
\hline & 35,444 & 24,334 & 8,944 & 34,858 & 24,698 & 9,940 \\
\hline & 35,788 & 23,892 & 9,311 & 35,305 & 24,234 & 10,380 \\
\hline & 36,200 & 22,210 & 8,973 & 34,893 & 22,534 & 9,975 \\
\hline & 40,226 & 15,176 & 11,585 & 38,517 & 15,273 & 12,851 \\
\hline & 42,372 & 12,172 & 12,597 & 40,898 & 12,175 & 13,423 \\
\hline & 44,096 & 9,292 & 11,436 & 42,117 & 9,288 & 10,572 \\
\hline & 45,069 & 8,907 & 10,520 & 43,620 & 8,931 & 8,023 \\
\hline & 42,969 & 8,283 & 8,609 & 38,632 & 8,369 & 7,215 \\
\hline & 42,566 & 10,830 & 11,830 & 40,207 & 10,838 & 12,372 \\
\hline & 41,756 & 14,907 & 14,051 & 41,845 & 14,903 & 15,621 \\
\hline & 37,779 & 21,473 & 11,535 & 38,010 & 21,685 & 13,040 \\
\hline & 35,798 & 23,464 & 9,042 & 34,977 & 23,808 & 10,058 \\
\hline Total & 480,063 & 194,940 & 128,434 & 463,879 & 196,734 & 133,471 \\
\hline
\end{tabular}

The predicted energy consumptions estimated from the above mentioned two tools and actual energy consumption in 2013 are presented in Table 5.2.2.

Table 5.2.2: Predicted vs Actual Energy Consumption - 2013

\begin{tabular}{|c|c|c|c|}
\hline & & \multicolumn{2}{|c|}{ Predicted Energy Usage } \\
\hline Year-2013 & Actual & Stat Package & EnPI \\
\hline Electricity (MMBtu) & 409,608 & 480,063 & 463,879 \\
\hline Natural Gas (MMBtu) & 183,881 & 194,940 & 196,734 \\
\hline Diesel (MMBtu) & 122,183 & 128,434 & 133,471 \\
\hline Total & $\mathbf{7 1 5 , 6 7 2}$ & $\mathbf{8 0 3 , 4 3 7}$ & $\mathbf{7 9 4 , 0 8 4}$ \\
\hline \% Difference & - & $\mathbf{1 2 \%}$ & $\mathbf{1 1 \%}$ \\
\hline
\end{tabular}

The above results show that there is no significant variation between the total energy consumption predicted by the commercial stat package regression models and the total energy consumption predicted by the EnPI tool in this particular case. 


\subsection{Future Work}

The energy assessment and reporting structure developed can assist a facility in implementing ISO 50001. As the M\&V protocols for the ISO 50001 are less stringent, EnPI tool can be used for developing the baseline energy consumption models and can be used to predict future energy estimates. When a facility opts for Superior Energy performance (SEP) certification, the regression models generated using EnPI tool often do not meet the SEP criteria. Since commercial statistical packages may be too expensive for some facilities, a tool should be developed for proper integration of the new assessment methodology with SEP process. ANSI/MSE 50021 standard requirements are not considered during the development of new assessment and reporting methodology. Hence, it is necessary to develop a new reporting format that integrates both ISO 50001 and ANSI/MSE 50021 thus helping facilities to apply for SEP

certification. An expert system can be developed using the developed methodology for easy identification of significant energy users. 


\section{Appendix}

Electricity
a) SAS Code

DATA a;

INPUT Y X1 X2 X3;

CARDS;

31497.48354111620

38468.4933398300

36707.8240798300

38622.04395031733

39113.38472186106

47077.3258831257

45388.3140770465

40935.4749830298

45408.79531849129

37322.0161533530

40362.2353635000

35970.8040137770

PROCREG;

MODEL Y=X1 X2 X3/r all influence;

RUN;

X1: Production data

X2: Heating Degree Days

X3: Cooling Degree Days

b) SAS Outputs

Table A.1: Electricity

\begin{tabular}{|c|c|c|c|c|c|}
\hline Variable & DF & $\begin{array}{c}\text { Parameter } \\
\text { Estimate }\end{array}$ & $\begin{array}{c}\text { Standard } \\
\text { Error }\end{array}$ & $\mathbf{t}$ Value & $\mathbf{P r}>|\mathbf{t}|$ \\
\hline Intercept & $\mathbf{1}$ & 38605 & 7820.05188 & 4.94 & 0.0011 \\
\hline $\mathbf{X 1}$ & $\mathbf{1}$ & 0.56519 & 1.27234 & 0.44 & 0.6687 \\
\hline $\mathbf{X} 2$ & $\mathbf{1}$ & -5.97704 & 4.14398 & -1.44 & 0.1872 \\
\hline $\mathbf{X 3}$ & $\mathbf{1}$ & 9.01092 & 8.81003 & 1.02 & 0.3363 \\
\hline
\end{tabular}


Table A.2: ANOVA- Electricity

\begin{tabular}{|c|c|c|c|c|c|}
\hline \multicolumn{7}{|c|}{ Analysis of Variance } \\
\hline Source & DF & $\begin{array}{c}\text { Sum of } \\
\text { Squares }\end{array}$ & $\begin{array}{c}\text { Mean } \\
\text { Square }\end{array}$ & F Value & Pr $>$ F \\
\hline Model & 3 & 162306110 & 54102037 & 7.48 & 0.0104 \\
\hline Error & 8 & 57831077 & 7228885 & & \\
\hline Corrected Total & 11 & 220137187 & & & \\
\hline
\end{tabular}

Regression Model: $38605+0.56519$ X1 -5.97704 X2 + 9.01092 X3

R-square: 0.7373

\section{Natural Gas}
a) SAS Code

DATA a;

INPUT Y X1 X2 X3;

CARDS;

28341.09354111620

22025.0433398300

22563.1940798300

15527.21395031733

11695.48472186106

10001.9558831257

6253.440770465

7855.5249830298

9753.42531849129

14860.6961533530

17148.8553635000

20150.7740137770

PROCREG;

MODEL Y $=\mathrm{X} 1 \mathrm{X} 2 \mathrm{X} 3 / \mathrm{r}$ all influence;

RUN; 
b) SAS Outputs

Table A.3: Natural Gas

\begin{tabular}{|c|c|c|c|c|c|}
\hline Variable & $\mathbf{D F}$ & $\begin{array}{c}\text { Parameter } \\
\text { Estimate }\end{array}$ & $\begin{array}{c}\text { Standard } \\
\text { Error }\end{array}$ & $\mathbf{t}$ Value & $\mathbf{P r}>|\mathbf{t}|$ \\
\hline Intercept & $\mathbf{1}$ & 10724 & 3015.08685 & 3.56 & 0.0074 \\
\hline $\mathbf{X 1}$ & $\mathbf{1}$ & -0.04033 & 0.49056 & -0.08 & 0.9365 \\
\hline $\mathbf{X 2}$ & $\mathbf{1}$ & 14.21355 & 1.59775 & 8.90 & $<.0001$ \\
\hline $\mathbf{X 3}$ & $\mathbf{1}$ & -7.76011 & 3.39678 & -2.28 & 0.0517 \\
\hline
\end{tabular}

Table A.4: ANOVA- Natural Gas

\begin{tabular}{|c|c|c|c|c|c|}
\hline \multicolumn{7}{|c|}{ Analysis of Variance } \\
\hline Source & DF & $\begin{array}{c}\text { Sum of } \\
\text { Squares }\end{array}$ & $\begin{array}{c}\text { Mean } \\
\text { Square }\end{array}$ & F Value & Pr $>$ F \\
\hline Model & 3 & 495180517 & 165060172 & 153.60 & $<.0001$ \\
\hline Error & 8 & 8596896 & 1074612 & & \\
\hline Corrected Total & 11 & 503777413 & & & \\
\hline
\end{tabular}

Regression Model: $\quad 10724-0.04033$ X1 +14.21355 X2 -7.76011 X3

R-square: 0.9829

Diesel

a) SAS Code

DATA a;

INPUT Y X1 X2 X3;

CARDS;

8191.55354111620

7808.0733398300

7957.0240798300

6823.58395031733

8254.55472186106

9905.3658831257

6362.6940770465 
7040.4249830298

9850.25531849129

12469.3261533530

14721.1353635000

13746.6940137770

PROCREG;

MODEL Y=X1 X2 X3/r all influence;

RUN;

b) SAS Outputs

Table A.5: Diesel

\begin{tabular}{|c|c|c|c|c|c|}
\hline Variable & DF & $\begin{array}{c}\text { Parameter } \\
\text { Estimate }\end{array}$ & $\begin{array}{c}\text { Standard } \\
\text { Error }\end{array}$ & $\mathbf{t}$ Value & $\operatorname{Pr}>|\mathbf{t}|$ \\
\hline Intercept & $\mathbf{1}$ & -2992.39006 & 6159.32595 & -0.49 & 0.6401 \\
\hline $\mathbf{X 1}$ & $\mathbf{1}$ & 2.48079 & 1.00214 & 2.48 & 0.0384 \\
\hline $\mathbf{X 2}$ & $\mathbf{1}$ & 3.44991 & 3.26394 & 1.06 & 0.3214 \\
\hline $\mathbf{X 3}$ & $\mathbf{1}$ & -4.16753 & 6.93907 & -0.60 & 0.5647 \\
\hline
\end{tabular}

Table A.6: ANOVA- Diesel

\begin{tabular}{|c|c|c|c|c|c|}
\hline \multicolumn{7}{|c|}{ Analysis of Variance } \\
\hline Source & DF & $\begin{array}{c}\text { Sum of } \\
\text { Squares }\end{array}$ & $\begin{array}{c}\text { Mean } \\
\text { Square }\end{array}$ & F Value & Pr > F \\
\hline Model & 3 & 50021156 & 16673719 & 3.72 & 0.0610 \\
\hline Error & 8 & 35876361 & 4484545 & & \\
\hline Corrected Total & 11 & 85897517 & & & \\
\hline
\end{tabular}

Regression Model: $\quad-2992.39006+2.48079$ X1 $\quad$ - 3.44991 X2 - 4.16753 X3

R-square: 0.5823 


\section{References}

[1] U.S. Energy Information Administration, "International Energy Outlook 2013, EIA", www.eia.gov/forecasts/ieo/

[2] Oak Ridge National Laboratory, "U.S. Manufacturing Energy Use and Greenhouse Gas Emissions Analysis, November 2012", http://info.ornl.gov/sites/publications/files/Pub39685.pdf

[3] Shahriar, S., Erkan T., "When will fossil fuel reserves be diminished", Journal of Energy Policy, Volume 37, Issue 1, 2009, pp. 181-189

[4] The Association of German Engineers, "VereinDeutscherIngenieure-Guideline VDI 4602", BeuthVerlag, Berlin, 2007, pp. 3-5

[5] Thesis by DaianePandolfo, "Implementing an Energy Management System", Politecnico Di Milano, 2009 - 2010.

[6] American National Standards Institute "A Management System for Energy: ANSI/MSE 2000:2008”, www.webstore.ansi.org

[7] Weidong, F., Hai, W., Wang, K., Huoyin, L., Jia, Z., "A Method to Establish and Run Management Systems for Energy”, Energy Procedia, Volume 5, 2011, pp. 1584-1588

[8] ISO-50001 Energy Management, International Organization for Standardization (www.iso.org)

[9] Gopalakrishnan, B., "Enhanced Energy Assessment Process", 2011 (obtained from author, Contact: Bhaskaran.Gopalakrishnan@mail.wvu.edu)

[10] Pacific Northwest National Laboratory, "A Guide to Energy Audits", 2011, pp. 2 (http://www.pnnl.gov/main/publications/external/technical_reports/pnnl-20956.pdf)

[11] American Society of Mechanical Engineers, www.asme.org (accessed December 20 ${ }^{\text {th }}, 2013$ ) [12] Olugbenga, O.N., Albert, I.O., and Mohammed, L.A., "Energy Audit of a Brewery - A Case Study of Vitamalt Nig. Plc, Agbara", Journal of Energy and Power Engineering, 2012, pp. 137143 
[13] Kumaresan, R., "Methods of Quantifying Energy Losses during Energy Auditing in Chemical Process Industries" Asian Journal of Scientific Research, 2012, pp. 263-270

[14] Imad, H.I., Marwan, M.M., "Energy efficiency improvement procedures and audit results of electrical, thermal and solar applications in Palestine", Energy Policy, Volume 33, 2005, pp. 651-658

[15] Nesreen, G., Toufic, M., "Modelling of current and future energy intensity and greenhouse gas emissions of the Lebanese industrial sector: assessment of mitigation options", Journal of Applied Energy, Volume 63, 1999, pp. 53-74

[16] Oyedepo., Sunday, O., Aremu, T. O., "Energy Audit of Manufacturing and Processing Industries in Nigeria: A case study of food processing industries and distillation \& bottling company", American Journal of Energy research, Volume 1, 2013, pp. 36-44

[17] Ali, H., Lynn, P., "Industrial energy Audit Guide Book: Guide Book for Conducting Energy Audit in Industrial Facilities", LBNL, 2010, pp. 4

[18] Walter, K.,Sibylle, K.,Johanna, K.,Ina, R., Silas, S., "DIN EN 16001: Energy management Systems in Practice: A Guide for Companies and Organization", Federal Ministry for the Environment, Nature Conservation and Nuclear Safety, 2010, pp. 12

[19] Henri, L., F. de Groot., Erik, T.V., Peter, N., "Energy Savings by Firms: Decision Making, Barriers and Policies", Energy Economics, Volume 23, 2010, pp. 718-724

[20] International Organization for Standardization, "Win the Energy Challenge with ISO 50001”, 2011, pp. 4 (http://www.iso.org/iso/iso_50001_energy.pdf)

[21] ISO 50001-2011, Annex A, Figure A-2, "Energy Management Systems-Requirements with Guidance for Use”, 2011

[22] Northwest Energy Efficiency Alliance, "Energy Baselining Methodologies for Industrial facilities”, 2013, pp. 1-15 (http://neea.org/docs/default-source/reports/energy-baselinemethodologies-for-industrial-facilities.pdf?sfvrsn=7)

[23] Eoin, O., Dong, O.C., Garret, E.O., “The Development of Energy Performance Indicators within a Complex Manufacturing Facility", International Journal of Advanced Manufacturing Technology", 2013: 2208

[24] David, B., Goldstein, A. A., "Developing a Suite of energy Performance Indicators (EnPIs) to Optimize Outcomes", ACEEE Summer Study on Energy Efficiency in Industry, 2013, Niagara Falls, NY, pp. 5-2

[25] Georgia Tech Research Corporation and U.S. Department of Energy, "Step 2.6.3-Checklist for Potential EnPIs", Document\#110411, 2013 
[26] Schneider Electric, "ISO 50001: Recommendations for Compliance", 2012, pp.13 (http://static.schneiderelectric.us/docs/Power\%20Management/Energy\%20Sustainability/ISO\%2 050001\%20Consulting/Iso50001Recommendations.pdf)

[27] Paul, E.S., Joe, A.A., Pamela, B.R., "Superior Energy Performance: A Roadmap for Continual Improvement in Energy Efficiency", Strategic Planning for Energy and the Environment, Volume 32, Issue 3, 2013, pp. 39-55

[28] Paul, S., Aimee, M., Vestal, T., Ryan, C., "System Assessment Standards: Defining the Market for Industrial Energy Assessments", LBNL, 2009 (can obtain at http://industrialenergy.lbl.gov/files/industrial-energy/active/0/rpt78618.PDF)

[29] Swords, B., Coyle, E., Norton, B., “An Enterprise Energy - Information System”, Journal of Applied Energy, Volume 85, Issue 1, 2008, pp. 61-69

[30] International Performance Verification and Measurement Protocol, "Concepts and Options for Determining Energy and Water Savings Volume 1”, U.S. DoE, 2002, pp. 21-24

[31] Katharina, B., Matthias, V., Paul, S., Marc, B., Frank, E., "Integrating energy efficiency performance in production management - gap analysis between industrial needs and scientific literature", Journal of Cleaner Production, 2011, pp. 667-669

[32] Lammers, N., Kissock, K., Abels, B., Sever, F., "Measuring progress with normalized energy intensity", SAE International Journal of Materials and Manufacturing, 2011, pp. 460-467

[33] Tsung, Y.C., Shang, L.L., Yung, Y.T., "Establishing an Integration-Energy-Practice Model for Improving Energy Performance Indicators in ISO 50001 Energy Management Systems", Energies Journal, 2012, pp. 5324-5339 